\title{
The Effect of Bovine Galectin-1, a Conceptus Secretory Protein, on the Endometrial Transcriptome
}

\author{
Lindsay Faye Grose
}

West Virginia University, Ifgrose@mix.wvu.edu

Follow this and additional works at: https://researchrepository.wvu.edu/etd

Part of the Beef Science Commons, Dairy Science Commons, Genetics Commons, Large or Food Animal and Equine Medicine Commons, and the Other Physiology Commons

\section{Recommended Citation}

Grose, Lindsay Faye, "The Effect of Bovine Galectin-1, a Conceptus Secretory Protein, on the Endometrial Transcriptome" (2019). Graduate Theses, Dissertations, and Problem Reports. 4088.

https://researchrepository.wvu.edu/etd/4088

This Thesis is protected by copyright and/or related rights. It has been brought to you by the The Research Repository @ WVU with permission from the rights-holder(s). You are free to use this Thesis in any way that is permitted by the copyright and related rights legislation that applies to your use. For other uses you must obtain permission from the rights-holder(s) directly, unless additional rights are indicated by a Creative Commons license in the record and/ or on the work itself. This Thesis has been accepted for inclusion in WVU Graduate Theses, Dissertations, and Problem Reports collection by an authorized administrator of The Research Repository @ WVU. For more information, please contact researchrepository@mail.wvu.edu. 
The Effect of Bovine Galectin-1, a Conceptus Secretory Protein, on the Endometrial Transcriptome

\author{
Lindsay Faye Grose
}

Thesis submitted to the Davis College of Agriculture, Natural Resources and Design at West Virginia University in partial fulfillment of the requirements for the degree of

Master of Science in Reproductive Physiology

\author{
Daniel J. Mathew, Ph.D., Chair \\ Robert A. Dailey, Ph.D. \\ Melanie Clemmer, Ph.D., HCLD
}

Division of Animal and Nutritional Sciences

Morgantown, West Virginia

2019

Keywords: galectins, lymphocytes, endometrium, conceptus Copyright 2019 Lindsay Grose 


\section{ABSTRACT \\ The Effect of Bovine Galectin-1, a Conceptus Secretory Protein, on the Endometrial Transcriptome}

\section{Lindsay Faye Grose}

Early embryonic loss in cattle is detrimental to reproduction thus, the profitability of both the beef and dairy industries. Therefore, an important aspect of study is to find techniques that beef or dairy producers could use to decrease early embryonic loss Galectin-1, the protein that was investigated in this research is important in modulating the maternal immune system in rodent and human early pregnancies by promoting fetomaternal immune tolerance. The role of galectin-1 within the reproductive tissues has not been thoroughly investigated in cattle.

Galectin-1 is located in the caruncular and intercaruncular regions of the bovine endometrium, specifically the maternal stroma, and in the day 7 blastocyst and the elongating day 16 conceptus. Expression of galectin-1 was reduced in in vitro produced bovine blastocysts when compared to in vivo produced blastocysts, which could cause high embryonic loss and poor pregnancy rates for in vitro produced blastocysts. Relative gene expression of galectin-1 was reduced in endometrium of low fertility dairy heifers. In this study, the impact of galectin-1 on the bovine endometrial transcriptome was evaluated through galectin-1 treatment of intact midluteal phase endometrium and bovine endometrial epithelial and fibroblast cells in a 3dimensional culture system. A third experiment compared gene expression of CXCR4, EIF4EBP2, IL-1B, IL-6, LIF, CHST15, MST1R, ATP11a, FOXP3, CD11c, IL-2RA, and IL-10 day 16 pregnant vs. day 17 cyclic bovine endometrium because of their potential importance during early pregnancy. 


\section{Acknowledgements}

Firstly I'd like to thank my advisor, Dr. Dan Mathew, for taking me as his first graduate student and allowing me the chance to earn my master's degree. I'd also like to thank Dr. Robert Dailey for also being an advisor and life coach. These two men have been available throughout this degree to advise me on everything from experiment trouble shooting, writing this thesis, and life advice. They have helped me gain confidence as a scientist and as a person and provided me with extensive opportunities to expand my knowledge. Without the two of them challenging me every day, I would not have grown or achieved as much as I have.

This research would not be possible without the hard work and determination of my lab mate, Heather Baldwin. She played a heavy part in helping collect tissues, culture cells, and perform general lab techniques to help with these experiments. She also became one of my closest friends through graduate school and was willing to lend a listening ear and give well thought advice when needed. All of the graduate students in the Animal Science Department have also been loyal friends, willing to share their knowledge in science or life at any given time. Those people include Todd Welch, Malia Berg, Jaelyn Current, Brynnan Russ, Denzel Middleton, Camren Maierle, and Jess Lemley. I’d also like to recognize the undergraduates, Jeanna LaBarbara, Adam Sirk, Jared Hitt, and Molly Powney, who assisted with this experiment. Their help was critical in making sure that all of the tasks for this project were accomplished.

Last but not least, I’d like to thank my support system outside of school that stuck with me through all my stressful times and all these years of schooling. My family has always been supportive of extending my education and have done everything in their power to help me along the way. My mom, dad, little brother, aunts and uncles, and grandparents have shaped me into the woman I am today with their unconditional love and support. 


\section{Table of Contents}

$\begin{array}{lll}\text { Abstract } & \text { ii }\end{array}$

$\begin{array}{ll}\text { Acknowledgements } & \text { iii }\end{array}$

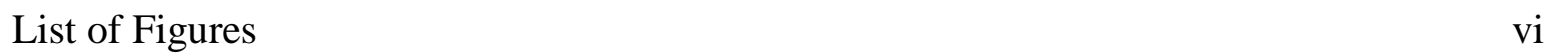

List of Tables $\quad$ viii

$\begin{array}{ll}\text { List of Abbreviations } & \mathrm{X}\end{array}$

Chapter

$\begin{array}{ll}\text { I. Introduction } & 1\end{array}$

$\begin{array}{ll}\text { II. Literature Review } & 2\end{array}$

Introduction $\quad 2$

Early Pregnancy 3

Maternal Recognition of Pregnancy 5

$\begin{array}{ll}\text { Attachment/Implantation } & 6\end{array}$

$\begin{array}{lr}\text { Conceptus Secretory Proteins } & 8\end{array}$

Early Embryonic Loss $\quad 9$

Galectins 11

Galectin-1 13

$\begin{array}{ll}\text { Galectins in Pregnancy } & 14\end{array}$

Galectin-1 and the Immune System 16

Galectin-1 Findings in Cattle 19

III. Effect of Galectin-1 on Anti-Inflammatory and Pro-Inflammatory Related Gene Expression in Intact Bovine Endometrium
Abstract
21
Introduction
22
Materials and Methods
23
Results
Discussion
Conclusion 
IV. Effect of Galectin-1 on Bovine Endometrial Epithelial and Fibroblast Cells in 3-Dimensional Cell Culture
Abstract
Introduction
46
Materials and Methods
Results
Discussion
Conclusion
61

V. Differential Gene Expression in Day 16 Pregnant and Day 17 Cyclic Bovine Endometrium

Abstract

Introduction

81

Materials and Methods

82

Results

85

Discussion

85

Conclusion

87

VI. Conclusions

97

References

100

Appendix A

109

Appendix B

113 


\section{List of Figures}

Figure Page

3.1 Least squares means relative expression values for FOXP3 in bovine 34 endometrial explants treated with increasing concentrations of LGALS1

3.2 Least squares means relative expression values for $I L-10$ in bovine endometrial explants treated with increasing concentrations of LGALS1

3.3 Least squares means relative expression values for $I L-2 R A$ in bovine endometrial explants treated with increasing concentrations of LGALS1

3.4 Least squares means relative expression values for $C D 11 c$ in bovine endometrial explants treated with increasing concentrations of LGALS1

3.5 Least squares means relative expression values for $I L-1 B$ in bovine endometrial explants treated with increasing concentrations of LGALS1

3.6 Least squares means relative expression values for $L I F$ in bovine endometrial explants treated with increasing concentrations of LGALS1

3.7 Least squares means relative expression values for $I L-6$ in bovine endometrial explants treated with increasing concentrations of LGALS1

3.8 Least squares means relative expression values for CXCR4 in bovine endometrial explants treated with increasing concentrations of LGALS1

4.1 Diagram representing 3D co-culture system of bovine endometrial epithelial 71 and fibroblast cells

4.2 Least squares means relative expression values for CXCR4 in bovine endometrial epithelial and fibroblast cells in 3D culture treated with increasing concentrations of LGALS1

4.3 Least squares means relative expression values for EIF4EBP2 in bovine endometrial epithelial and fibroblast cells in 3D culture treated with increasing concentrations of LGALS1

4.4 Least squares means relative expression values for $I L-1 B$ in bovine endometrial epithelial and fibroblast cells in 3D culture treated with increasing concentrations of LGALS1

4.5 Least squares means relative expression values for $I L-6$ in bovine endometrial epithelial and fibroblast cells in 3D culture treated with increasing concentrations of LGALS1 
4.6 Least squares means relative expression values for LIF in bovine endometrial epithelial and fibroblast cells in 3D culture treated with increasing concentrations of LGALS1

4.7 Least squares means relative expression values for CHST15 in bovine endometrial epithelial and fibroblast cells in 3D culture treated with increasing concentrations of LGALS1

4.8 Least squares means relative expression values for MST1R in bovine endometrial epithelial and fibroblast cells in 3D culture treated with increasing concentrations of LGALS1

4.9 Least squares means relative expression values for ATP11a in bovine 79 endometrial epithelial and fibroblast cells in 3D culture treated with increasing concentrations of LGALS1

5.1 Experimental design. Co- Synch 7-day CIDR fixed time AI protocol

5.2 Least squares means relative expression values for CXCR4 in day 16 pregnant and day 17 cyclic endometrium

5.3 Least squares means relative expression values for FOXP3 in day 16 pregnant and day 17 cyclic endometrium

5.4 Least squares means relative expression values for LGALS1 in day 16 pregnant and day 17 cyclic endometrium

5.5 Least squares means relative expression values for $I L-1 B$ in day 16 pregnant 93 and day 17 cyclic endometrium

5.6 Least squares means relative expression values for $I L-2 R A$ in day 16 pregnant and day 17 cyclic endometrium

5.7 Least squares means relative expression values for $I L-6$ in day 16 pregnant and day 17 cyclic endometrium

5.8 Least squares means relative expression values for LIF in day 16 pregnant 96 and day 17 cyclic endometrium

6.1 Proposed pathway for the effect of embryo produced LGALS1 on 99 endometrial epithelial cells in the cow

A.1 Immunohistochemistry for FOXP3 and CD4 in bovine caruncular endometrium treated with LGALS1 


\section{List of Tables}

Table

3.1 GenBank Accession number, gene name, primer sequence (forward and reverse), product size, amplication efficiency, and source of primer for gene cDNA amplified using RT-qPCR in bovine endometrial explants.

3.2 Summary of relative expression data for genes amplified by RT-qPCR in bovine endometrial explants treated with increasing concentrations of LGALS1

3.3 Summary of relative expression data for anti-inflammatory related genes amplified by RT-qPCR in endometrial explants treated with increasing concentrations of LGALS1

3.4 Summary of relative expression data for pro-inflammatory related genes amplified by RT-qPCR in endometrial explants treated with increasing concentrations of LGALS1

4.1 Gene Ontology Biological Process Direct for genes up-regulated in bovine endometrial epithelial cells treated with 100ng/mL of bovine LGALS1 in 3D culture

4.2 Gene Ontology Biological Process Direct for genes down-regulated in bovine endometrial epithelial cells treated with 100ng/mL of bovine LGALS1 in 3D culture

4.3 KEGG Pathway Analysis for genes up-regulated in bovine endometrial epithelial cells treated with 100ng/mL of bovine LGALS1 in 3D culture

4.4 KEGG Pathway Analysis for genes down-regulated in bovine endometrial epithelial cells treated with 100ng/mL of bovine LGALS1 in 3D culture

4.5 Genbank Accession number, gene name, primer sequence (forward and reverse), product size, amplification efficiency, and source of primer for gene cDNA amplified during RT-qPCR endometrial epithelial and fibroblast cells.

4.6 Summary of relative expression data for genes amplified by RT-qPCR in bovine endometrial epithelial and fibroblast cells treated with LGALS1 
5.1 Genbank Accession number, gene name, primer sequence (forward and reverse), product size, amplification efficiency, and source of primer for gene cDNA amplified during RT-qPCR in day 16 pregnant and day 17 cyclic endometrium

B.1 Additional Gene Ontology direct Pathways up-regulated in epithelial cells treated with 100ng/mL of LGALS1

B.2 KEGG pathways that were up-regulated in epithelial cells treated with 100 ng/mL LGALS1 


\section{List of Abbreviations}

ABAM

AC

AI

ATP11a

BATF2

bIFNT

BMST2

BP

bPAG

bPL

cAMP

CCL20

CD

CDC4EP3

CIDR

CL

CRD

CSF

CSP

CXCL10

CXCL12

CXCR4

DC
Anti-biotic anti-mycotic

Adenylate cyclase

Artificial insemination

ATP-ase phospholipid transporting 11a

Basic leucine zipper ATF-like transcription factor 2

Bovine interferon tau

Bone marrow stromal antigen 2

Base pair

Bovine pregnancy associated glycoprotein

Bovine placental lactogen

Cyclic adenosine monophosphate

C-C motif chemokine ligand 20

Cluster of differentiation

CDC42 effector protein 3

Controlled internal drug release

Corpus luteum

Carbohydrate recognition domain

Conceptus secretory factor

Conceptus secretory protein

C-X-C motif chemokine ligand 10

C-X-C motif chemokine ligand 12

C-X-C chemokine receptor 4

Dendritic cell 


\begin{tabular}{|c|c|}
\hline DPBS & Dulbecco's phosphate buffer \\
\hline $\mathrm{E}$ & Efficiency \\
\hline E2 & Estradiol \\
\hline ECM & Extracellular matrix \\
\hline EIF4EBP2 & $\begin{array}{l}\text { Eukaryotic translation initiation factor } 4 \mathrm{E} \text { binding protein } \\
\text { family } 2\end{array}$ \\
\hline ER & Estrogen receptor \\
\hline ET & Embryo transfer \\
\hline $\mathrm{EtOH}$ & Ethyl alcohol \\
\hline FBS & Fetal bovine serum \\
\hline FGR & FGR proto-oncogene src family tyrosine kinase \\
\hline FNDC3B & Fibronectin type III domin containing 3B \\
\hline FOXP3 & Forkhead box P3 \\
\hline FSD1 & Fibronectin type III and SPRY domain containing 1 \\
\hline FSH & Follicle stimulating hormone \\
\hline FTAI & Fixed time artificial insemination \\
\hline GLM & General linear model \\
\hline $\mathrm{GnRH}$ & Gonadotropin releasing hormone \\
\hline GO & Gene ontology \\
\hline H3F3A & H3 histone family member 3a \\
\hline HBSS & Hank's balanced salt solution \\
\hline hLIF & Human leukemia inhibitory factor \\
\hline HTLV-1 & Human t-cell leukemia virus type 1 \\
\hline
\end{tabular}




\begin{tabular}{ll} 
IFN & Interferon \\
IFNT & Interferon tau \\
IHC & Immunohistochemistry \\
IL & Interleukin \\
IM & Intramuscular \\
IPA & Ingenuity pathway analysis \\
IRF & Interferon regulatory factor 9 \\
ISG & Interferon stimulated gene \\
ITGB1 & Fibronectin receptor beta 1 \\
IVF & In vitro fertilization \\
KEGG & Kyoto encyclopedia of genes and genomes \\
LDL & Low-density lipoprotein \\
LE & Luminal epithelium \\
LGALS1 & Galectin-1 \\
LH & Mitochondrial ribosomal protein L36 \\
LHR & Mammary serum amyloid A3.2 \\
LIF & Loginizing hormone \\
LOC112441507 & Luteinizing hormone receptor \\
Log10 & Leukemia inhibitory factor \\
LPS & Least square mean \\
MRPL36 & Bopolysaccharide \\
\hline
\end{tabular}




\begin{tabular}{|c|c|}
\hline MSD2 & Nuclear receptor binding SET domain protein 2 \\
\hline MSRB1 & Methionine sulfoxide reductase B1 \\
\hline MST1R & Macrophage stimulating 1 receptor \\
\hline MUC1 & Mucin 1 \\
\hline NBF & Neutral buffered formalin \\
\hline NFKB & Nuclear factor kappa B \\
\hline NOD & Nucleotide binding oligomerization \\
\hline NRQ & Normalized relative expression quantities \\
\hline OAS & 2', 5’- oligoadenylate synthetase \\
\hline P4 & Progesterone \\
\hline PBS & Phosphate buffered solution \\
\hline PGF2a & Prostaglandin F2 alpha \\
\hline PGR & Progesterone receptor \\
\hline PIAS2 & Protein inhibitor of activated STAT2 \\
\hline PIBF & Progesterone-induced blocking factor \\
\hline PPIA & Peptidyl-prolyl isomerase A \\
\hline RARA & Retinoic acid receptor alpha \\
\hline RIG-1 & Retinoic acid-inducible gene-I \\
\hline RIN & RNA integrity number \\
\hline RNA-Seq & RNA sequencing \\
\hline RNF11 & Ring Finger Protein 11 \\
\hline RPMI & Rosewell Park Memorial Institute \\
\hline SAA & Serum amyloid A protein \\
\hline
\end{tabular}


SAS

SDHA

SEM

SI00A9

SLC15A3

Sqrt

SRF

STARD7

STEAP4

TEER

$\mathrm{TF}$

TGC

Th

Thy1

TLR

TNF

TNFAIP2

Treg

ULF

USDA

USP6NL

WT

YWHAZ
Statistical analysis software

Succinate dehydrogenase complex flavoprotein subunit A

Standard error of least square mean

S100 calcium binding protein A9

Solute Carrier Family 15 Member 3

Square root

Serum response factor

StAR related lipid transfer domain containing 7

STEAP4 metalloreductase

Transepithelial electric resistance

Transcription factor

Trophoblast giant cell

T-helper cell

Thymus cell antigen

Toll-like receptor

Tumor necrosis factor

Tumor necrosis factor alpha-induced protein 2

Regulatory T-cell

Uterine luminal fluid

United States Department of Agriculture

USP6 N-terminal like

Wild-type

Tyrosine 3-monooxygenase/ tryptophan 5monooxygenase activation protein zeta 


\section{CHAPTER ONE}

\section{INTRODUCTION}

Early embryonic loss in cattle affects all aspects of the cattle industry. Research has shown that $20-50 \%$ of pregnancies may be lost between days $0-7$ of gestation. Another $30 \%$ may be lost between days 8-27 (Wiltbank et al., 2016, Diskin et al., 2006). Overall, reproductive failure costs the beef and dairy industries a significant amount of money annually, thus having a large impact on U.S. agriculture (Bellows et al., 2002). These findings indicate that the majority of pregnancy loss occurs prior to implantation of the conceptus thus, this stage of gestation is an important time point for research. A better understanding of pregnancy during this time could provide technologies to prevent economic losses for the producer.

Galectin-1 (LGALS1) is an important protein during pregnancy for the modulation of immune cell function through regulatory T-cells (Treg) in human and rodent endometrium (Blois et al., 2007, Camby et al., 2006). In cattle LGALS1 is in the caruncular regions of the endometrium and has been found on the conceptus as early as day 16 of gestation (Mamo et al., 2012, Mohan et al., 2004). Further, LGALS1 expression was reduced in in vitro compared to in vivo produced bovine blastocysts and in the endometrium of low fertility dairy heifers (Killeen et al., 2014). Possibly, LGALS1 could play a role in the immune modulation in the uterine environment of cattle prior to implantation. 


\section{CHAPTER TWO}

\section{LITERATURE REVIEW}

\section{INTRODUCTION}

Reproductive failure in cattle results in decreased milk and beef production as well as increased treatment and preventative costs, leading to economic losses. Although reproduction can be negatively affected by many factors, reproductive failure is a major reason for culling animals. The United States Department of Agriculture (USDA) estimated \$441-\$502 million in losses for beef producers and \$473-\$484 million in losses for dairy producers annually due to female reproductive failure. This sums to an aggregate national total of about $\$ 1$ billion annually for the entire cattle industry (Bellows et al., 2002). In beef cattle, although estimates indicate that fertilization rate is approximately $90 \%$, the average calving rate to a single insemination is approximately 55\%, suggesting an embryonic/fetal mortality rate of approximately $45 \%$. Seventy to eighty percent of total embryonic loss is believed to occur between days 8 and 16 after insemination (Diskin et al., 2006, Spencer and Hansen, 2015b). Early pregnancy loss is even greater in the high-producing dairy cow, which is a major limitation to milk production, and improvements to reproduction could improve the profitability of dairy farms (Moore and Thatcher, 2006, Spencer and Hansen, 2015a, Spencer and Hansen, 2015b).

During pregnancy, a necessary line of communication is established between the developing conceptus and the uterus. Communication prevents luteolysis, structural and functional regression of the corpus luteum (CL), and maintains pregnancy. During this time, the 
conceptus secretes interferon tau (IFNT), the maternal recognition of pregnancy signal in the cow, initiating a cascade of events that allows the CL to be maintained with continued progesterone (P4) secretion. Possibly, deficiencies in uterine function or failure of the conceptus to secrete IFNT during this time and results in failure to undergo implantation and placentation (Bazer et al., 2012).

Nonetheless, pregnancy loss negatively affects economic performance of cattle herds. Wiltbank et al. (2016) described four pivotal periods for pregnancy loss during the first trimester of gestation in the lactating dairy cow. The first period is the first week of pregnancy with failure being attributed to lack of fertilization or loss of the early embryo. The second period is between days 8-27 of gestation with inadequate communication from the embryo, uterus and/or ovary, causing a loss in pregnancy. The third period is between days 28-60 of gestation. During this time the conceptus attaches to the uterus and forms the placenta. The last pivotal period is between the days of 60-90 of gestation. This encompasses the time of increased fetal growth and increased volume of placental membranes. Approximately 1-3\% of pregnancy loss occurs during this time possibly because of multiple offspring and overcrowding in the uterus.

Knowledge of the complex biological and genetic mechanisms governing conceptus elongation and implantation and/or factors contributing to the early embryonic loss will lead to strategies that improve reproductive success in cattle (Ulbrich et al., 2013, Geary et al., 2016, Lonergan et al., 2016, Forde et al., 2015).

\section{Early Pregnancy}

Following ovulation, the oocyte enters the infundibulum of the oviduct where it will be guided through the oviduct by the wave-like motions of the fimbriae. Fertilization occurs in the 
ampillary-isthmic junction of the oviduct by a single sperm penetrating the oocyte through a series of complex reactions (Langlais and Roberts, 1985).

The first reaction is decapitation of the sperm to reveal zona pelucida binding proteins, followed by the acrosomal reaction to penetrate the zona pelucida. Vesiculation follows, where the two membranes of the oocyte and sperm fuse. After germinal vesicle breakdown, female and male pronuclei migrate to the center of the oocyte and the first mitotic division occurs, producing a two-celled embryo. The two cells (blastomeres) are smaller than the initial single cell before cleavage as a result of cytoplasmic partitioning. The blastomeres will undergo a second division within 24 hours following fertilization producing a four-celled embryo. Although blastomeres continue to undergo mitosis, the rate of cleavage slows, occurring once every 24 to $26 \mathrm{~h}$. The cleavage between blastomeres may not be a synchronized event, as some cells divide faster than others. In accordance with the cleavage-driven model, blastomeres that divide more quickly may be positioned more toward the exterior of the cell mass, giving rise to the trophoblastic lineage. Cells that divide more slowly may be positioned toward the interior, giving rise to the inner cell mass (Piotrowska and Zernicka-Goetz, 2001).

The bovine conceptus enters the uterine horn approximately 4-5 days after ovulation, undergoing first morulation followed by blastulation. During morulation, blastomeres located on the surface of the morula produce tight cell junctions. The blastomeres pump sodium ions into the interior of the morula, resulting in accumulation of fluid and formation of the inner cell mass, which ultimately gives rise to the conceptus and fetal body. Hatching occurs near day 10 of gestation when thinning of the zona pellucida by the actions of fluid accumulation, growth, contraction of the blastocyst, and proteolytic enzymes lead to the expulsion of the blastocyst. Once hatched from the zona pellucida, the blastocyst is a free-floating conceptus within the 
uterine lumen and is dependent on the uterine environment for survival. At this time the conceptus undergoes extensive growth. Near day 13, the bovine blastocyst is approximately 3 $\mathrm{mm}$ in diameter. However, by day 17 of gestation, the conceptus is approximately $250 \mathrm{~mm}$ in length. At this time, the blastocyst will appear as a filamentous thread like structure (Senger, 2005). After day 19 in cattle, the elongating conceptus will initiate adherence to the uterine luminal epithelium (LE) and begin the process of placentation (Spencer et al., 2017, Guillomot et al., 1981).

\section{Maternal Recognition of Pregnancy}

In order for embryogenesis to continue and the pregnancy to be maintained, luteolysis must be prevented and high concentrations of P4 must be maintained. In the non-pregnant cow, the CL produces oxytocin that stimulates the endometrial cells to synthesize prostaglandin F2alpha (PGF2a). The production of PGF2a is dependent upon a threshold number of oxytocin receptors that are synthesized by endometrial cells during the estrous cycle. When these receptors are available in sufficient numbers, pulsatile secretion of PGF2a occurs in response to luteal oxytocin secretion and luteolysis follows. In order to block this luteolytic mechanism, the trophoblastic cells of the blastocyst secrete IFNT in the cow and ewe. The IFNT then acts on the endometrial cells of the uterus to inhibit the production of oxytocin receptors thus preventing oxytocin from stimulating PGF2a. The IFNT also causes secretion of proteins from the uterine glands into the uterine lumen to nourish the conceptus. These proteins include alpha- fetoprotein (a-FP), bovine placental lactogen (bPL), glycoproteins, and might other uncharacterized proteins (Thatcher et al., 1984). The IFNT can exit the uterus through the uterine vein and will reach the ovary by counter current exchange with the ovarian artery (Senger, 2005). Progesterone acts on the uterus to stimulate and maintain uterine functions that are necessary for early embryonic 
development, implantation, placentation, and successful fetal and placental development to term. The conceptus must signal its presence to the dam through the process of maternal recognition of pregnancy. If the conceptus does not do so in a timely manner, luteolysis will occur and the pregnancy will be terminated. In cattle, the maternal recognition of pregnancy signal is IFNT, the bovine conceptus must secrete IFNT at sufficient concentration between days 15-16 after ovulation. This is referred to as the critical period, and at this time the conceptus is in the ovoid stage (Degrelle et al., 2005). The bovine blastocyst prevents luteolysis by secreting the

pregnancy recognition protein, bINF-T. Elongation of the blastocyst is critical for efficient production of IFNT and for implantation (Thomas et al., 2004, Farin et al., 1989, Guillomot et al., 1990, Gray et al., 2001). It is detectable in the bovine uterus as early as gestational day 7 (Rashid et al., 2018).

\section{Attachment/Implantation}

Synchrony between the developing conceptus and uterine environment is critical for survival. The endometrium must be receptive to the conceptus, which must attach to the uterine surface epithelium between days 18-22 after ovulation (Senger, 2005). Attachment is enhanced within endometrial caruncles, specialized maternal sites of nutrient exchange with the placental tissues. There are approximately 100 evenly distributed caruncles within the uterine horns of cattle (Schlafer et al., 2000). The trophoblast cells form a continuous epithelial layer of the chorion, over the entire surface of the chorioallantois, which is a fusion of the chorionic and allantoic tissues. As the fetal placenta forms and develops, villous projections that interdigitate with the surface of the caruncle forming a specialized placental tissue referred to as a cotyledon. Together, the caruncle and cotyledon tissues form a placentome, a specialized unit for nutrient and waste exchange between the mother and the placental tissues. The interdigitation of these 
two tissues enchances the fetomaternal interface and greatly increases surface contact between the cow and fetal calf (Schlafer et al., 2000).

The bovine endometrium and placenta consist of binucleate trophoblast giant cells (TGC) (Wooding and Wathes, 1980). Approximately one-fifth of the bovine trophoblast cells are binucleated. These develop from mononuclear trophoblast cells by actokinetic mitosis that migrate beyond the maternal luminal epithelial cells or fuse with single maternal epithelial cells to form fetomaternal hybrid cells (Schlafer et al., 2000).

Ultrastructural studies using phosphotungstic acid to stain cytoplasmic granules of binucleate cells demonstrated the translocation of binucleate trophoblast cells from the chorionic layer of the cotyledonary villi to penetrate the single epithelial cell layer lining the caruncules. Similar migration occurs in the interplacentomal areas. As the binucleate cells migrate, they routinely fuse with a single endometrial epithelial cell and discharge their cytoplasmic granules. The fusion of a fetal binucleate cell with a maternal cell temporarily forms a hybrid cell with three nuclei (Schlafer et al., 2000). Since migration does not extend beyond the maternal basement membrane, this process is considered as restricted trophoblast invasion. Thus, through regulated cell adhesion, migration, and restricted invasion, a complex interface is generated that encompasses both fetal and maternal cells. Its functionality is critical for trophoblast/endometrium contact and maintenance of pregnancy (Froehlich et al., 2012)

The binding of integrins to their extra-cellular membrane (ECM) proteins with regulatory functions during implantation and trophoblast invasion has been confirmed for the hemochorial human placenta (Fisher and Damsky, 1993). Large amounts of ECM proteins, like collagen type IV, fibronectin, and laminin were shown during all stages of gestation in the placenta of macaques (Blankenship et al., 1992, Blankenship and King, 1993). In contrast, understanding of 
the cell-cell interactions in other types of placentation is limited to either the secreted products of the conceptus or to the time around implantation. Research suggests that the proteins secreted from the conceptus aid in its attachment to the uterus. The ECM, specifically fibronectin, plays a role in the early development and attachment to the uterine surface of bovine embryos (Larson et al., 1992).

The pregnant bovine endometrium expresses integrin subunits $\alpha 1, \alpha 3$, and $\alpha 6$ as well as their ligand, integrin $\beta 1$ subunit, in the epithelium of the endometrium. Along with these are ECM proteins, collagen IV and laminin, which are increased around the time of attachment in the uterus compared to during normal cyclicity. As the attachment of the bovine trophectoderm to the uterine epithelium proceeds, expression of these adhesion molecules changes. The trophectoderm down-regulates integrin subunit $\alpha 1$ but increases $\alpha 6$ from days 18-24 of gestation. Uterine epithelium constitutively expressed $\alpha 3$ and $\alpha 6$ integrin subunits, but $\alpha 1$ was downregulated as the luminal epithelium was modified. Collagen IV and laminin reactivity increased in the basal lamina and underlying subepithelial stroma as pregnancy proceeded. Binucleate cell fusion with the maternal epithelium initiates integrin and ECM changes in the subepithelial stroma (MacIntyre et al., 2002).

\section{Conceptus Secretory Proteins}

The IFNT induces expression of classical and nonclassical interferon-stimulated genes (ISGs) in the cellular compartments of the endometrium that are proposed to regulate conceptus elongation (Mansouri-Attia et al., 2009, Bazer et al., 2008, Bauersachs et al., 2006, Forde et al., 2011). The conceptus also produces prostaglandins on Day 13 that can modify the endometrium prior to pregnancy recognition (Spencer et al., 2013). In a study analyzing Day 16 conceptus 
culture medium, 1005 proteins, including IFNT, were detected within 6 h of culture. A comparison of the proteins in the $6 \mathrm{~h}$ and $24 \mathrm{~h}$ culture media resulted in identification of 875 proteins in common compared to uterine luminal fluid (ULF) of cyclic heifers, and 30 proteins that were unique to ULF from Day 16 pregnant heifers and were also produced by the Day 16 conceptus after $6 \mathrm{~h}$ and $24 \mathrm{~h}$ of culture. Ten of the conceptus derived proteins were considered to influence genes that were modified in the endometrium during pregnancy recognition. Five conceptus derived proteins were considered to influence genes that were down-regulated in the endometrium of pregnant heifers compared to cyclic heifers, while nine conceptus-derived proteins interacted with genes that were upregulated in pregnant compared to cyclic endometrium during pregnancy recognition (Forde et al., 2015).

Bovine trophoblast cells produce a number of hormones and growth factors including P4, bPL, pregnancy-associated glycoproteins (bPAG), and transforming growth factor beta, and many more genes (Munson et al., 1996). The bPAGs have been localized to binucleate cells, and are expressed during early pregnancy (Patel et al., 1997). Pregnancy detection methods have been developed utilizing the presence of bPAGs thus far as early as 28 days after insemination (Pohler et al., 2016). Peripheral systemic levels of bPAG have been shown to increase over the last 10 days of pregnancy (Patel et al., 1997). Around this time is also when marked binucleate cell degranulation occurs. It has been suggested that bPAG-1 is a proteinase, but its specific role in placental release is not known (Roberts et al., 1995).

\section{Early Embryonic Loss}

Early embryonic loss greatly affects the cattle industry. Specifically, in dairy herds reproductive efficiency is suboptimal and the act of improving reproduction can increase the profitability of dairy operations. Many factors can affect early embryonic loss including but not 
limited to, environmental factors, genetics, and management. In heifers and moderate-producing dairy cattle, fertilization rates are generally high (90-100\%) after natural mating or AI (Mapletoft, 2013). Cattle experience a high rate of pregnancy loss between fertilization and calving, that ranges from 40\% to 56\% (Diskin et al., 2006, Sreenan et al., 1986, Wiltbank et al., 2016, Spencer et al., 2017, Diskin and Morris, 2008). Beef cattle have an embryonic and fetal mortality rate of approximately $40 \%$ based on an average calving rate of $55 \%$. Pregnancy loss is important to the cattle conceptus transfer (ET) industry, in which more than 750,000 embryos are produced annually from superovulated donors and more than 450,000 embryos are produced using in vitro techniques (Mapletoft, 2013). Indeed, 485,595 in vivo-derived and 364,727 in vitro-produced bovine embryos were transferred commercially worldwide in 2014 (Perry, 2015). Mean survival rate to calving following the transfer of in vivo-derived embryos from superovulated donors ranges from $31 \%$ to $60 \%$, whereas the mean survival rate after transfer of in vitro-produced embryos is lower and ranges from 30\% to 40\% (McMillan, 1998, Hansen and Block, 2004). There are four pivotal periods of loss during the first trimester of pregnancy.

The first of which occurs the first week after breeding with lack of fertilization or death of the early embryo. Between $10 \%$ and $50 \%$ of potential pregnancies are lost during this period. Decreasing pregnancy loss during this period targets improving oocyte quality by eliminating heat stress, inflammatory diseases, and body condition loss. Pregnancy loss during this time could also be decreased by adjusting circulating progesterone concentrations during preovulatory follicle growth, reducing the size of the ovulatory follicle, reducing heat stress, and improving the metabolic state of the lactating dairy cows.

The second pivotal period is from days 8 to 27 of pregnancy, during the conceptus elongation and maternal recognition of pregnancy phases. This being said, maternal recognition 
of pregnancy occurs from days 16-25 in cattle while a definitive pregnancy diagnosis can be made on day 28. The critical period for maternal recognition of pregnancy in cattle is about day 16 after estrus. Embryos transferred on day 16 were able to maintain a pregnancy while embryos that were transferred on day 17 or later were not able to maintain pregnancy (Betteridge et al., 1980). During this time the conceptus undergoes elongation of its trophoblast cells while secreting bINF-T and other regulatory factors that alter the uterine endometrium to cause cells to produce and/or transport growth factors, and nutrients for embryonic nutrition and elongation. Interferon-T signals the conceptus' presence to the maternal system which allows for the suppression of the maternal immune system, maintenance of the CL, P4 concentrations to remain high, and conceptus elongation. Suboptimal patterns of circulating P4 can lead to altered gene expression in uterine endometrial cells, suboptimal growth of the embryo, and reduced pregnancy success. Failure of the conceptus, uterus, or ovaries to communicate at this stage will result in luteolysis, reduced P4, return to cyclicity, and early embryonic mortality (Wiltbank et al., 2016).

The third pivotal period occurs between days 28 and 60. During this time placentomes will develop and the conceptus will also develop allantoic tissue, leading to adherence and later attachment to the maternal membranes. Risk factors at this point include inadequate placentation, difficulty in the transition of nutrition, alterations in vascularization of the placenta, underdevelopment of the embryo/fetus, disease, metabolic dysfunction, and irregular hormonal conditions. Pregnancy losses during this period are estimated to be $12 \%$ in dairy cattle (Wiltbank et al., 2016).

\section{$\underline{\text { Galectins }}$}


Galectins are a phylogenetically conserved group of lectins composed of approximately 130 amino acids with a carbohydrate recognition domain (CRD) responsible for binding to Bgalactosides. Thus far, 19 galectins have been identified and can be organized into three groups based on the CRD structure (Barrientos et al., 2014). The "prototype” galectin, or dimeric galectin, encompasses most mammalian galectins (galectins-1,-2,-5,-7,-10,-13,-14,-15,-16,-17,19,-20). These prototype galectins are most commonly homodimers of two identical galectin subunits although they can also function as monomers. The "tandem-repeat-type" galectins (galectins-4,-6,-8,-9,-12) consist of two homologous CRDs linked by a small peptide domain, which allows for multivalent binding. Galectin-3 (LGALS3), the only type-3 galectin, possesses a carboxy-terminal CRD and an amino-terminal non-lectin domain. The $\mathrm{N}$-terminal domain allows for multimerization and crosslinking between galectin proteins, each containing a CRD. As a result, LGALS3 is referred to as chimeria-type and may form lattices between tissues (Camby et al., 2006).

Galectin proteins are primarily in the cytoplasm. Galectins lack a secretory signal sequence but can be transported from cells in a non-classical secretory fashion. In this process, galectins are incorporated into intracellular vesicles under the plasma membrane and are secreted, but avoid the endoplasmic reticulum and golgi vesicles. They then gather on the cell surface to form lipid rafts and crosslink with receptor ligands. This type of secretion is increased in response to cellular stress and damage. They can be used as stress sensors, or alarmins, that can signal tissue damage and elicit immune cells to activate or resolve an immune response (Barrientos et al., 2014).

Galectins do not have specific receptors, therefore, they bind to a variety of cell- surface or ECM molecules which carry their carbohydrate ligands. Most members of the galectin family 
thus far bind simple beta-galactosides, such as disaccharides or trisaccharides, but the affinity is relatively weak. When galectins bind to natural glycoconjugate ligands expressed on cell surfaces or in the ECM they usually bind with a much higher affinity. (Cummings and Liu, 2009).

By binding these distinct glycans on cell surfaces, they form a lattice of galectin-glycan bonds and effects cell growth, survival, metabolism, cytokine secretion, and cell-cell/ECM interactions. Various galectins have been shown to influence cell adhesion, induce or prevent apoptosis, and due to their cytokine-like properties, are major activators or inhibitors of immune responses (Than et al., 2012).

\section{$\underline{\text { Galectin-1 }}$}

Galectin-1 (LGALS1) was the first galectin discovered and is encoded by the gene LGALS1, which is located on chromosome 22 of cattle. Galectin-1 is a protein of 135 amino acids and functions as a prototypic galectin that can form monomers and homodimers. The monomer CRD has a "jelly roll” folding structure with five to six stranded antiparallel $\beta$-sheets arranged in a $\beta$-sandwich. At high concentrations, LGALS1 can be found as a non-covalent dimer with interactions at the carboxy- and amino-terminal domains of each subunit leaving the glycan binding sites in the CRD located at opposite ends. Like other galectin family members, the LGALS1 CRD binds to beta-galactosides including lactose and N-acetyl-d-lactosamine (Barrientos et al., 2014), as well as other ligands like the carbohydrate portion of ganglioside GM1 (Kopitz et al., 1998). This protein functions intracellularly with protein-protein interactions and extracellularly with N-acetyllactosamine interactions (Barrientos et al., 2014, Liu et al., 2002). Galectin-1 has effects on many cell-signaling pathways such as cell growth, adhesion, motility, and invasion. 
Galectin-1 is mitogenic for both normal and pathological cells in mice and humans such as murine thymus cell antigen 1 (Thy-1) negative spleen or lymph node cells, mammalian vascular cells, and hepatic stellate cells (Maeda et al., 2004, Sanford and Harris-Hooker, 1990, Moiseeva et al., 2000). It also inhibits the growth of cells such as neuroblastoma and stromal bone marrow cells (Andersen et al., 2009, Kopitz et al., 1998). The action of LGALS1 is dose dependent; when given in high doses LGALS1 will inhibit cell proliferation independently of LGALS1 sugar binding activity, while low doses are mitogenic and susceptible to inhibition by lactose (Adams et al., 1996, Vas et al., 2009). The positive and negative effects of LGALS1 on cell type and cell activation status are influenced by the relative distribution of monomeric and dimeric forms, and intracellular and extracellular forms (Camby et al., 2006).

Galectin-1 increases the adhesion of normal and cancer cells to the ECM by cross-linking various glycoproteins, such as $\beta 1$ integrins, exposed on the cell surface. Galectin-1 also can regulate atypical cell interactions such as those between cancer cells and endothelium, causing the dispersion of tumors. Galectin-1 causes increased motility of glioma cells and reorganization of the actin cytoskeleton while the knockdown of LGALS1 expression in glioma cells reduces motility and adhesiveness. By using highly and poorly invasive mammary carcinoma cell lines, it was shown that the membrane expression of LGALS1 was a mark of cell invasiveness (Camby et al., 2006).

\section{Galectins in Pregnancy}

In women, LGALS1 expression is regulated by steroid hormones and varies during the menstrual cycle and early phases of gestation. Progesterone and E2 increase LGALS1 mRNA levels while blocking the P4 receptor (PGR) and estrogen (ER) reduced this effect (Diep et al., 2016). In delayed implantation experiments in mice, E2 together with P4, but not P4 alone, 
increased uterine LGALS1 expression suggesting that LGALS1 may be important for uterine receptivity (Choe et al., 1998). Crosstalk between LGALS1 and P4 is important for the establishment and maintenance of immune tolerance during pregnancy through endocrine and immune-mediated mechanisms (Diep et al., 2016). In vivo experiments in mice demonstrated that LGALS1 increases circulating levels of P4 and progesterone-induced blocking factor (PIBF), which mediate the effects of $\mathrm{P} 4$ and exerts pregnancy-protective effects by promoting a T-helper (Th) 2-type cytokine profile. Reciprocally, the LGALS1 expression is up-regulated in stromal and decidua cells after supplementary administration of a P4 derivative (Barrientos et al., 2014, Blois et al., 2007, Blois et al., 2004, Arck et al., 2007)

Expression of LGALS1 has been detected in day 3 and day 5 human trophectoderm. Human conceptuses also secrete LGALS1 into the medium in which they are cultured, suggesting that the extracellular functions of this lectin are important for uterine blastocyst attachment during the window of implantation. This may be initiated through LGALS1 binding of mucin 1 (MUC1) via the transcription factor (TF) epitope (Jeschke et al., 2009). Similarly the mouse trophectoderm also expresses LGALS1 that promotes attachment and invasion functions to the uterine wall during the implantation period (Poirier et al., 1992). Studies profiling LGALS1 in the female reproductive tract led to the hypothesis that the balanced action of maternal and fetal sources of expression is most critical for healthy gestations. Maternal LGALS1 has been implicated in the process of decidualization, the transformation of endometrial stroma into a specialized tissue that supports trophoblast invasion and provides nourishment to the conceptus before the establishment of a definite placenta (Ramathal et al., 2010). In humans, LGALS1 expression is elevated during endometrial stromal cells decidualization. Further, the LGALS1 expression is increased in the decidua of the first trimester 
of pregnancy (von Wolff et al., 2005, Bevan et al., 1994). Mice differ slightly because their decidualization is triggered by the attachment of the conceptus but is otherwise similar in the distribution of endometrial LGALS1 expression. Galectin-1 is expressed in all uterine tissues except the glandular and luminal epithelium and is particularly strong in the cytoplasm of decidualized stromal cells (Barrientos et al., 2014). Galectin-1 expression increases significantly in the late secretory phase of the human endometrium. Galectin-1 is expressed in decidual tissue and trophoblastic tissue. During the first trimester of human gestation, LGALS1 is expressed in connective tissue, smooth and striated muscle, and some epithelia such as the skin, gonads, thyroid, and kidneys. Galectin-1 has been shown to have effects on nerve structure development, differentiation of hematopoietic lineage, and differentiation of the myogenic lineage (Camby et al., 2006, von Wolff et al., Maquoi et al., 1997, Vićovac et al., 1998).

\section{Galectin-1 and the Immune system}

Galectins, especially LGALS1, are immensely involved in the initiation, amplification, and resolution of inflammatory responses (Camby et al., 2006). The effects of LGALS1 on the innate and adaptive immune system are consistent with its role as a tolerogenic and antiinflammatory signal through its mechanisms of tumor immune evasion and autoimmune diseases. Galectin-1 assists the decidua of pregnancy in the modulation of inflammation and immune cell activation where it hosts an environment that prevents damage to the developing fetus while retaining the ability to protect the mother from infections (Camby et al., 2006).

Based on cytokine production, Th cells are classified into Th1 and Th2. Th1 cells generate cytokines such as interferon (IFN)- $\gamma$, interleukin (IL)-1 $\beta$, and tumor necrosis factor (TNF)- $\alpha$, and support cell-mediated immunity. Th2 cells produce IL-4, IL-5, and IL-10, and 
down-regulate Th1 responses. Th1 cytokines inhibit the outgrowth of trophoblast cells (Corthay, 2009).

Galectin-1 seems to be essential for maintaining the balance between pro-inflammatory Th-1 and tolerogenic Th2 cytokines needed for a successful pregnancy. This effect has been demonstrated in the mouse model of immunological abortions by Blois et al. (2007) as an increase in fetal loss rate caused by the increase of abortogenic Th1 cytokines due to stress. These stress challenged mice exhibited a decrease in decidual LGALS1 expression, and by supplementation of LGALS1 protein during early pregnancy, they were able to prevent fetal rejection. Blois et al. (2007) hypothesized that LGALS1 restored the Th1 to Th2 cytokine ratio of decidual mononuclear cells (Barrientos et al., 2014, Blois et al., 2007).

Placental LGALS1 expression was higher in women with severe preeclampsia when compared to normal pregnant women. The authors concluded that increased expression of LGALS1 in preeclampsia patients may represent a fetal response to an exaggerated systemic maternal inflammation and that LGALS1 may be implicated in maternal-fetal immune tolerance in humans (Than et al., 2008).

It has been suggested that LGALS1 is able to regulate the Th1 to Th2 cytokine ratio through the process of positive and/or negative selection within the thymus. Galectin-1 is able to induce the differentiation of tolerogenic cluster of differentiation (CD) 11c dendritic cell (DCs) that in turn promotes the expansion of IL-10 producing CD4+CD25+ regulatory $\mathrm{T}$ cells (Blois et al., 2007). Galectin-1 null mice display exacerbated Th1 and Th17 responses and a higher frequency of immunogenic DC compared to the wild type (WT) counterpart. They were able to reproduce normally when mated but showed increased fetal loss rates and enhanced susceptibility to stress-induced abortions (Garin et al., 2007). 
Galectin-1 also suppresses the secretion of the pro-inflammatory cytokine interleukin-2 (IL-2) (Garin et al., 2007). It induces the inhibition of cell growth and cell cycle arrest and promotes the apoptosis of activated, but not resting, immune cells. Dimeric LGALS1 is more potent in inducing apoptosis in T-cells than wild-type LGALS1 in vitro (Bättig et al., 2004). The effects of LGALS1 on immune cells are likely due to the binding and crosslinking of cell surface glycoproteins on cells. When present as a dimer, LGALS1 binds to glycoproteins on the surface of T-cells in a carbohydrate-dependent manner (CD2, CD3, CD7, CD43, and CD45). In vivo studies have discovered the capability of LGALS1 to shift the balance toward a Th2-type cytokine response by reducing the levels of IFN $\gamma$, TNF $\alpha$, IL-2, and IL-12 while increasing IL-5 secretion (Camby et al., 2006, Bättig et al., 2004).

Found in the bovine placenta are fetal macrophages, also referred to as "Hofbauer cells" (Benirschke and Kaufmann, 1995). Fetal placental macrophages may originate either from chorionic mesenchyme early in gestation or from fetal bone marrow-derived monocytes. These cells produce pro-inflammatory cytokines and function in antigen presentation suggesting that they can serve as the first line or an important mediator of defense and may contribute to the transplacental transmission of microbial agents (Schlafer et al., 2000).

Pregnancy losses in cows due to increased Th1 cytokine production during inflammation or immune activation have been reported (Maeda et al., 2013). Previous studies have found that P4 inhibited the expression of IFN- $\gamma$ and IL-17 dose-dependently in both pregnant and nonpregnant cows and strongly inhibits the differentiation of Th cells into Th1 and Th17 especially in the pregnant cows. Progesterone significantly increased the expression of IL-4 only in pregnant cow endometrium has a high level of the Th2 cell transcription factor, GATA-3, 
indicating that early pregnancy in cattle is associated with a skew towards Th2 immune cell profile (Maeda et al., 2013).

\section{$\underline{\text { Galectin-1 findings in cattle }}$}

Galectin-1 expression was shown to be 2.93 fold higher in blastocysts produced in vivo compared to in vitro produced (IVP) blastocysts (Mohan et al., 2004). Expression of LGALS1 by the pre-attachment conceptus may function to protect the implanting conceptus from the harmful effects of the maternal immune system. Reduced expression of LGALS1 by IVP embryos may be partially responsible for the high embryonic loss and poor pregnancy rates following the transfer of IVP embryos (Mohan et al., 2004). Galectin-1 receptors/binding proteins have been found on the conceptus and endometrium on day 16 of gestation (Mamo et al., 2012). There was also reduced expression of LGALS1 in the endometrium of low fertility dairy heifers (Killeen et al., 2014).

A study by R. Froehlich et al. (2012) showed LGALS1 was present at the fetal-maternal interface of the placentome. Through the techniques of immunohistochemistry (IHC), LGALS1 was localized to fibrocytes of the maternal lamina propria and monocytes of the uterine vessel walls. In the fetal smooth chorion, mononuculeate trophoblast cells showed weak staining in some areas during the late implantation period (day 30-60) but the intensity of the staining increased until day 100, then decreased until the end of gestation. Trophoblastic giant cells showed strong staining in the implantation period and early pregnancy until day 100 and was not reactive past that time. In the placentome, the maternal connective tissue was weakly stained, which increased steadily after day 180 . The smooth muscle cells of the vessel walls in the maternal and fetal compartment showed a uniform reaction. In early gestation, fetal endothelia in the vicinity of the maternal compartment displayed weak staining intensity, which increased 
continuously during mid and late gestation. In contrast to interplacentomal tissue, the caruncular epithelium in the placentome was positive throughout the course of pregnancy. The same applied to uninucleate trophoblast cells. In many TGC, LGALS1 was present in early pregnancy. However, the number of positive cells decreased with progressing gestation stage until day 270 when TGC was negative (Froehlich et al., 2012).

Galectin-1 was found to be a differentially expressed gene in the endometrium of AI pregnant cows when compared to cyclic cows. In vitro cell culture experiments of endometrial fibroblasts and glandular epithelial cells treated with IFNT showed that C11ORF34, LGALS1, and SCARA5 were not regulated by IFNT in either type of endometrial cell cultures. In situ hybridization was performed on the pregnant and cyclic endometrium and it was observed that LGALS1 expression was prominent in the stroma of cyclic and pregnant cows, but the staining of the endometrial glands appeared dimmer upon pregnancy (Mansouri-Attia et al., 2009). 


\title{
CHAPTER THREE
}

\section{EFFECT OF GALECTIN-1 ON ANTI-INFLAMMATORY AND PRO-INFLAMMATORY RELATED GENE EXPRESSION IN INTACT BOVINE ENDOMETRIUM}

\begin{abstract}
Early embryonic mortality, a major cause of pregnancy failure in cattle, may result from inappropriate maternal immune responses to the conceptus. Galectin-1 (LGALS1), an immunemodulatory protein, secreted by the bovine conceptus. Studies suggest LGALS1 increases expression of genes associated with regulatory T cells (Treg) and anti-inflammatory proteins within the bovine caruncle. The present study investigated the effect of LGALS1 on the expression of genes related to Treg and anti-inflammatory (FOXP3, IL-2RA, CD11c, and IL-10) as well as pro-inflammatory (CXCR4, $L I F, I L-33, I L-1 B$, and $I L-6)$ activities in inter-caruncular endometrium. Bovine inter-caruncular endometrial explants were collected from uteri (n=4) during the mid-luteal phase of the estrous cycle and cultured in Roswell Park Memorial Institute Medium (RPMI) media containing 0, 10, 100, or 1000 ng/mL of recombinant bovine LGALS1 for 6 or $24 \mathrm{~h}$. Explant mRNA abundance was then determined using RT-qPCR. A MIXED procedure in SAS was utilized to analyze the data. A contrast statement was included comparing control to all LGALS1 treatments. Treatment did not affect the expression of $I L-33$. At $6 \mathrm{~h}$, there was an effect of treatment on $I L-10(\mathrm{P} \leq 0.01), L I F, I L-1 B$, and $I L-6(\mathrm{P} \leq 0.001)$ mRNA. At $24 \mathrm{~h}$,
\end{abstract}


there was an effect of treatment on CXCR4, CD11c, IL-2RA, FOXP3 $(\mathrm{P} \leq 0.05), I L-10, L I F(\mathrm{P} \leq$ 0.01), $I L-6$, and $I L-1 B(\mathrm{P} \leq 0.001)$ mRNA. Expression in both pro- and anti-inflammatory genes increased with increasing concentration of LGALS1. Thus, bovine conceptus-derived LGALS1 may have important functions in the regulation of the maternal immune environment prior to implantation by inducing a balance of pro-inflammatory and anti-inflammatory states.

\section{INTRODUCTION}

In the cattle industry, reproductive success drives profitability and early embryonic is a large contributor to the economic loss in animal agriculture (Bellows et al., 2002, Wiltbank et al., 2016). Following fertilization, the conceptus enters the uterus approximately 5 days later.

Starting near day 13, the bovine conceptus begins to rapidly elongate into a long, filamentous structure. On day 13, the conceptus is approximately $5.3 \mathrm{~mm}$ in length. By day 16, the conceptus will be approximately 52mm in length (Grealy et al., 1996). During elongation the conceptus secretes interferon-tau (IFNT), which disrupts luteolysis and prevents the CL from regressing thus, providing adequate concentrations of progesterone (P4) to support pregnancy (Spencer et al., 2017). This process is termed as maternal recognition of pregnancy. As the conceptus develops and elongates, it also increases the production of conceptus secretory proteins (CSP), many of which are uncharacterized (O'Hara et al., 2013). Galectins, a conserved group of lectins that are characterized by their carbohydrate recognition domain (CRD), are considered bovine CSP. The galectin CRD on the galectins bind to $\mathrm{N}$-acetyllacosamine saccharide ligands on the cell surface. There are three classifications of galectins, type 1, 2, and 3 based on their CRD. Type 1 galectins are biologically active as homodimers while type 2 form heterodimers and type 3 are active as a chimera (Barrientos et al., 2014). In rodents, LGALS1, a type 1 galectin, reduced fetal loss in sound stressed mice (Blois et al., 2007). The LGALS1 effects were 
attributed to suppression of the endometrial immune system during implantation. Specifically, LGALS1 increased endometrial tolerogenic dendritic cells characterized by expression of CD11c, also known as ITGAX, and regulatory T-cells (Treg) that express CD4, FOXP3 and IL2RA (Blois et al., 2007). In cattle, LGALS1is present in the conceptus as well as caruncular and intercaruncular regions of pregnant bovine endometrium, specifically the maternal stroma, at all stages of gestation (Froehlich et al., 2012). The LGALS1 also was found to be expressed by the endometrium and early bovine conceptus as early as day 16 of gestation (Mansouri-Attia et al., 2009, Mamo et al., 2012, Forde et al., 2015). Further, studies have shown reduced LGALS1 expression in in vitro produced blastocysts compared to in vivo produced bovine blastocysts, which could be cause for high embryonic loss and poor pregnancy rates following transfer of an in vitro produced blastocyst (Mohan et al., 2004). Galectin-1 relative mRNA expression was also reduced in the endometrium of low fertility dairy heifers and was found to be involved in cellular growth and proliferation, cell death, cell morphology, small molecule biochemistry, and lipid metabolism through integrated pathway analysis (IPA) analysis. Thus, LGALS1 may have important functions during early gestation in cattle (Killeen et al., 2014). The precise role of LGALS1 during early pregnancy in cattle is unknown. Based on rodent studies and information presented in Chapter IV, LGALS1 may increase expression of both Treg and anti-inflammatory genes as well as pro-inflammatory related genes within the endometrium. Many of these genes are thought to be important for the establishment of pregnancy in mammals. This study investigated their expression in bovine endometrial explants in response to increasing concentrations of LGALS1.

\section{MATERIALS AND METHODS}

$\underline{\text { Tissue Collection }}$ 
Reproductive tracts $(\mathrm{n}=4)$ in the mid-luteal phase of the estrous cycle, based on the classification described by (Ireland et al., 1980), were collected from a local abattoir and placed on ice and transported to the laboratory (within approximately $1 \mathrm{~h}$ of slaughter). Intercaruncular endometrial explants were prepared as described (Borges et al., 2012). In the laboratory, the uterine horn ipsilateral to the CL was dissected longitudinally to expose the endometrium. The endometrium was washed with pre-warmed $\left(38.8^{\circ} \mathrm{C}\right) 1 \%$ PBS containing $1 \%$ anti-biotic antimycotic (ABAM; Gibco, Gaithersburg, MD). An 8 mm biopsy punch was used to dissect the intercaruncular tissue from the middle third of the uterine horn. Using sterile scissors, the myometrium was dissected, and the endometrial explants (50-80 mg) were then washed in 25 mL of Hank's Balanced Salt Solution (HBSS; Gibco) containing 1\% ABAM. Explants were then placed in culture wells (6-well plates; one explant/well) containing $3 \mathrm{~mL}$ of RPMI (pre-treatment medium,Gibco) containing 1\% ABAM. Explants were cultured endometrial side up in 5\% $\mathrm{CO}_{2}$ at $38.8^{\circ} \mathrm{C}$ for approximately $1 \mathrm{~h}$ before treatment. At treatment, pre-treatment media was removed and explants were treated with treatment media alone (Control) or treatment media containing 10, 100, or $1000 \mathrm{ng} / \mathrm{mL}$ of recombinant bovine LGALS1 (Cusabio, Houston, TX). The explants were treated for 6 or $24 \mathrm{~h}$ at $38.8^{\circ} \mathrm{C}$ at $5 \% \mathrm{CO}_{2}$. All treatments were applied to each uterus. After treatment, explants were cut in half, and one half of the explant was snap frozen in liquid nitrogen and stored at $-80^{\circ} \mathrm{C}$ until RNA extraction and the other half was fixed in $10 \%$ neutral buffered formalin (NBF).

\section{Explant RNA Extraction}

Total RNA extraction was carried out as described by Forde et al. (2009). Briefly, total RNA was extracted from $~ 50 \mathrm{mg}$ of endometrial explant tissue using Trizol reagent (Invitrogen, Carlsbad, CA) per the manufacturer's instructions. On-column RNA clean-up was performed 
using the Qiagen mini kit (Qiagen, Hilden, Germany). The quantity and quality of RNA samples were determined using the Nano Drop 1000 (Thermo Fisher Scientific, Waltham, MA) and the Agilent Bioanalyzer (Agilent Technologies, Santa Clara, CA), respectively. The RNA integrity number (RIN) \pm the standard deviation was $7.4 \pm 0.3$.

\section{$\underline{R T-q P C R}$}

Explant mRNA (500ng) was reverse transcribed into cDNA using the High-capacity cDNA Reverse Transcription Kit (Applied Biosystems, Foster City, CA), and cDNA samples were diluted 1:20 in nuclease free water. Reactions were $20 \mu \mathrm{L}$ including $10 \mu \mathrm{L}$ of PowerUP SYBR Green Master Mix (Bio-Rad; Hercules, CA), 1.2 $\mu \mathrm{L}$ of each primer, and 2.6 $\mu \mathrm{L}$ of DNase RNase free water, and $5 \mu \mathrm{L}$ of sample following the manufacturer's instructions. No reverse transcriptase controls were included. The RT-qPCR reactions were carried out using PowerUp SYBR Green Master Mix (Applied Biosystems) and the CFX96 Touch Real-Time PCR Detection System (Bio-Rad, Hercules, CA) following the manufacturer's recommendations. All samples were analyzed in duplicate and no reverse transcriptase controls and no template controls were included. Primers were created using Primer3Plus or obtained from previously published research. The PCR primer amplification efficiencies $\left(E ; E=\left[10^{(-1 / \text { lope })}-1\right]\right)$ for each PCR target sequence were calculated from the standard curve generated from seven cDNA dilutions made from a pool of cDNA samples. Diluted in a buffer containing 1\% 100X Tris EDTA (Sigma Aldrich) 0.4\% lambda DNA (Invitrogen, Carlsbad, CA) and DNase and RNase free water. Dilutions were 1:1, 1:4, 1:16, 1:64, 1:256, 1:1024, 1:4096, respectively. Slope generated from plotting Ct values against dilution for each serial dilution. Percent primer efficiency was calculated by dividing E by 2 and then multiplying by 100. Only primers with efficiencies between $90-110 \%$ were used. A dissociation analysis was included for each primer 
pair to evaluate primer specificity for the target sequence. Gel electrophoresis was used to confirm the primer pair by amplicon size.

Qbase+ qPCR analysis software (Biogazelle, Zwijnaarde, Belgium) was used to calculate the normalized relative expression quantities (NRQ) of target genes based on a generalized deltadelta quantification cycle method ( $\Delta \Delta \mathrm{Cq}$; also known as $\Delta \Delta \mathrm{CT}$ ) (Hellemans et al., 2007). To identify potential normalization targets, RT-qPCR was carried out for eight potential genes across a subset of samples representing all treatments. Tyrosine 3-monooxygenase/ tryptophan 5monooxygenase activation protein zeta (YWHAZ) and peptidyl-prolyl isomerase A (PPIA) were the most stably expressed across treatments using the geNorm analysis (geNorm $\mathrm{M}<0.25$; Vandesompele et al., 2002). The RT-qPCR thermo cycler settings for all reactions consisted of an initial temperature of $50^{\circ} \mathrm{C}$ for $2 \mathrm{~min}, 95^{\circ} \mathrm{C}$ for $2 \mathrm{~min}$ followed by 40 PCR cycles consisting of melting at $95^{\circ} \mathrm{C}$ for $15 \mathrm{sec}$ and annealing and extension at $60^{\circ} \mathrm{C}$ for 1 min. Genes $\mathrm{H} 3$ histone family member 3A (H3F3A) and succinate dehydrogenase complex flavoprotein subunit A (SDHA) were found to be the most stably expressed across treatments using the geNorm analysis (geNorm $\mathrm{M}<0.25$ ) (Vandesompele et al., 2002). The RT-qPCR thermo cycler settings for all reactions consisted of an initial temperature of $50^{\circ} \mathrm{C}$ for $2 \mathrm{~min}, 95^{\circ} \mathrm{C}$ for 2 min followed by 40 PCR cycles consisting of melting at $95^{\circ} \mathrm{C}$ for $15 \mathrm{sec}$ and annealing and extension at $60^{\circ} \mathrm{C}$ for 1 $\min$.

\section{$\underline{\text { Statistical Analysis }}$}

A mixed procedure in the statistical analysis software (SAS) was used to analyze for an effect of treatment on the log base $10(\log 10)$ explant relative expression data. A Tukey-Kramer adjustment was included for multiple comparisons. One contrast compared Control to all LGALS1 treatments $(10,100,1000 \mathrm{ng} / \mathrm{mL})$. Data residuals were scrutinized for normality using 
the PLOTS=(diagnostics residuals) statement. All relative expression values are presented in their original format; however, all p-values are that of the log10 transformation. If $\log 10$ transformed residual data were not normally distributed, they were transformed by squareroot (sqrt) transformation. Data are presented as least squares means \pm standard error of the least squares mean $(\mathrm{LSM} \pm \mathrm{SEM})$. Statistical significance was declared at $\mathrm{P} \leq 0.05$.

\section{RESULTS}

\section{Intercaruncular mRNA Expression of Regulatory T-cell Related Genes}

Treatment affected endometrial relative gene expression of FOXP3 at 24 h compared to control (Figure 3.1; Control, 10, 100 and 1000 ng/mL LGALS1; LSM + SEM; 0.57, 0.75, 0.78 and $0.75 \pm 0.23 ; \mathrm{P} \leq 0.05)$. Treatment increased the endometrial relative expression of $I L-2 R A$ at 24 h compared to Control (Figure 3.3; 0.54, 0.65, 1.00 and 1.26 $\pm 0.33 ; \mathrm{P} \leq 0.05$ ).

\section{Intercaruncular mRNA Expression of Anti-Inflammatory Related Genes}

Treatment affected endometrial relative gene expression of $I L-10$ at $6 \mathrm{~h}$ and $24 \mathrm{~h}$ compared to Control (Figure 3.2; 6 h 1.15, 1.40, 2.21 and 2.76 \pm 0.41; P $\leq 0.01 ; 24$ h 0.52, 0.52, 0.70 and $0.91 \pm 0.14 ; \mathrm{P} \leq 0.01$ ). There was a tendency for treatment to affect endometrial gene expression of $C D 11 c$ at 24 h (Figure 3.4; 0.77, 0.91, 1.21 and $1.37 \pm 0.17$; sqrt transformation; P $=0.06)$.

\section{Intercaruncular mRNA Expression of Pro-Inflammatory Related Genes}

There was an effect of treatment on endometrial relative expression of $I L-1 B$ at $6 \mathrm{~h}$ and $24 \mathrm{~h}$. Expression of $I L-1 B$ mRNA at $6 \mathrm{~h}$ was greater when all LGALS1 treatments were compared to Control (Figure 3.5; 0.33, 0.70, 1.34 and $2.54 \pm 0.31$; sqrt transformed; $\mathrm{P} \leq 0.001$ ), Expression of $I L-1 B$ mRNA at $24 \mathrm{~h}$ was greater when all LGALS1 treatments were compared to 
Control (Figure 3.5; 0.50, 1.24, 2.90 and $2.66 \pm 0.43 ; \mathrm{P} \leq 0.001$ ). There was an effect of treatment on endometrial relative gene expression of $L I F$ at $6 \mathrm{~h}$ and $24 \mathrm{~h}$. Expression of mRNA was greater when all LGALS1 treatments were compared to Control (Figure 3.6; 0.44, 0.65, 1.10 and $1.91 \pm 0.17 ; \mathrm{P} \leq 0.001)$. Endometrial relative expression of LIF mRNA at $24 \mathrm{~h}$ was greater when all LGALS1 treatments were compared to Control (Figure 3.6; 0.65, 1.20, 1.43 and $2.13 \pm$ 0.28 ; sqrt transformed; $\mathrm{P} \leq 0.01$ ). There was an effect of treatment on endometrial relative gene expression of $I L-6$ at 6 and $24 \mathrm{~h}$. Expression of IL-6 mRNA was greater when all LGALS1 treatments were compared to Control for $6 \mathrm{~h}$ (Figure 3.7; 0.34, 1.12, 4.07 and $6.98 \pm 1.09$; $\mathrm{P} \leq$ 0.001 ) and $24 \mathrm{~h}$ (Figure 3.7; 0.23, 0.61, 1.10 and $1.77 \pm 0.20 ; \mathrm{P} \leq 0.001$ ). There was an effect of treatment on endometrial expression of $C X C R 4$ at $24 \mathrm{~h}$. Expression of CXCR4 mRNA was greater when all LGALS1 treatments were compared to Control (Figure 3.8; 3.10, 4.00, 4.50, $4.20 \pm 0.52 ; \mathrm{P} \leq 0.05)$.

\section{DISCUSSION}

Expression of LGALS1 has been found in the trophectoderm of human preimplantation embryos as well as in the mouse uterus during implantation (Choe et al., 1997), Tirado-Gonzalez et al., 2013). Evidence suggests that human LGALS1 plays important roles in implantation, angiogenesis, maternal-fetal immunotolerance, and placentation (Bojić-Trbojević et al., 2015). Studies have shown expression of LGALS1 in the bovine day 7 blastocyst and in the conceptus

and endometrium on day 16 of gestation (Mamo et al., 2012, (Forde et al., 2015), Mansouri-Attia et al., 2009). However, the effect of LGALS1 within the bovine endometrium has not been investigated.

The aim of this study was to investigate the role of bovine conceptus LGALS1 in bovine endometrium with a specific emphasis on Treg and anti-inflammatory as well as pro- 
inflammatory gene expression. Our findings indicate increased gene expression of Treg markers such as $I L-2 R A$ and FOXP3, and tolerogenic dendritic cell (DC) marker CD11c with increasing concentrations of LGALS1.

Galectin-1 has been described as a pro-adhesive molecule (Barrientos et al., 2014). Recently, research has pointed to LGALS1 also being a regulator of immune responses during pregnancy (Blois et al., 2007). In mice and humans, LGALS1 selectively induces apoptosis of pro-inflammatory Th1 and Th17 cell subsets but not naïve Th2 or Treg (Toscano et al., 2007). A particular Th subset of interest is Treg which includes CD4+ T cells that co-express high levels of CD25 (IL-2RA) and the transcription factor FOXP3. This particular phenotype has been identified in the human and mouse (Tan et al., 2011, Jonuleit et al., 2001, Baecher-Allan et al., 2001, Klages et al., 2010). Research has shown that Tregs promote immunosuppression. Data suggest that IL-10 and TGF- $\beta$ are important mediators of Treg activity. In a study to investigate the Treg-specific immunosuppressive molecules in mice and humans, LGALS1 was identified as a significantly expressed and secreted by Tregs. The investigator also showed that Treg immunosuppressive activity was blocked by the use of anti-LGALS1 in vitro (Garin et al., 2007).

In a previous study, LGALS1 reduced fetal loss in sound stressed rodents (Blois et al., 2007). The author found that LGALS1 increased the presence of Treg in the uterus and hypothesized that LGALS1 was promoting fetomaternal tolerance. When the presence of Treg was reduced, the effects were abrogated and there was a higher percentage of fetal loss. The author also suggests that LGALS1 may act upstream of IL-10 to promote fetal survival by increasing CD11c tolerogenic dendritic cell activity. Through these findings, we can conclude that LGALS1 plays a pivotal role in the fetomaternal tolerance through modulation of multiple immunoregulatory mechanisms (Blois et al., 2007). 
Findings of the current study coincide with previous research as we also found an increase in the gene expression of $C D 11 c, F O X P 3, I L-2 R A$, and $I L-10$ with the treatment of LGALS1. This suggests that bovine conceptus-derived LGALS1 may have important functions in the regulation of the maternal immune environment prior to implantation possibly through bovine endometrial Treg activity.

Nuclear factor kappa B (NFKB) is a transcription factor known to be involved in cellular signaling, it is activated by IL-1B. In turn, NFKB can increase expression of IL-1B in an auto feedback loop (Mathew et al., 2015). It has been suggested that IL-1 is increased by progesterone and estrogen at implantation, and that it maintains a delicate and complex balance that exists during the establishment of pregnancy (Martal et al., 1997). In ruminants IL-1B, an adhesion molecule in the IL-1 family, is produced by the embryo, trophoblast and endometrium (Mathialagan et al., 1992). IL-1 has been shown to increase LIF and IL-6 production in endometrial epithelial cells (Laird et al., 2000). The pro-inflammatory cytokines IL-6 and LIF have been found to be important for implantation and conceptus viability, in sheep, humans, rodents, and pigs (Ashley et al., 2011, Fry et al., 1992, Mathew et al., 2016, Laird et al., 2000). The promoter regions of $L I F$ and $I L-6$ genes contain NFKB binding sites and expression of these cytokines in other cells has been shown to be controlled by NFKB (Van der Burg and Van der Saag, 1996).

Importance of LIF in the endometrium was discovered in studies conducted with LIF knock-out mice in which implantation did not occur (Stewart et al., 1992). In human endometrium, LIF concentrations peak around the time of implantation and, are decreased in women with unexplained infertility (Laird et al., 1997). Studies have shown habitual abortion in women can be associated with a decrease in expression of IL-1B and IL-6 (Wolff et al., 2000). 
LIF was increased in pregnant bovine endometrium compared to cyclic endometrium until day 13 of gestation where it then remained constant (Oliveira et al., 2017). IL-6 is produced by the bovine trophoblast as well as in mice, pigs, and sheep (Mathialagan et al., 1992). IL-6 increases the production of complement inhibitors and proteases which may play a role in chorionic placentation (Martal et al., 1997). It also increases the permeability of endothelial cells, suggesting it may play a similar role in ability of the trophoblast to implant during early pregnancy (Maruo et al., 1992).

Based on findings in Chapter IV, expression of these cytokines may be along the bovine uterine surface epithelium to promote enhanced conceptus quality and attachment. The majority of immune cells can be found in the underlying stroma which may be the source of LGALS1 induced regulation of T-cell markers FOXP3 and IL-2RA and anti-inflammatory markers IL-10 and tolerogenic dendritic cells CD11c.

The relevance of this study applies to the cattle industry and can be used to further advance the knowledge of the immune environment within bovine endometrium before implantation of the bovine conceptus. Blois et al. (2007) found that LGALS1 was able to rescue pregnancies in rodents at risk of pregnancy failure. This could be caused by inducing a balance of pro-inflammatory state in the uterine surface epithelium while an anti-inflammatory state, promoted by uterine immune cells in the sub-epithelial tissue. Further research is needed to identify which cell types are involved in the expression of pro- vs. anti-inflammatory genes.

\section{CONCLUSION}

In conclusion, this study identified LGALS1 responsive genes in bovine intercaruncular endometrium related to anti-inflammatory and pro-inflammatory states. Here, LGALS1 could 
play a role in modulating the maternal immune environment within the endometrium during conceptus implantation by inducing cell type-specific expression of pro- and anti-inflammatory related genes. 
Table 3.1- GenBank accession number, gene name, primer sequence (forward and reverse), product size, amplication efficiency, and source of primer for gene cDNA amplified using RT-qPCR.

\begin{tabular}{|c|c|c|c|c|c|c|}
\hline $\begin{array}{l}\text { GenBank } \\
\text { Acc. Number }\end{array}$ & Gene & Primer & 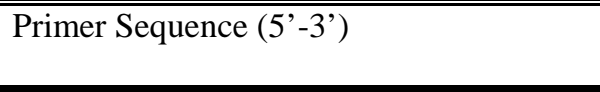 & $\begin{array}{l}\text { Product } \\
\text { Size (bp) }\end{array}$ & Amp. E. & Source of Primer \\
\hline NM_174301.3 & CXCR4 & $\begin{array}{l}\text { Forward } \\
\text { Reverse }\end{array}$ & $\begin{array}{l}\text { AAGGCTCAGAAGCGCAAG } \\
\text { GAGTCGATGCTGATCCCAAT }\end{array}$ & 102 & $102.2 \%$ & (Weiner et al., 2012) \\
\hline NM_015459645.2 & MST1R & $\begin{array}{l}\text { Forward } \\
\text { Reverse }\end{array}$ & $\begin{array}{l}\text { GAAAAGGGCGTAGAGCACTG } \\
\text { CAACAGCCCGTTGAATAGGT }\end{array}$ & 195 & $107.2 \%$ & Primer3Plus \\
\hline NM_001191189.1 & TNFAIP2 & $\begin{array}{l}\text { Forward } \\
\text { Reverse }\end{array}$ & $\begin{array}{l}\text { GCCTTTGATGGATTTCTGGA } \\
\text { CTGCGTGAACCTCTTGAACA }\end{array}$ & 239 & $103.6 \%$ & Primer3Plus \\
\hline NM_001243311.1 & OTUD4 & $\begin{array}{l}\text { Forward } \\
\text { Reverse }\end{array}$ & $\begin{array}{l}\text { AGCCTTTACCAGGACCCACT } \\
\text { GGGACCTTTGGGTACATCCT }\end{array}$ & 242 & $111.3 \%$ & Primer3Plus \\
\hline NM_025000176.1 & ATP11A & $\begin{array}{l}\text { Forward } \\
\text { Reverse }\end{array}$ & $\begin{array}{l}\text { GGTGATGGTGCTCACAGTCA } \\
\text { CCAGATGACTCCTCCCCAGA }\end{array}$ & 133 & $98.6 \%$ & Primer3Plus \\
\hline NM_001102526.1 & PROSER2 & $\begin{array}{l}\text { Forward } \\
\text { Reverse }\end{array}$ & $\begin{array}{l}\text { CCTTGAACGCAAGAAAGAGG } \\
\text { GGGAAGTGGACCTCAAAACA }\end{array}$ & 197 & $95.5 \%$ & Primer3Plus \\
\hline XM_002699238.6 & SLC15A3 & $\begin{array}{l}\text { Forward } \\
\text { Reverse }\end{array}$ & $\begin{array}{l}\text { GGTGGCCTTTATCCAACAGA } \\
\text { GGACAGCAGTTTTGGAGAGC }\end{array}$ & 174 & $103.8 \%$ & Primer3Plus \\
\hline XM_024986067.1 & CHST15 & $\begin{array}{l}\text { Forward } \\
\text { Reverse }\end{array}$ & $\begin{array}{l}\text { TCTGCTCTCTTGTGTGCGAG } \\
\text { CCTGGGTAGTGAGAGAGGCT }\end{array}$ & 119 & $97.1 \%$ & Primer3Plus \\
\hline NM_174358.2 & $I L-2 R A$ & $\begin{array}{l}\text { Forward } \\
\text { Reverse }\end{array}$ & $\begin{array}{l}\text { ACATCGGCAGTGGTCTCAG } \\
\text { GAACCTCCACATCAGCAAGC }\end{array}$ & 59 & $109.1 \%$ & (Zoldan et al., 2014) \\
\hline XM_024985296.1 & $C D 11 C$ & $\begin{array}{l}\text { Forward } \\
\text { Reverse }\end{array}$ & $\begin{array}{l}\text { CCCCAAATAAGAACCCCACC } \\
\text { ACCCAGATACGAGTCCСТCA }\end{array}$ & 71 & $101.1 \%$ & (Mathew et al., 2018) \\
\hline NM_001045933.1 & FOXP3 & $\begin{array}{l}\text { Forward } \\
\text { Reverse }\end{array}$ & $\begin{array}{l}\text { TGGTGCTGGAGAAGGAGAAG } \\
\text { GTCAGATGATGCCGCAGATG }\end{array}$ & 92 & $100.6 \%$ & (Mathew et al., 2018) \\
\hline NM_174088.1 & $I L-10$ & $\begin{array}{l}\text { Forward } \\
\text { Reverse }\end{array}$ & $\begin{array}{l}\text { CCAAGCCTTGTCGGAAATGA } \\
\text { GTTCACGTGCTCCTTGATGTCA }\end{array}$ & 91 & $99.7 \%$ & (Fonseca et al., 2009) \\
\hline NM_173923.2 & $I L-6$ & $\begin{array}{l}\text { Forward } \\
\text { Reverse }\end{array}$ & $\begin{array}{l}\text { CGCATGGTCGACAAAATCTCT } \\
\text { GCTGCTTTCACACTCATCATTCTT }\end{array}$ & 69 & $95.3 \%$ & (Mathew et al., 2019) \\
\hline NM_001076409.1 & NFKB1 & $\begin{array}{l}\text { Forward } \\
\text { Reverse }\end{array}$ & $\begin{array}{l}\text { ATACTGAACAATGCCTTCCGG } \\
\text { CACGTCAATGGCCTCAGTGTAG }\end{array}$ & 135 & $96.0 \%$ & (Meade et al., 2008) \\
\hline NM_174093.1 & $I L-1 B$ & $\begin{array}{l}\text { Forward } \\
\text { Reverse }\end{array}$ & $\begin{array}{l}\text { ACCTGAACCCATCAACGAAATG } \\
\text { TAGGGCCATCAGCCTCAAATAACA }\end{array}$ & 74 & $93.0 \%$ & (Mathew et al., 2019) \\
\hline NM_173931.1 & LIF & $\begin{array}{l}\text { Forward } \\
\text { Reverse }\end{array}$ & $\begin{array}{l}\text { GGGACAACTCAACAGCAGTG } \\
\text { GCACAGCTTGTCCAGGTTG }\end{array}$ & 91 & $96.0 \%$ & Primer3Plus \\
\hline NM_001075297.1 & $I L-33$ & $\begin{array}{l}\text { Forward } \\
\text { Reverse }\end{array}$ & $\begin{array}{l}\text { TTGTTTTGGAGGATGGAAGC } \\
\text { TTTGTGGGCTCAGGTTTAC }\end{array}$ & 163 & $97.8 \%$ & (Killeen et al., 2014) \\
\hline NM_174355.2 & $I L-12 a$ & $\begin{array}{l}\text { Forward } \\
\text { Reverse }\end{array}$ & $\begin{array}{l}\text { GAATGCAAAGCTTCTGATGGA } \\
\text { GGCACAGTCTCACTGTCGAA }\end{array}$ & 111 & $92.4 \%$ & Primer3Plus \\
\hline NM_174368.3 & ITGB1 & $\begin{array}{l}\text { Forward } \\
\text { Reverse }\end{array}$ & $\begin{array}{l}\text { TCAGACTTCCGAATTGGGTTTG } \\
\text { AAATGGGCTCGTGCAGTTCT }\end{array}$ & 118 & $97.5 \%$ & (Oliveira et al., 2017) \\
\hline NM_001014389.2 & H3F3A & $\begin{array}{l}\text { Forward } \\
\text { Reverse }\end{array}$ & $\begin{array}{l}\text { CATGGCTCGTACAAAGCAGA } \\
\text { ACCAGGCCTGTAACGATGAG }\end{array}$ & 136 & - & \\
\hline NM_174178.2 & $S D H A$ & $\begin{array}{l}\text { Forward } \\
\text { Reverse }\end{array}$ & $\begin{array}{l}\text { ACTTCACCGTTGATGGCAA } \\
\text { GCAGAAATCGCATCTGAAA }\end{array}$ & 59 & - & \\
\hline
\end{tabular}




\section{FOXP3 (24h)}

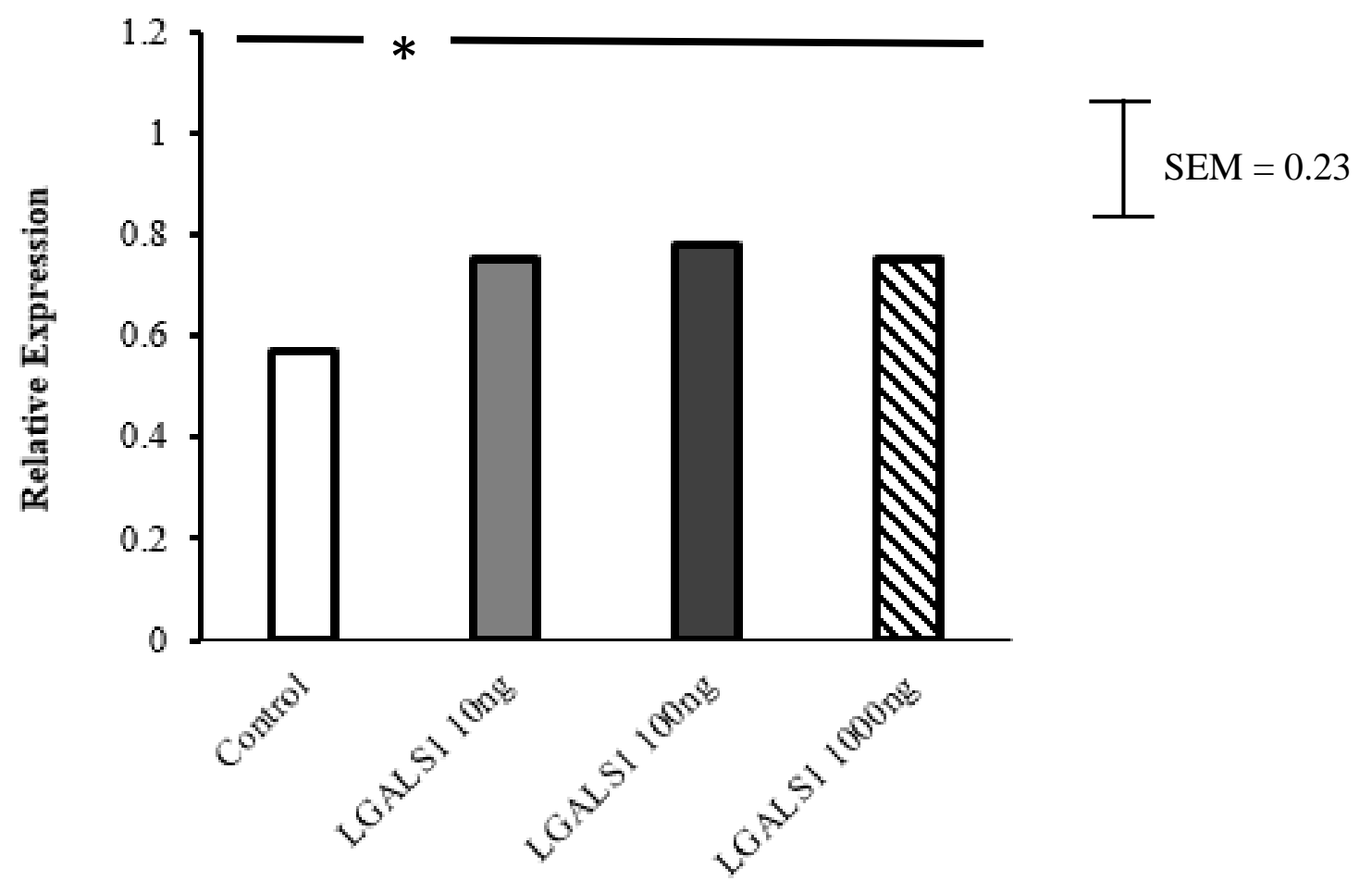

Figure 3.1 Least squares means relative expression values for FOXP3 in endometrial explants ( $\mathrm{n}=4$ uteri) treated with increasing concentrations of LGALS1 (Control, 10, 100 , or $1000 \mathrm{ng} / \mathrm{mL}$ ). There was a significant effect of treatment (Contrast; $\mathrm{P} \leq 0.05$ ) when all LGALS1 treatments were compared to Control. (SEM= 0.23). 

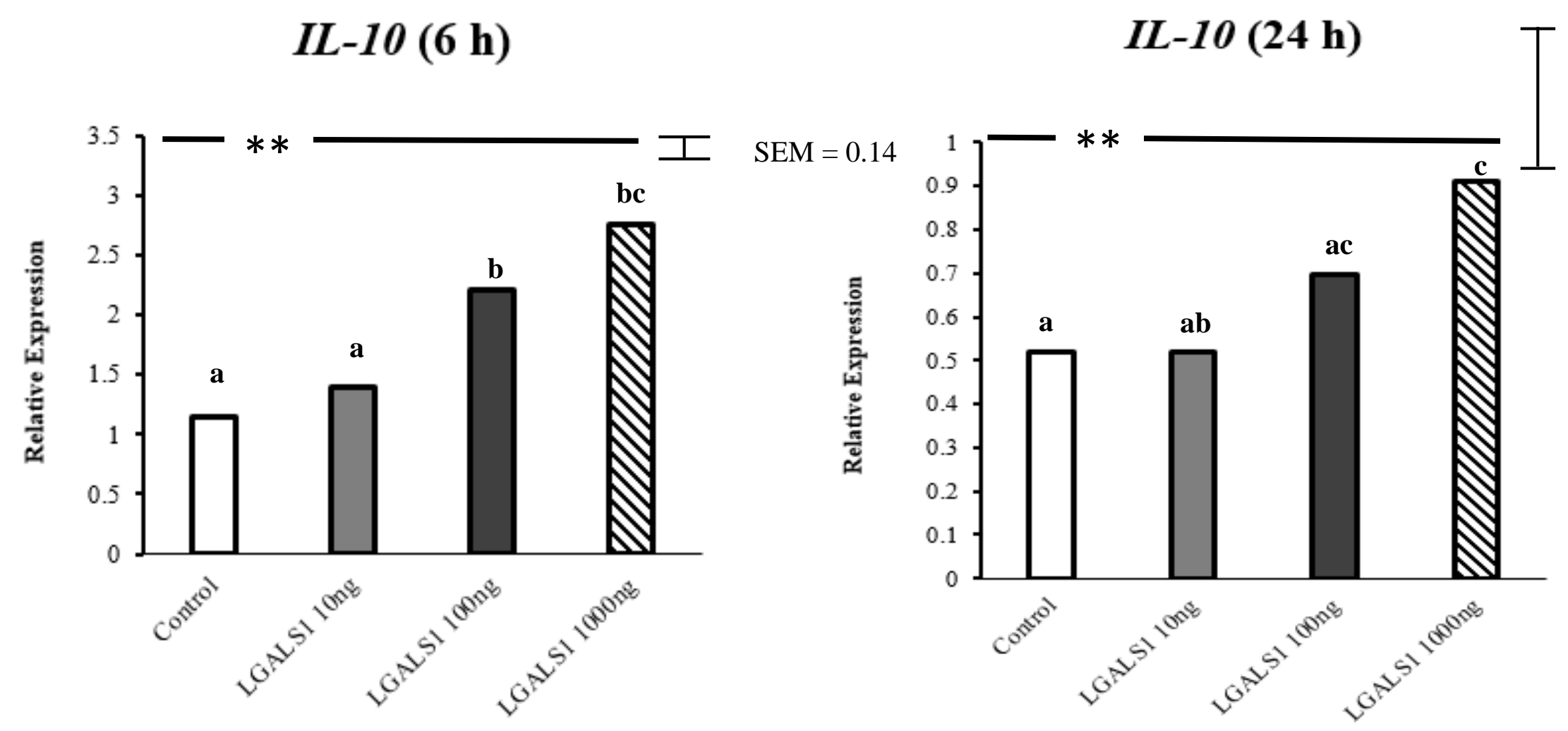

Figure 3.2 Least squares means relative expression values for $I L-10$ in endometrial explants ( $\mathrm{n}=4$ uteri) treated with increasing concentrations of LGALS1 (Control, 10, 100, or $1000 \mathrm{ng} / \mathrm{mL}$ ). There was a significant effect of treatment (Contrast; $\mathrm{P} \leq 0.01$ ) when all LGALS1 treatments were compared to control. At $6 \mathrm{~h}(\mathrm{SEM}=0.14)$ at $24 \mathrm{~h}$ $(\mathrm{SEM}=0.41)$. 


\section{$\operatorname{IL2RA}(24 \mathrm{~h})$}

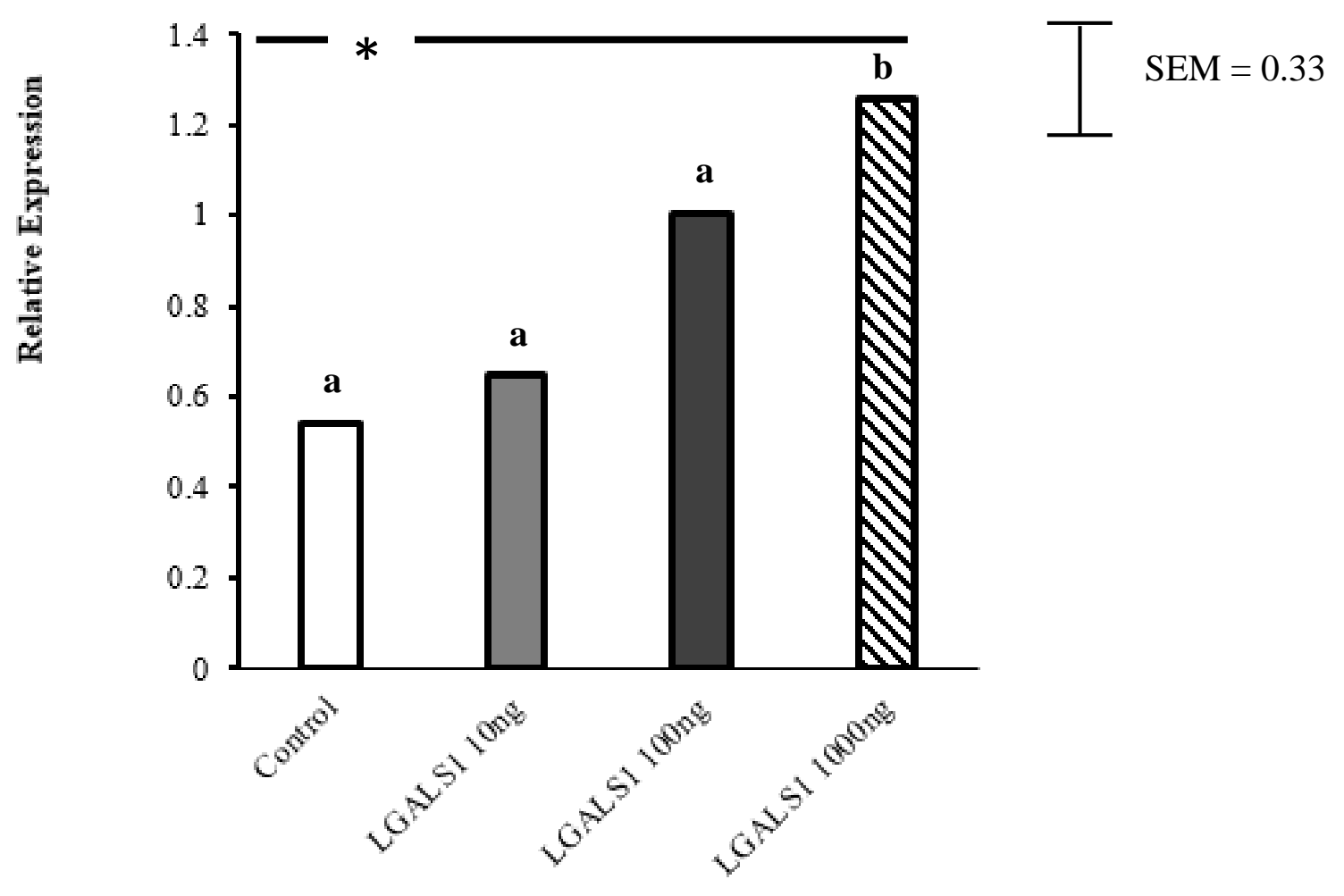

Figure 3.3 Least squares means relative expression values for $I L-2 R A$ in endometrial explants ( $\mathrm{n}=4$ uteri) treated with increasing concentrations of LGALS1 (Control, 10, 100, or $1000 \mathrm{ng} / \mathrm{mL}$ ). There was a significant effect of treatment (Contrast; $\mathrm{P} \leq 0.05$ ) when all LGALS1 treatments were compared to Control. (SEM=0.33). 


\section{CD11c (24 h)}

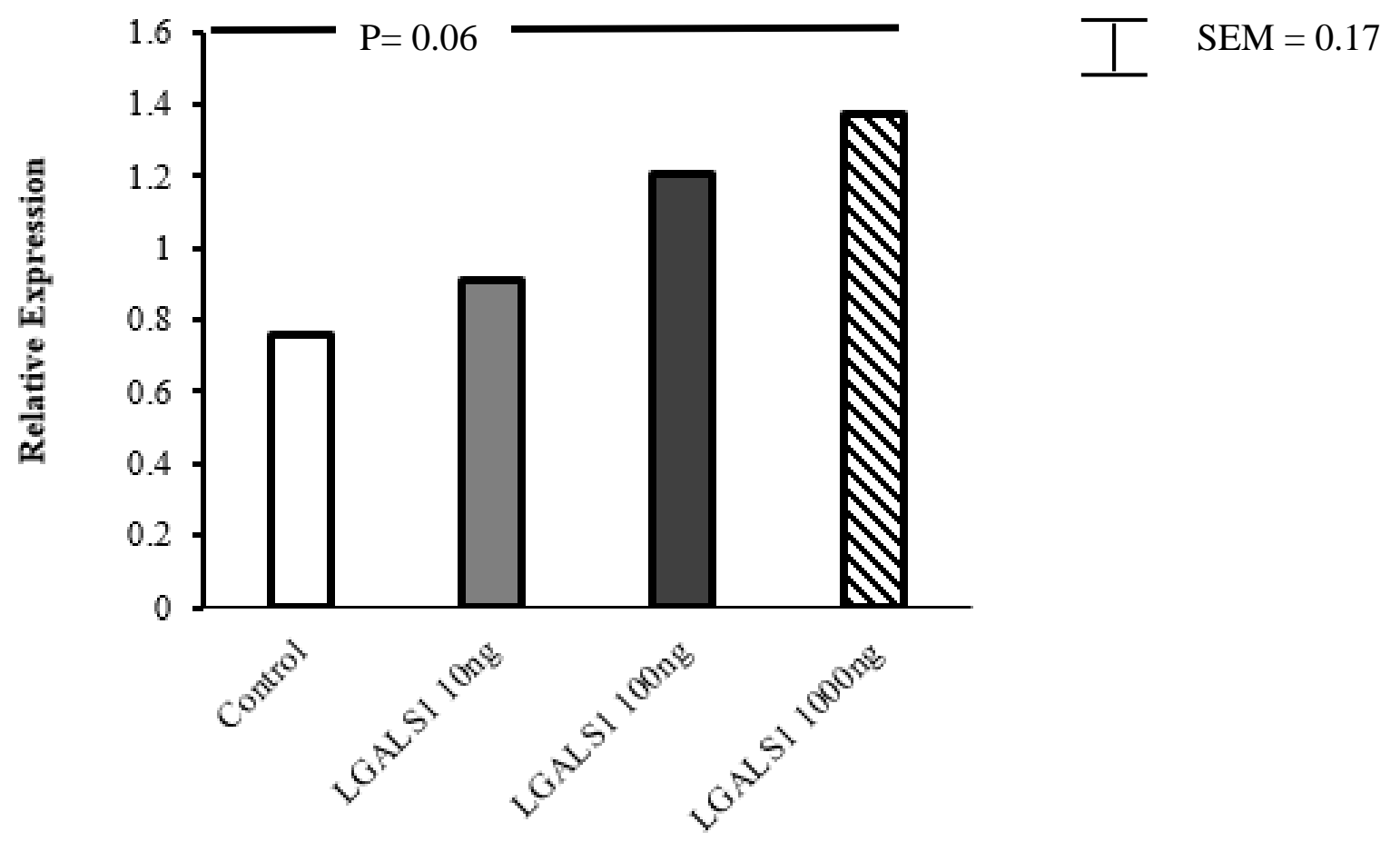

Figure 3.4 Least squares means relative expression values for CD11c in endometrial explants ( $n=4$ uteri) treated with increasing concentrations of LGALS1 (Control, 10, 100, or $1000 \mathrm{ng} / \mathrm{mL}$ ). There was a tendency for an effect of treatment (Contrast; $\mathrm{P}=0.06$ ) when all LGALS1 treatments were compared to Control. (SEM; 0.17). 
$I L-1 B(6 \mathrm{~h})$
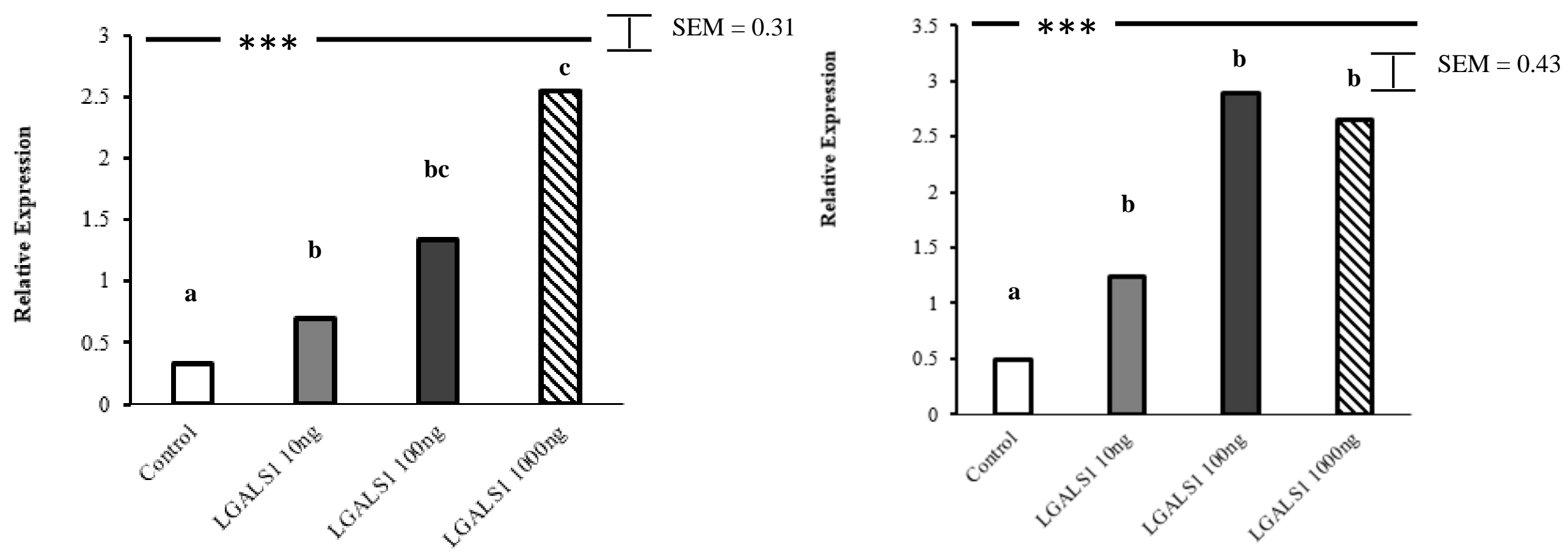

Figure 3.5 Least squares means relative expression values for $I L-1 B$ in endometrial explants ( $n=4$ uteri) treated with increasing concentrations of LGALS1 (Control, 10, 100, or $1000 \mathrm{ng} / \mathrm{mL}$ ). There was a significant effect of treatment (Contrast; $\mathrm{P} \leq 0.001$ ) when all LGALS1 treatments were compared to Control. At $6 \mathrm{~h}(\mathrm{SEM}=0.31)$ at $24 \mathrm{~h}$ $(\mathrm{SEM}=0.43)$. 
$L I F(6$ h)

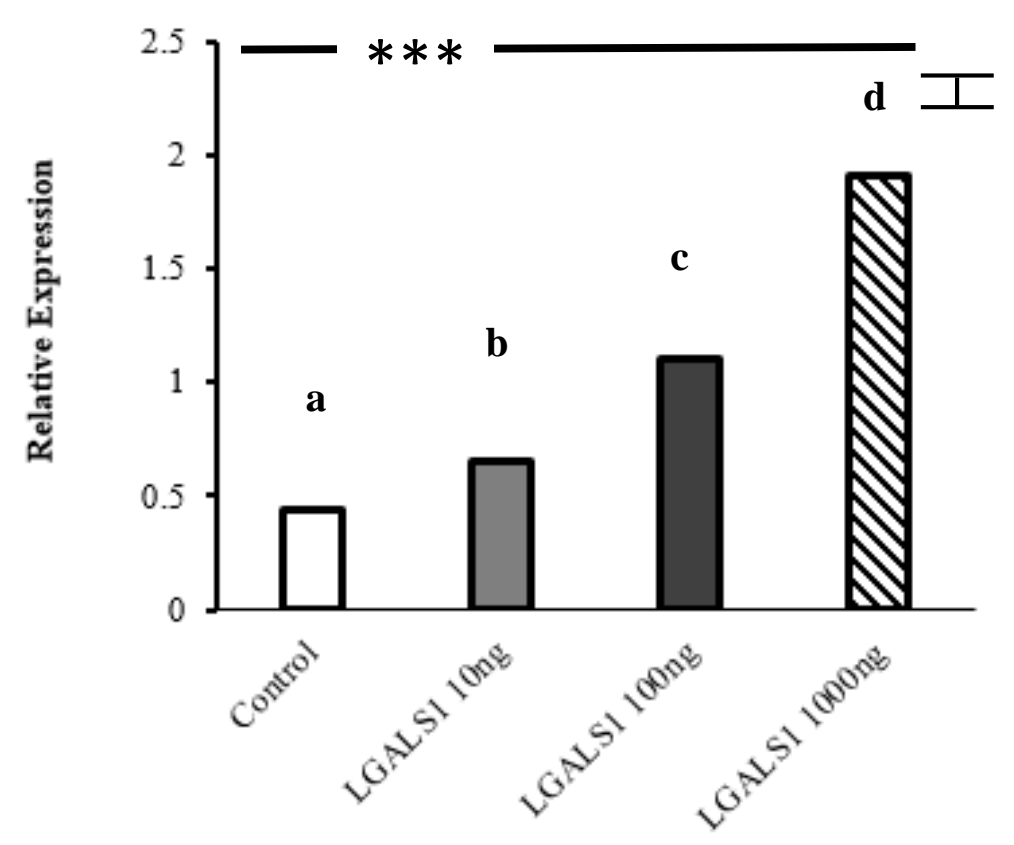

LIF (24 h)

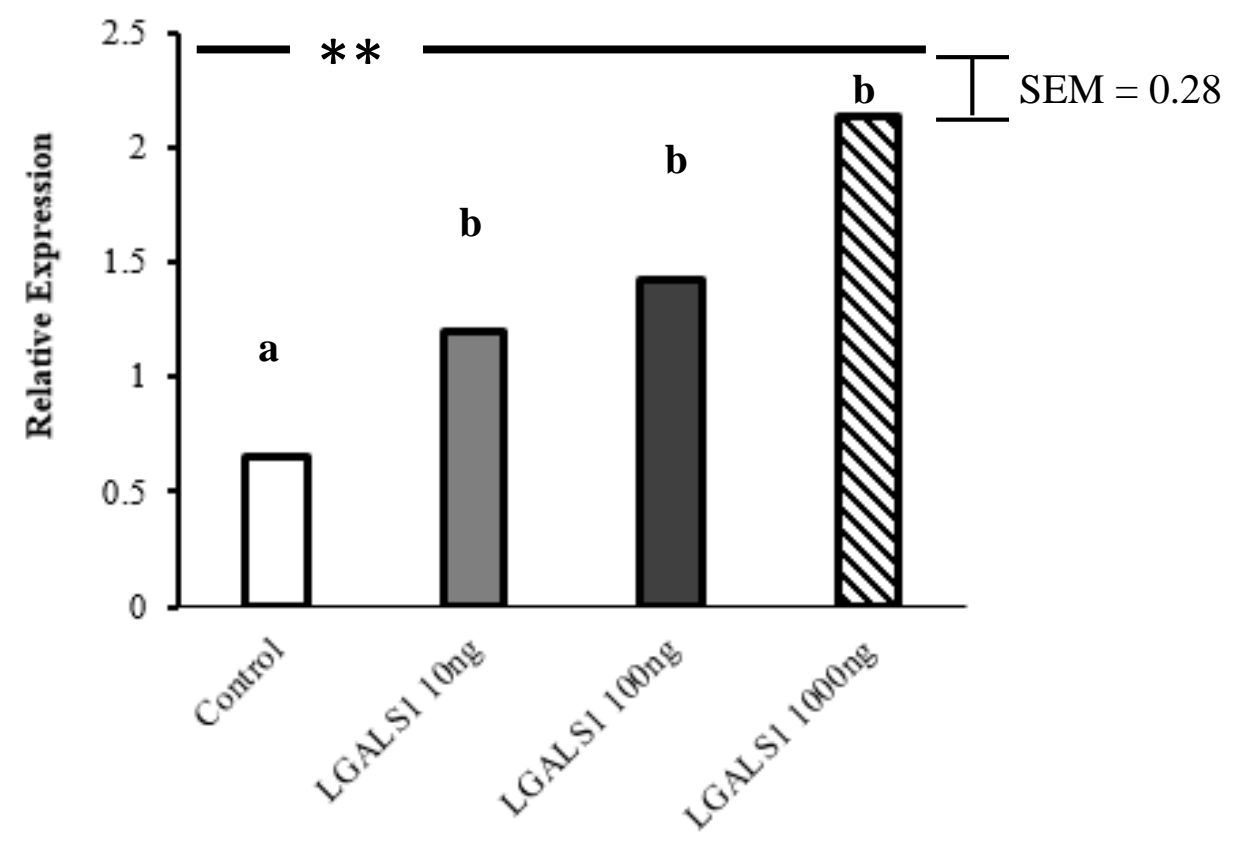

Figure 3.6 Least squares means relative expression values for LIF in endometrial explants ( $\mathrm{n}=4$ uteri) treated with increasing concentrations of LGALS1 (Control, 10, 100, or $1000 \mathrm{ng} / \mathrm{mL}$ ). There was a significant effect of treatment at $6 \mathrm{~h}$ (Contrast; $\mathrm{P} \leq 0.001$ ) and at $24 \mathrm{~h}$ (Contrast; $\mathrm{P} \leq 0.01)$ when all LGALS1 treatments were compared to Control. At $6 \mathrm{~h}(\mathrm{SEM}=0.17)$ at $24 \mathrm{~h}(\mathrm{SEM}=0.28)$. 
$I L-6(6 \mathrm{~h})$

$\operatorname{IL}-6(24 \mathrm{~h})$

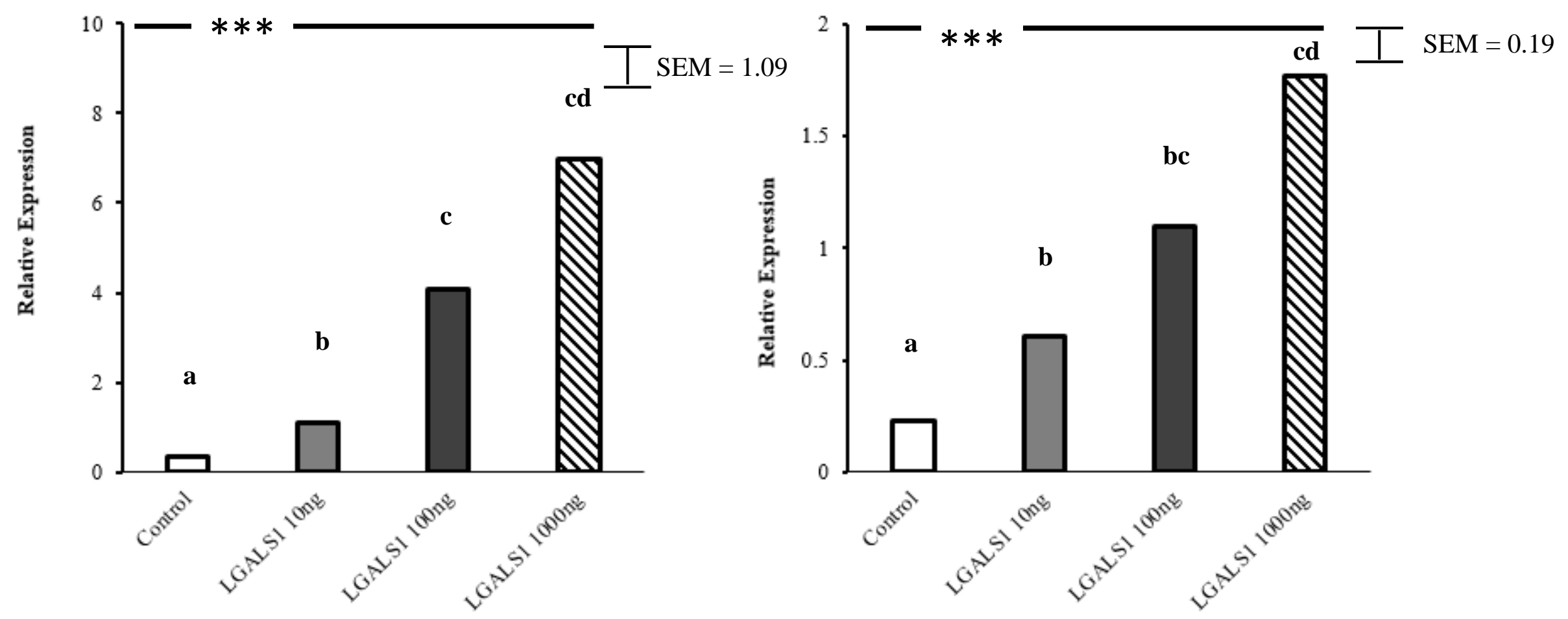

Figure 3.7 Least squares means relative expression values for $I L-6$ in endometrial explants ( $\mathrm{n}=4$ uteri) treated with increasing concentrations of LGALS1 (Control, 10, 100, or $1000 \mathrm{ng} / \mathrm{mL}$ ). There was a significant effect of treatment (Contrast; $\mathrm{P} \leq 0.001$ ) when all LGALS1 treatments were compared to Control. At $6 \mathrm{~h}(\mathrm{SEM}=1.09)$ at $24 \mathrm{~h}$ $(\mathrm{SEM}=0.19)$. 


\section{CXCR4 (24 h)}

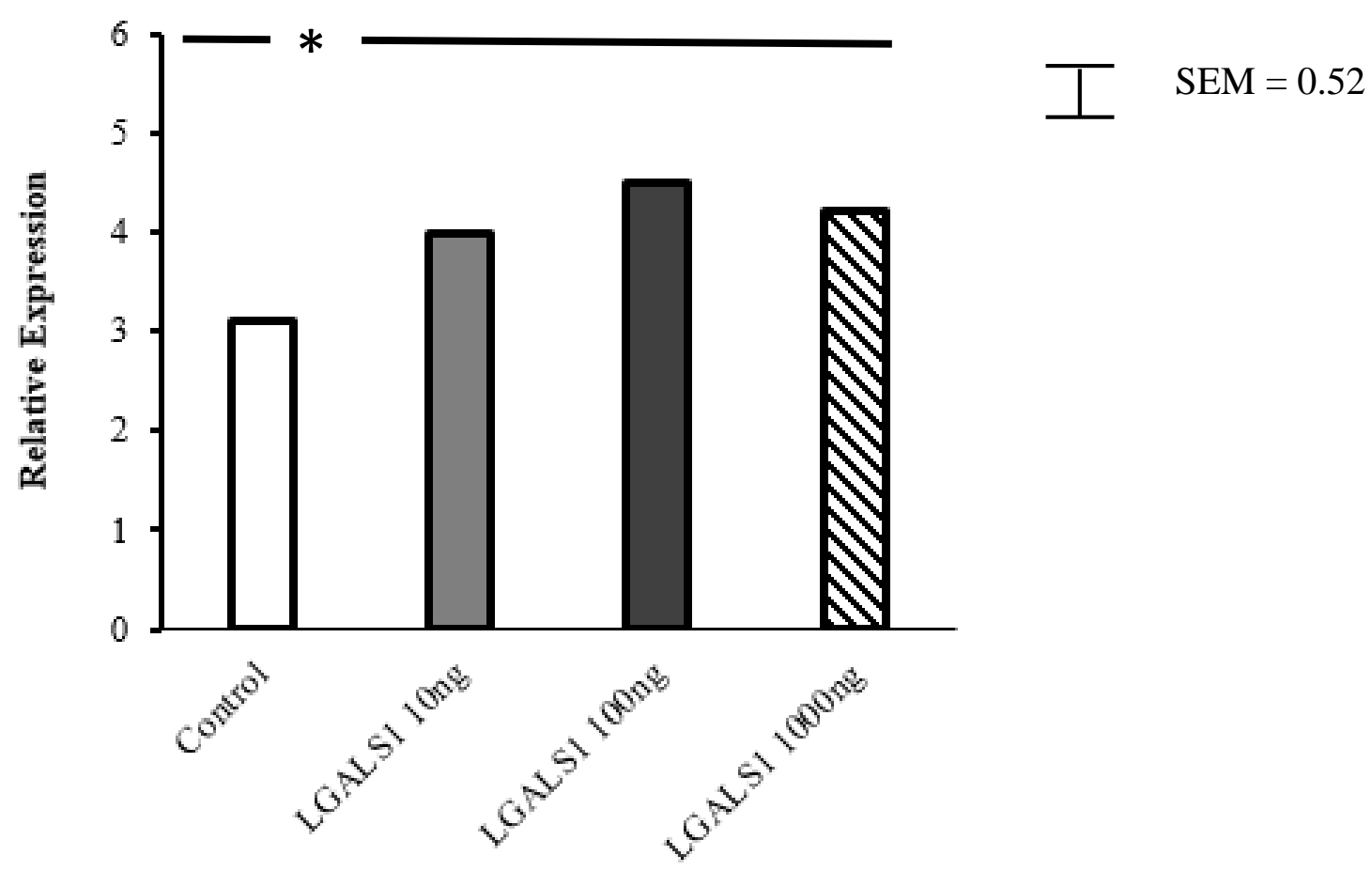

Figure 3.8 Least squares means relative expression values for CXCR4 in endometrial explants ( $\mathrm{n}=4$ uteri) treated with increasing concentrations of LGALS1 (Control, 10, 100, or $1000 \mathrm{ng} / \mathrm{mL}$ ). There was a significant effect of treatment (Contrast; $\mathrm{P} \leq 0.05)$ when all LGALS1 treatments were compared to Control. (SEM= 0.52). 
Table 3.2 Summary of relative expression data for genes amplified by RT-qPCR in endometrial explants treated with increasing concentrations of LGALS1. LSM \pm SEM. P-values are that of the log-transformed data. Contrast: Control vs. Galectin-1 (10, 100 and 1000ng/mL).

\begin{tabular}{|c|c|c|c|c|c|c|c|c|}
\hline \multicolumn{8}{|c|}{ Treatment } & \multirow{2}{*}{$\frac{\text { Contrast }}{\mathrm{C}}$} \\
\hline Gene & Time & Control & 10 & 100 & 1000 & SEM & TRT & \\
\hline \multirow[t]{3}{*}{ ATP11a } & 6 & 1.13 & 1.12 & 0.87 & 1.24 & 0.21 & NS & NS \\
\hline & 24 & 0.70 & 1.00 & 0.70 & 1.05 & 0.16 & NS & NS \\
\hline & $6+24$ & 0.92 & 1.06 & 0.79 & 1.14 & 0.13 & NS & NS \\
\hline \multirow[t]{3}{*}{ CHST15 } & 6 & 0.51 & 0.53 & 0.48 & 0.50 & 0.13 & NS & NS \\
\hline & 24 & 2.15 & 2.45 & 2.40 & 2.56 & 0.44 & NS & NS \\
\hline & $6+24$ & 1.70 & 2.13 & 2.39 & 2.26 & 0.47 & NS & NS \\
\hline \multirow[t]{3}{*}{ EIF4EBP2 } & 6 & 1.25 & 1.02 & 1.00 & 0.79 & 0.21 & NS & NS \\
\hline & 24 & 1.04 & 1.28 & 0.91 & 1.00 & 0.27 & NS & NS \\
\hline & $6+24$ & 1.15 & 1.15 & 0.95 & 0.89 & 0.18 & NS & NS \\
\hline \multirow[t]{3}{*}{ FSD1 } & 6 & 0.93 & 0.92 & 1.14 & 0.98 & 0.25 & NS & NS \\
\hline & 24 & 0.89 & 1.17 & 1.18 & 1.41 & 0.28 & NS & NS \\
\hline & $6+24$ & 0.91 & 1.04 & 1.16 & 1.19 & 0.19 & NS & NS \\
\hline \multirow[t]{3}{*}{$F N D C 3 B$} & 6 & 0.98 & 0.99 & 1.06 & 1.16 & 0.21 & NS & NS \\
\hline & 24 & 0.91 & 1.23 & 1.09 & 0.92 & 0.09 & NS & NS \\
\hline & $6+24$ & 0.95 & 1.11 & 1.07 & 1.04 & 0.13 & NS & NS \\
\hline \multirow[t]{3}{*}{$I L-34$} & 6 & 0.98 & 0.85 & 1.28 & 1.17 & 0.22 & NS & NS \\
\hline & 24 & 1.79 & 1.47 & 0.99 & 0.87 & 0.59 & NS & NS \\
\hline & $6+24$ & 1.38 & 1.16 & 1.34 & 1.02 & 0.31 & NS & NS \\
\hline \multirow[t]{3}{*}{ ITGB1 } & 6 & 0.82 & 0.87 & 0.87 & 0.79 & 0.07 & NS & NS \\
\hline & 24 & 1.10 & 1.37 & 1.31 & 1.27 & 0.20 & NS & NS \\
\hline & $6+24$ & 0.96 & 1.12 & 1.09 & 1.03 & 0.18 & NS & NS \\
\hline \multirow[t]{3}{*}{ LGALS1 } & 6 & 0.78 & 1.00 & 1.24 & 1.02 & 0.21 & NS & NS \\
\hline & 24 & 1.13 & 1.61 & 1.46 & 0.96 & 0.46 & NS & NS \\
\hline & $6+24$ & 0.96 & 1.30 & 1.35 & 0.99 & 0.30 & NS & NS \\
\hline \multirow[t]{3}{*}{ LGALS9 } & 6 & 0.82 & 0.84 & 0.73 & 0.80 & 0.82 & NS & NS \\
\hline & 24 & 1.23 & 1.32 & 1.99 & 1.25 & 0.12 & NS & NS \\
\hline & $6+24$ & 1.02 & 1.08 & 1.06 & 1.02 & 0.16 & NS & NS \\
\hline \multirow[t]{3}{*}{ MST1R } & 6 & $0.73^{\mathrm{a}}$ & $0.49^{\mathrm{a}}$ & $1.18^{\mathrm{ab}}$ & $1.33^{\mathrm{ac}}$ & 0.37 & $\leq 0.01$ & NS \\
\hline & 24 & 1.19 & 1.56 & 1.68 & 2.40 & 0.78 & NS & NS \\
\hline & $6+24$ & 0.96 & 1.02 & 1.43 & 1.86 & 0.23 & NS & NS \\
\hline \multirow[t]{3}{*}{ SLC15A3 } & 6 & 0.87 & 0.94 & 1.39 & 1.40 & 0.37 & NS & NS \\
\hline & 24 & 1.03 & 0.99 & 1.20 & 1.13 & 0.33 & NS & NS \\
\hline & $6+24$ & 0.95 & 0.96 & 1.30 & 1.27 & 0.24 & NS & NS \\
\hline
\end{tabular}


Table 3.3 Summary of relative expression data for Treg and anti-inflammatory related genes amplified by RT-qPCR in endometrial explants treated with increasing concentrations of LGALS1. LSM \pm SEM. P-values are that of the log-transformed data. Contrast: Control vs. Galectin-1 (10, 100 and 1000ng/mL).

\begin{tabular}{ccccccccc}
\hline \hline & \multicolumn{9}{c}{ Treatment } & \multicolumn{3}{c}{ Contrast } \\
\hline Gene & Time & Control & 10 & 100 & 1000 & SEM & TRT & C \\
\hline FOXP3 & 6 & 1.74 & 1.58 & 1.76 & 1.81 & 0.30 & NS & NS \\
& 24 & 0.57 & 0.75 & 0.78 & 0.75 & 0.23 & NS & $\leq 0.05$ \\
& $6+24$ & 1.16 & 1.16 & 1.27 & 1.28 & 0.31 & NS & NS \\
\hline IL2-RA & 6 & $1.13^{\mathrm{a}}$ & $1.08^{\mathrm{a}}$ & $2.19^{\mathrm{ab}}$ & $3.11^{\mathrm{bc}}$ & 0.67 & $\leq 0.01$ & 0.06 \\
& 24 & $0.54^{\mathrm{a}}$ & $0.65^{\mathrm{a}}$ & $1.00^{\mathrm{a}}$ & $1.26^{\mathrm{b}}$ & 0.33 & $\leq 0.05$ & $\leq 0.05$ \\
& $6+24$ & $0.84^{\mathrm{a}}$ & $0.86^{\mathrm{a}}$ & $1.59^{\mathrm{ac}}$ & $2.19^{\mathrm{bc}}$ & 0.51 & $\leq 0.01$ & 0.07 \\
\hline CD11c & 6 & 1.24 & 0.89 & 1.43 & 1.59 & 0.60 & $\mathrm{NS}$ & $\mathrm{NS}$ \\
& 24 & 0.76 & 0.91 & 1.21 & 1.37 & 0.17 & 0.10 & 0.06 \\
& $6+24$ & 1.00 & 0.90 & 1.32 & 1.48 & 0.34 & $\mathrm{NS}$ & $\mathrm{NS}$ \\
\hline IL-10 & 6 & $1.15^{\mathrm{a}}$ & $1.94^{\mathrm{a}}$ & $2.21^{\mathrm{b}}$ & $2.76^{\mathrm{bc}}$ & 0.41 & $\leq 0.01$ & $\leq 0.01$ \\
& 24 & $0.52^{\mathrm{a}}$ & $0.52^{\mathrm{ab}}$ & $0.70^{\mathrm{ac}}$ & $0.91^{\mathrm{c}}$ & 0.14 & $\leq 0.001$ & $\leq 0.01$ \\
& $6+24$ & 0.83 & 0.96 & 1.45 & 1.83 & 0.34 & $\mathrm{NS}$ & $\mathrm{NS}$ \\
\hline
\end{tabular}


Table 3.4 Summary of relative expression data for pro-inflammatory related genes amplified by RT-qPCR in endometrial explants treated with increasing concentrations of LGALS1.

LSM + SEM. P-values are that of the log-transformed data. Contrast: Control vs.

Galectin-1 (10, 100 and 1000ng/mL).

\begin{tabular}{|c|c|c|c|c|c|c|c|c|}
\hline \multicolumn{8}{|c|}{ Treatment } & \multirow{2}{*}{$\begin{array}{c}\text { Contrast } \\
\text { C }\end{array}$} \\
\hline Gene & Time & Control & 10 & 100 & 1000 & SEM & TRT & \\
\hline \multirow[t]{3}{*}{ CXCR4 } & 6 & 0.31 & 0.27 & 0.27 & 0.31 & 0.07 & NS & NS \\
\hline & 24 & 3.10 & 3.99 & 4.50 & 4.20 & 0.52 & NS & $\leq 0.05$ \\
\hline & $6+24$ & 1.70 & 2.13 & 2.39 & 2.26 & 0.74 & NS & NS \\
\hline \multirow[t]{3}{*}{$L I F$} & 6 & $0.44^{\mathrm{a}}$ & $0.65^{\mathrm{b}}$ & $1.10^{c}$ & $1.91^{\mathrm{d}}$ & 0.17 & $\leq 0.001$ & $\leq 0.001$ \\
\hline & 24 & 0.65 & 1.20 & 1.43 & 2.13 & 0.28 & $\leq 0.05$ & $\leq 0.01$ \\
\hline & $6+24$ & $0.54^{\mathrm{a}}$ & $0.93^{b}$ & $1.26^{\mathrm{bc}}$ & $2.02^{\mathrm{d}}$ & 0.17 & $\leq 0.001$ & $\leq 0.001$ \\
\hline \multirow[t]{3}{*}{$I L-33$} & 6 & $1.25^{\mathrm{a}}$ & $1.32^{\mathrm{a}}$ & $1.27^{\mathrm{a}}$ & $1.67^{b}$ & 0.33 & NS & NS \\
\hline & 24 & 0.87 & 1.08 & 1.14 & 0.76 & 0.24 & NS & NS \\
\hline & $6+24$ & 1.06 & 1.20 & 1.21 & 1.21 & 0.22 & NS & NS \\
\hline \multirow[t]{3}{*}{$I L-1 B$} & 6 & $0.33^{a}$ & $0.70^{\mathrm{b}}$ & $1.35^{\mathrm{bc}}$ & $2.54^{\mathrm{C}}$ & 0.31 & $\leq 0.001$ & $\leq 0.001$ \\
\hline & 24 & $0.49^{\mathrm{a}}$ & $1.24^{\mathrm{b}}$ & $2.90^{\mathrm{b}}$ & $2.65^{b}$ & 0.43 & $\leq 0.01$ & $\leq 0.001$ \\
\hline & $6+24$ & $0.41^{\mathrm{a}}$ & $0.97^{\mathrm{b}}$ & $2.12^{\mathrm{cd}}$ & $2.59^{\mathrm{d}}$ & 0.33 & $\leq 0.001$ & $\leq 0.001$ \\
\hline \multirow[t]{3}{*}{$I L-6$} & 6 & $0.34^{\mathrm{a}}$ & $1.12^{\mathrm{b}}$ & $4.07^{c}$ & $6.98^{\mathrm{cd}}$ & 1.09 & $\leq 0.001$ & $\leq 0.001$ \\
\hline & 24 & $0.23^{\mathrm{a}}$ & $0.61^{\mathrm{b}}$ & $1.10^{\mathrm{bc}}$ & $1.77^{\mathrm{cd}}$ & 0.19 & $\leq 0.001$ & $\leq 0.001$ \\
\hline & $6+24$ & $0.29^{a}$ & $0.86^{\mathrm{b}}$ & $2.59^{c}$ & $4.38^{\mathrm{d}}$ & 0.76 & $\leq 0.001$ & $\leq 0.001$ \\
\hline \multirow[t]{3}{*}{ TNFAIP2 } & 6 & $1.52^{\mathrm{a}}$ & $1.34^{\mathrm{a}}$ & $3.80^{\mathrm{ac}}$ & $8.29^{b}$ & 1.80 & $\leq 0.01$ & $\leq 0.05$ \\
\hline & 24 & 0.47 & 0.49 & 0.42 & 0.49 & 0.12 & $\mathrm{NS}$ & NS \\
\hline & $6+24$ & 1.00 & 0.91 & 2.11 & 4.39 & 1.16 & NS & NS \\
\hline \multirow[t]{3}{*}{$I L-12 a$} & 6 & 1.31 & 1.18 & 1.55 & 1.78 & 0.46 & NS & NS \\
\hline & 24 & 1.13 & 0.88 & 0.87 & 0.77 & 0.26 & NS & NS \\
\hline & $6+24$ & 1.22 & 1.03 & 1.21 & 1.27 & 0.27 & NS & NS \\
\hline \multirow[t]{3}{*}{ NFKB1 } & 6 & $0.67^{a}$ & $0.88^{\mathrm{a}}$ & $1.48^{\mathrm{bc}}$ & $1.86^{\mathrm{C}}$ & 0.23 & $\leq 0.001$ & $\leq 0.001$ \\
\hline & 24 & $0.75^{a}$ & $0.85^{\mathrm{a}}$ & $1.12^{\mathrm{a}}$ & $1.31^{\mathrm{b}}$ & 0.18 & $\leq 0.05$ & $\leq 0.05$ \\
\hline & $6+24$ & $0.71^{\mathrm{a}}$ & $0.86^{\mathrm{ab}}$ & $1.30^{\mathrm{b}}$ & $1.58^{\mathrm{bc}}$ & 0.16 & $\leq 0.001$ & $\leq 0.01$ \\
\hline
\end{tabular}




\title{
CHAPTER FOUR
}

\section{EFFECT OF GALECTIN-1 ON BOVINE ENDOMETRIAL EPITHELIAL AND FIBROBLAST CELLS IN 3-DEMENTIONAL CELL CULTURE}

\begin{abstract}
Galectin-1 plays an important role during reproduction in humans and rodents. Galectin-1 is expressed by the early bovine conceptus. This study investigated the effects of LGALS1 on bovine endometrial epithelial and fibroblast cell $(n=4)$ transcriptomes in a 3-D-culture system treated with media only (Control) or media containing 10 or $100 \mathrm{ng} / \mathrm{mL}$ of bovine LGALS1 for 6 h. Transcriptomes of Control cells and cells treated with $100 \mathrm{ng} / \mathrm{mL}$ of bovine LGALS1 were assayed by RNA Sequencing. Transcriptomes of Control cells and cells treated with 10 and 100 ng/mL of bovine LGALS1 were assayed by RT-qPCR. In epithelial cells treated with LGALS1 there were 1260 up-regulated genes. The top ten up-regulated genes were $I L-1 B, F G R, B A T F 2$, STEAP4, SAA, CCL20, CXCL10, IL36A, S100A9, and M-SAA3.2. There were 2021 downregulated genes in epithelial cells. The top ten were MSRB1, MSD2, USP6NL, SRF, STARD7, RARA, PIAS2, CDC42EP3, MRPL36, and PDLIM5. In fibroblast cells treated with LGALS1 there were seven up-regulated genes and no down-regulated genes. The up-regulated genes were of OAS1Y, OAS1X, OAS1Z, ISG15, LOC112441507, BMST2, and IRF9. Other genes of interest, LIF and CXCR4 were investigated because of their well-known role in reproduction and upregulation by LGALS1. Gene ontology (GO) showed that up-regulated genes contributed to pathways involved in many immune and inflammatory pathways. This study provides evidence
\end{abstract}


that bovine LGALS1 affects bovine endometrial epithelial and fibroblast cells gene expression. Considering, LGALS1 is expressed by the early bovine conceptus, conceptus LGALS1 may modulate endometrial cell gene expression during early gestation. The LGALS1 may increase expression of inflammatory type genes at the uterine surface.

\section{INTRODUCTION}

Most researchers use a 2-dimensional (D) monoculture system to study endometrial epithelial cell function in vitro. However, the development of a 3-D culture system used in this study provides a more realistic reflection of the tissue functions and 3-D architecture of the tissue. This system allows cells of different types to be co-cultured in an arrangement similar to in vivo tissue allowing for cell to cell communication and measurement of apical and basolateral protein secretions. Further, cells can be easily collected after the co-culture for mRNA and protein analysis (MacKintosh et al., 2015).

In a study conducted on mice with colitis, endogenous LGALS1 was highly expressed in the epithelial cells in the colon of unaffected mice while markedly reduced in the colon of mice with colitis. The mice with colitis had epithelial architecture damage; however, with treatment of LGALS1, the epithelial layer architecture was almost completely restored. In this study, LGALS1 was also found to regulate the immune system by creating and maintaining tolerance by causing selective apoptosis of activated mature lymphocytes to maintain immune homeostasis (Santucci et al., 2003).

Previous research has shown that LGALS1 is important for the maintenance of a successful pregnancy in humans and rodents; however, its importance in bovine pregnancy has not been well characterized. In a previous study, LGALS1 reduced fetal loss in sound stressed 
rodents. Investigators discovered that LGALS1 increased the presence of regulatory T- cells (Treg) in the uterus, thus promoting fetomaternal tolerance. In cases where the presence of Treg was reduced, the effects were lost and there was a higher percentage of fetal loss. Through these findings, the investigator concluded that LGALS1 plays a pivotal role in the fetomaternal tolerance through modulation of immunoregulatory mechanisms (Blois et al., 2007). There is limited research on the role of LGALS1 in cattle but studies have identified the presence of LGALS1 in the conceptus as well as caruncular and intercaruncular regions of pregnant bovine endometrium, specifically the maternal stroma, at all stages of gestation (Froehlich et al., 2012). Through RNA- Sequencing (RNA-Seq), LGALS1 was found to be expressed by the pregnant endometrium and early bovine conceptus as early as day 16 of gestation (Mansouri-Attia et al., 2009, Mamo et al., 2012, Forde et al., 2015). Studies have shown reduced LGALS1 expression in vitro produced blastocysts compared to in vivo produced bovine blastocysts, which could be cause for high embryonic loss and poor pregnancy rates following transfer of an in vitro produced blastocyst (Mohan et al., 2004). Galectin-1 relative mRNA expression was also reduced in the endometrium of low fertility dairy heifers and was found to be involved in cellular growth and proliferation, cell morphology, small molecule biochemistry, and lipid metabolism through IPA analysis. These mechanisms could be contributing to the endometrial facilitated infertility in cattle, thus showing the importance of LGALS1 in the species (Killeen et al., 2014). Considering that the bovine conceptus is hypothesized to secrete LGALS1 onto the uterine surface, we investigated the effect of LGALS1 on the bovine endometrial epithelium and fibroblast transcriptomes during 3-D culture.

\section{MATERIALS AND METHODS}

\section{Cell Collection, Isolation, and Culture}


Bovine uteri $(\mathrm{n}=4)$ were collected at a local slaughter facility and endometrium was collected from mid-luteal phase uteri; ipsilateral to the corpus luteum (CL) (Cronin et al., 2014). Briefly, uteri were transported on ice to the laboratory where they were washed with $1 \mathrm{X}$ Dulbecco’s Phosphate-Buffered Saline (DPBS; Gibco, Gaithersburg, MD) containing 1\% antibiotic-antimycotic (ABAM; ThermoFisher Scientific, Waltham, MA). The broad ligament was removed, and the uterine horn ipsilateral to the CL was dissected free from the reproductive tract. The uterine horn was washed again with 1X DPBS (1\% ABAM) and sprayed with 70\% EtOH. Under sterile procedures the uterine horn was dissected longitudinally to obtain intercaruncular endometrial strips which were washed in a series of 3 washes of Hank's Balanced Salt Solution (HBSS; Gibco), the last containing 1\% ABAM. Before the last HBSS wash, endometrial strips were cut into approximately $3 \mathrm{~mm}$ pieces. The endometrium in HBSS was then incubated at $38.8^{\circ} \mathrm{C}$ with $5 \% \mathrm{CO}_{2}$ for 10 min. Tissue was then transferred into a digestive solution containing HBSS, 100X Trypsin-EDTA (7\%, Sigma Aldrich, St. Louis, MO), collagenase II (25 mg; Sigma Aldrich), DNase 1 (125 $\mu \mathrm{L}$; Sigma Aldrich), and bovine serum albumin (50 mg BSA; Sigma Aldrich), and incubated for 1 hour in a $38.8^{\circ} \mathrm{C}$ water bath with manual agitation every $10 \mathrm{~min}$. Digested tissue was filtered through a $100 \mu \mathrm{M}$ over a $40 \mu \mathrm{M}$ cell strainer (Falcon, Corning, NY) into $5 \mathrm{~mL}$ of pre-warmed HBSS and 10\% fetal bovine serum ( FBS; Sigma Aldrich). Epithelial cells were collected by back washing the $40 \mathrm{uM}$ cell strainer with $30 \mathrm{~mL}$ of Rosewell Park Memorial Institute (RPMI) medium (Gibco) containing 10\% FBS and 1\% ABAM (Complete media). Fibroblast cells were collected in the filtered flow-through media. Cells were plated into T75 flasks (CELLSTAR, Monroe, NC) and incubated at $38.8^{\circ} \mathrm{C}$ in $5.0 \% \mathrm{CO}_{2}$ and atmospheric oxygen. Media on epithelial cells was changed every two days and every other day for fibroblast cells. When cells became $80 \%$ confluent they were detached using 
Accutase cell detachment solution (Sigma Aldrich) and passed into three new T75 flasks in complete media.

In preparation for 3-D culture and once epithelial cells were 95-100\% confluent, they were detached using Accutase and plated into hanging cell culture inserts (Millipore Sigma) coated with a thin coat of Matrigel Matrix (1:8; Matrigel: RPMI; Corning Incorporation, Corning, NY) at a concentration of 3 X $10^{5}$ cells $/ \mathrm{mL}$. Inserts were placed into wells of 24 well plates (CELLSTAR) containing $800 \mu \mathrm{l}$ of complete media. Media was replaced every two days. Transepithelial electrical resistance (TEER $>1500 \Omega \mathrm{cm} 2$ ) was met after 8 days and fibroblasts were then prepared for 3-D culture. Fibroblast cells were plated into 24 well plates at $1 \mathrm{X}$ $10^{5} \mathrm{cell} / \mathrm{mL}$. After $18 \mathrm{~h}$, and on day of treatment, the fibroblast media was replaced with RPMI containing 5\% FBS and 1\% ABAM (treatment media) the media of epithelial cells in transwell inserts was also replaced with treatment media, and the inserts were added to the 24 well plates with fibroblasts. After $2 \mathrm{~h}$, epithelial cell media was removed and replaced with $300 \mu \mathrm{l}$ of treatment media (Control), or treatment media containing 10 or $100 \mathrm{ng} / \mathrm{mL}$ of recombinant bovine (Cusabio, Houston, TX) for $6 \mathrm{~h}$. Four uteri were used to prepare four different 3-D cultures and cell treatments were applied in triplicate for each uterus. The FBS included in the treatment media for each uterus was from a single aliquot.

\section{$\underline{\text { RNA Extraction }}$}

Following treatment, epithelial cells were collected by removing the transwell membrane and placing it in the Qiagen RNeasy Kit (Qiagen, Hilden, Germany) lysis buffer. The lysis buffer was also added to fibroblast cells which were then scraped off the bottom of the 24 well plates. Briefly, total RNA was extracted from fibroblast and epithelial cells separately following the Qiagen RNeasy Kit instructions. The quantity of isolated RNA for each cell type was determined 
using the NanoDrop 1000 (Thermo Fisher Scientific, Waltham, MA) and quality was assessed using Agilent 2100 Bioanalyzer (Agilent Technologies, Santa Clara, CA). The RNA integrity number (RIN) was between 7 and 10 for all samples. For each uteri 3-D cell culture, triplicate epithelial cell and fibroblast cell RNA for each treatment were pooled furing RNA isolation and prior to cDNA synthesis.

\section{$\underline{\text { RNA-Sequencing }}$}

The RNA samples from endometrial fibroblast and epithelial cells treated with 100 $\mathrm{ng} / \mathrm{mL}$ of recombinant bovine LGALS1 were submitted for RNA sequencing. RNA library preparation and sequencing was conducted by the University of Missouri DNA Core facility as described by (Moraes et al., 2018). The raw sequences (fastq) underwent adapter removal and quality trimming utilizing Trimmomatic (Bolger et al., 2014). The quality reads were then mapped to the bovine reference genome ARS-UCD1.2 using Hisat2 mapper, a sensitive and fast alignment program of next-generation sequencing data (Kim et al., 2015). The sorted binary alignment maps and the NCBI gene annotation of the ARS-UCD1.2 assembly were subjected to FeatureCounts to quantify read counts of genes for each sample (Liao et al., 2014). Differential gene expression analysis between sample groups was performed by robustly fitting the expression data to a weighted generalized linear model (GLM) using edgeR robust (Zhou et al., 2014). The DAVID Bioinformatics Resource 6.8 was used to carry out a GO analysis of transcripts found to be statistically significant during the RNA-Seq analysis (Huang da et al., 2009). An enriched biological process (BP) and Kyoto Encyclopedia of Genes and Genomes (KEGG) pathway analyses were included. The GO Direct category was used during the annotation and provides mappings directly annotated by the source database. The Homo sapien 
background was used during the analysis, and GO Direct and KEGG categories were considered enriched when $\mathrm{P} \leq 0.05$ with Benjamini-Hochberg procedure.

\section{$\underline{R T-q P C R}$}

Explant mRNA (500ng) was reverse transcribed into cDNA using the High-capacity cDNA Reverse Transcription Kit (Applied Biosystems, Foster City, CA), and cDNA samples were diluted 1:20 in nuclease free water. Reactions were $20 \mu \mathrm{L}$ including $10 \mu \mathrm{L}$ of PowerUP SYBR Green Master Mix (Bio-Rad; Hercules, CA), 1.2 $\mu \mathrm{L}$ of each primer, and 2.6 $\mu \mathrm{L}$ of DNase RNase free water, and $5 \mu \mathrm{L}$ of sample following the manufacturer's instructions. No reverse transcriptase controls were included for a subset of samples. The RT-qPCR reactions were carried out using PowerUp SYBR Green Master Mix (Applied Biosystems) and the CFX96 Touch Real-Time PCR Detection System (Bio-Rad, Hercules, CA) following the manufacturer's recommendations. All samples were ran in duplicate and no reverse transcriptase controls and no template controls were included. Primers were created using Primer3Plus or obtained from previously published research. The PCR primer amplification efficiencies (E) for each PCR target sequence were calculated from the standard curve generated from seven cDNA dilutions made from a pool of cDNA samples. Diluted in a buffer containing 1\% 100X Tris EDTA (Sigma Aldrich) 0.4\% lambda DNA (Invitrogen, Carlsbad, CA) and DNase and RNase free water. Dilutions were 1:1, 1:4, 1:16, 1:64, 1:256, 1:1024, 1:4096, respectively. The equation used for the efficiency calculation was $E=\left[10^{(-1 / \text { slope })}-1\right]$. Slope generated from plotting Ct values against dilution for each serial dilution. Percent primer efficiency was calculated by dividing E by 2 and then multiplying by 100 . Only primers with efficiencies between $90-110 \%$ were used. A dissociation analysis was included for each primer pair to evaluate primer specificity for the target sequence. Gel electrophoresis was used to confirm the primer pair by amplicon size. 
Qbase+ qPCR analysis software (Biogazelle, Zwijnaarde, Belgium) was used to calculate the normalized relative expression quantities (NRQ; relative expression) of target genes based on a generalized delta-delta quantification cycle method ( $\Delta \Delta \mathrm{Cq}$; also known as $\Delta \Delta \mathrm{CT}$ ) (Hellemans et al., 2007). To identify potential normalization targets, RT-qPCR was carried out for eight potential genes across a subset of samples representing all treatments. Genes tyrosine 3monooxygenase/ tryptophan 5-monooxygenase activation protein zeta (YWHAZ) and peptidylprolyl isomerase A (PPIA) were found to be the most stably expressed across treatments using the geNorm analysis (geNorm $\mathrm{M}<0.25$ ) (Vandesompele et al., 2002). The RT-qPCR thermo cycler settings for all reactions consisted of an initial temperature of $50^{\circ} \mathrm{C}$ for $2 \mathrm{~min}, 95^{\circ} \mathrm{C}$ for 2 min followed by 40 PCR cycles consisting of melting at $95^{\circ} \mathrm{C}$ for $15 \mathrm{sec}$ and annealing and extension at $60^{\circ} \mathrm{C}$ for $1 \mathrm{~min}$.

\section{$\underline{\text { Statistical Analysis }}$}

A mixed procedure (proc MIXED) in the statistical analysis software (SAS) was used to analyze the RT-qPCR relative expression data. The statistical analysis tested the effect of treatment on relative gene expression for selected genes of interest. All treatments were applied to each uterus, therefore, uterus was considered a block and specified as a random variable in the model. Data residuals were scrutinized for normality using the PLOTS=(diagnostics residuals) statement. All p-values for gene expression data presented are that of a log base-10 $(\log 10)$ correction. If the residuals were not normal after $\log 10$ transformation, the residual data were normalized using square root (sqrt) transformation. All relative expression values are presented in their original format; however, the p-values are of the log10 or sqrt transformed data. Three treatments were included in the analysis including Control, 10 , or $100 \mathrm{ng} / \mathrm{mL}$ of recombinant bovine LGALS1. One orthogonal contrast statement was included, Contrast 1 (C1), comparing 
the media only treatment (Control) vs. both LGALS1 treatments (10 and $100 \mathrm{ng} / \mathrm{mL}$ ). Data are presented as least squares means (LSM) \pm standard error of the least squares means (SEM). Statistical significance was declared at a $\mathrm{P} \leq 0.05$.

\section{RESULTS}

\section{Up-regulated Genes in Epithelial Cells}

Compared to controls, epithelial cells treated with 100ng/mL of LGALS1 had 1260 upregulated genes. The ten most up-regulated genes were; 1) Interleukin-1 beta (IL-1B), 2) FGR proto- oncogene, Src family tyrosine kinase (FGR), 3) basic leucine zipper transcriptional factor ATF-like 2 (BATF2), 4) STEAP4 metalloreductase (STEAP4) 5) serum amyloid A protein (SAA), 6) C-C motif chemokine ligand 20 (CCL20),7) C-X-C chemokine ligand 10 (CXCL10), 8) IL36A, 9) S100 calcium binding protein A9 (S100A9), and 10) mammary serum amyloid A3.2 (MSAA3.2).

Gene ontology analysis of the 1260 up-regulated genes in response to $100 \mathrm{ng} / \mathrm{mL}$ of LGALS1 identified 64 enriched pathways (Table 4.1). The ten most enriched pathways were 1) inflammatory response, 2) positive regulation of NFKB transcription factor activity, 3) type-1 interferon signaling pathway, 4) apoptotic process, 5)innate immune response, 6) Interferon (IFN)- $\gamma$ mediated signaling pathway, 7) immune response, 8) defense response to virus, 9) response to virus, and 10) response to lipopolysaccharide (LPS). The KEGG pathway analysis identified 35 enriched pathways in epithelial cells treated with 100 ng/mL of LGALS1 (Table 4.3). The top ten most enriched KEGG pathways were 1) tumor necrosis factor (TNF) signaling

pathway, 2) influenza A, 3) nuclear factor kappa B (NFKB) signaling pathway, 4) C-X-C chemokine receptor (CXCR) interaction, 5) herpes simplex infection, 6) measles, 7) NOD-like 
receptor signaling pathway, 8) pertussis, 9) Retinoic acid-inducible gene-1 (RIG-I) -like receptor signaling pathway, and 10) toll-like receptor (TLR) signaling pathway.

\section{$\underline{\text { Down-regulated Genes in Epithelial Cells }}$}

Compared to controls, epithelial cells treated with $100 \mathrm{ng} / \mathrm{mL}$ of LGALS1, there were 2921 down-regulated genes. The 10 most up-regulated genes were; 1) methionine sulfoxide reductase B1 (MSRB1), 2) nuclear receptor binding SET domain protein 2 (MSD2), 3) USP6 Nterminal like (USP6NL), 4) serum response factor (SRF), 5) StAR related lipid transfer domain containing 7 (STARD7), 6) retinoic acid receptor alpha (RARA), 7) protein inhibitor of activated STAT2 (PIAS2), 8) CDC42 effector protein 3 (CDC42EP3), 9) mitochondrial ribosomal protein L36 (MRPL36), and 10) PDZ and LIM domain 5 (PDLIM5).

Gene ontology analysis of the 2921 down-regulated genes in response to $100 \mathrm{ng} / \mathrm{mL}$ of LGALS1 identified 9 enriched pathways (Table 4.2). The 9 enriched pathways were 1) DNA replication, 2) G1/S transition of mitotic cell cycle, 3) DNA replication initiation, 4) DNA strand elongation involved in DNA replication, 5) telomere maintenance via recombination, 6) positive regulation of transcription from RNA polymerase II promoter, 7) cell division, 8) regulation of transcription involved in G1/S transition of mitotic cell cycle, and 9) positive regulation of peptidyl-threonine phosphorylation. When subjected to KEGG Pathway analysis, there were 5 down-regulated pathways in epithelial cells treated with $100 \mathrm{ng} / \mathrm{mL}$ of LGALS1 (Table 4.4). The 5 down-regulated pathways were 1) DNA replication, 2) cell cycle, 3) pathways in cancer, 4) signaling pathways regulating pluripotency of stem cells, and 5) human T-cell leukemia virus type-1 (HTLV-I) infection.

\section{$\underline{\text { Up-requlated Genes in Fibroblasts }}$}


The treatment of epithelial cells in transwell inserts over fibroblasts were treated with $100 \mathrm{ng} / \mathrm{mL}$ of recombinant bovine LGALS1, resulted in up-regulation of 7 genes in the fibroblasts. There were no down-regulated genes in the fibroblasts compared to Control. Upregulated fibroblast genes included 1) 2', 5'- oligoadenylate synthetase 1Y (OAS1Y), 2) OAS1X, 3) $O A S 1 Z$, 4) IFN stimulated gene 15 (ISG15), 5) bone marrow stromal antigen 2-like (LOC112441507), 6) bone marrow stromal antigen 2 (BMST2), and 7) interferon regulatory factor 9 (IRF9).

Reference Appendix B for additional significant $(\mathrm{P} \leq 0.05)$ KEGG and GO Direct pathways with Benjamini-Hochberg procedure. Particular genes of interest that were either upor down-regulated in the RNA Seq results were validated using RT-qPCR.

\section{$\underline{R T-q P C R}$}

There was an effect of treatment on relative gene expression of $C X C R 4$ in the epithelial cells. Expression of CXCR4 mRNA was greater when both LGALS1 treatments were compared to Control (Figure 4.2; Control, 10, $100 \mathrm{ng} / \mathrm{mL}$ respectively; 6.12, 6.15, $13.77 \pm 0.89 ; \mathrm{P} \leq 0.05$ ). There was no effect of treatment on relative expression of fibroblast cell CXCR4 mRNA. There was an effect of treatment on relative gene expression of EIF4EP2 on epithelial and fibroblast cells. Expression of EIF4EBP2 mRNA in epithelial cells decreased when both LGALS1

treatments were compared to Control (Figure 4.3; 2.43, 0.93, $1.04 \pm 0.18$; $\mathrm{P} \leq 0.001$ ). Expression of EIF4EBP2 mRNA on fibroblast cells was decreased when both LGALS1 treatments were compared to Control (Figure 4.3; 2.06, 0.88, $0.83 \pm 0.17 ; \mathrm{P} \leq 0.001$ ). There was an effect of treatment on relative gene expression of $I L-1 B$ in epithelial cells. Expression of $I L-1 B$ mRNA was greater when both LGALS1 treatments were compared to Control (Figure 4.4; 0.40, 21.41, $265.44 \pm 34.95 ; \mathrm{P} \leq 0.001)$. There was not an effect of treatment on relative expression of 
fibroblast cell $I L-1 B$. There was an effect of treatment on relative gene expression of $I L-6$ in the epithelial cells. Expression of IL-6 mRNA was greater when both LGALS1 treatments were compared to Control (Figure 4.5; 1.74, 3.18, $4.89 \pm 1.33$; $\mathrm{P} \leq 0.01$ ). There was not an effect of treatment on relative expression of $I L-6$ in fibroblast cells. There was an effect of treatment on relative expression of LIF in the fibroblast cells. Expression of LIF mRNA was decreased when both LGALS1 treatments were compared to control (Figure 4.6; 0.79, 0.48, $0.52 \pm 0.28$; $\mathrm{P} \leq$ 0.05). There was an effect of treatment on relative expression of LIF at $100 \mathrm{ng}$ but not at $10 \mathrm{ng}$ in the epithelial cells. There was an effect of treatment on relative expression of CHST15 in the fibroblast cells. Expression of CHST15 mRNA was decreased when both LGALS1 treatments were compared to control (Figure 4.7; 3.86, 1.41, $1.16 \pm 0.89 ; \mathrm{P} \leq 0.01$ ). There was not an effect of treatment on relative expression of CHST15 in epithelial cells. There was an effect of treatment on relative expression of $M S T 1 R$ in the fibroblast cells. Expression of $M S T 1 R$ mRNA was decreased when both LGALS1 treatments were compared to control (Figure 4.8; 3.79, 2.53, $2.60 \pm 0.53 ; \mathrm{P} \leq 0.01)$. There was not an effect of treatment on relative expression of $M S T 1 R$ in epithelial cells. There was an effect of treatment on relative gene expression of ATP11a in epithelial and fibroblast cells. Expression of ATP11a mRNA in epithelial cells was decreased when both LGALS1 treatments were compared to Control (Figure 4.9; 8.42, 3.03, $2.66 \pm 0.68$; P $\leq$ 0.001). Expression of ATP11a mRNA in fibroblast cells was decreased when both LGALS1 treatments were compared to Control (Figure 4.9; 3.40, 1.82, $1.72 \pm 0.63 ; \mathrm{P} \leq 0.001$ ).

\section{DISCUSSION}

Many of the genes up-regulated in the epithelial cells treated with LGALS1 are associated with adhesion and immune regulation. One gene in particular, CXCR4, is important for implantation in ruminants. The protein CXCR4 is a G-protein coupled chemokine receptor. 
This protein plays many roles, one being allowing migration of progenitor cells to their destination where they will differentiate to become organs and tissues during embryonic development. In the innate immune system, phagocytic cells such as neutrophils and macrophages express CXCR4 (Domanska et al., 2013). In humans, a previous study presented evidence of LGALS1 up-regulating CXCR4 gene expression through nuclear factor kappa B (NFKB) in kidney cancer patients, which promoted progression and invasiveness of tumors (Huang et al., 2014). Another study examined first-trimester human trophoblast cells for chemokines and chemokine receptors. Their study found evidence that CXCR4 and CXCL12 were highly expressed in the trophoblast cells and their function may be to stimulate trophoblast cell proliferation or differentiation in an autocrine manner, which may play an important role in early pregnancy (Wu et al., 2004). In relation to livestock species, a few studies have been conducted in sheep with CXCR4 and have determined that CXCR4 mRNA and protein was greater on day 15 of pregnancy compared to the estrous cycle and greatest on days 21 and 30 compared to earlier days. This study provided evidence to conclude that CXCR4/CXCL12 pathway is activated during implantation and placentation in sheep and is likely playing a role in the communication between trophoblast cells and the maternal endometrium (Ashley et al., 2011). Similar to Huang et al., (2014), we also observed an increase in CXCR4 with LGALS1 treatment in endometrial epithelial cells. It is possible that the CXCR4/CXCL12 pathway is also activated during implantation and placentation of the cow and contributes to communication between the conceptus and endometrium similarly to that in sheep. This suggests a role for CXCR4 in bovine endometrium and it is possible that conceptus LGALS1 stimulates its expression. Interestingly, CXCR4 was specifically down-regulated in explants cultured with IVF produced conceptuses (Mathew et al., 2019). It is possible that down-regulation of CXCR4 is 
attributed to decreased expression of LGALS1 by IVF produced conceptuses as evidence suggests that LGALS1 increases CXCR4 (Huang et al., 2014).

Another important gene that was shown to be important in the present study was leukemia inhibitory factor (LIF). Importance of LIF in the endometrium was discovered in studies conducted with LIF knock-out mice in which implantation did not occur (Stewart et al., 1992). In human endometrium, LIF concentrations peak around the time of implantation however, are decreased in women with unexplained infertility (Laird et al., 1997). The promoter region of LIF contains NFKB binding sites and expression of these cytokines in other cells has been shown to be controlled by NFKB (Van der Burg and Van der Saag, 1996). This gene has been shown to be important in numerous human studies for the regulation of multiple processes prior to and during implantation such as uterine transformation into a receptive state, decidualization, blastocyst growth and development, embryo- endometrial interaction, trophoblast invasion, and immune modulation (Shuya et al., 2011). In a study conducted on cultured ovine embryos, researchers found that the addition of human LIF (hLIF) to the culture medium significantly improved the development of the embryos compared with control embryos prior to transfer. Through their research, they concluded that hLIF has potential as an embryotrophic or embryo-protective agent (Fry et al., 1992). Studies in cattle have shown LIF is increased in pregnant endometrium compared to cyclic endometrium until day 13 of gestation where it then remained constant (Oliveira et al., 2017). Interestingly, LIF expression increased in response to $100 \mathrm{ng} / \mathrm{mL}$ of LGALS1 in epithelial cells but decreased in the fibroblast cells in the 3-D culture system in response to 10 and $100 \mathrm{ng} / \mathrm{mL}$ of LGALS1. It is possible that higher concentrations of LGALS1 up-regulates LIF in the uterine epithelium. The LIF gene is considered an embryokine, and might promote development and growth of the conceptus. 
The most highly expressed gene in epithelial cells treated with LGALS1 was the proinflammatory cytokine, $I L-1 B$. The transcription factor, NFKB is known to be involved in cellular signaling from IL-1 in many cell types. It has been suggested that IL-1 secretion is stimulated by seminal plasma at the time of fertilization, is increased by progesterone and estrogen at implantation, and that it maintains a delicate and complex balance that exists through the establishment of pregnancy (Martal et al., 1997). The cytokine, IL-1 has been shown to increase LIF production in endometrial epithelial cells (Laird et al., 2000). Studies have shown habitual abortion in women can be associated with a decrease in the expression of $I L-1 B$ (Wolff et al., 2000). In ruminants IL-1B is produced by the conceptus and endometrium (Mathialagan et al., 1992). Endometrial epithelial cells treated with LGALS1 had increased expression of $I L-1 B$ and LIF. It is possible that LGALS1 is causing an increased expression in $I L-1 B$ which is then causing increased expression of LIF within the endometrial epithelium of cattle similarly to previous research.

The genes EIF4EBP2, CXCR4, CHST15, MST1R, and ATP11a were of specific interest to this study due to their differential expression in a study conducted by (Mathew et al., 2019). The genes EIF4EBP2, CHST15, and MST1R have been shown to be involved in tumorigenesis, tumor development and progression, and have been found in the epithelial cells of tumors (Benight and Waltz, 2012, Ito et al., 2017, Musunuru, 2003). The gene ATP11a has been found to have flippase activiy which transports phospholipids across the plasma membrane (Takatsu et al., 2014). In a study conducted by Mathew et al., (2019), endometrial explants were cultured with artificial insemination (AI) or in vitro fertilization (IVF) derived conceptuses or in culture medium containing interferon-tau (IFNT) in this study. Interestingly, genes CHST15, ATP11a, and EIF4EBP2 were down-regulated in endometrial explants treated with AI produced embryos. 
The genes were found to be independent of IFNT and possibly differentially expressed in response to conceptus secretory factors (CSF) (Mathew et al., 2019). We did not observe an increase in epithelial or fibroblast cell ATP11a in response to LGALS1. In fact, expression decreased in both cell types (10 or $100 \mathrm{ng} / \mathrm{mL}$ ). It is possible that additional CSF, other than LGALS1, also modify expression of ATP11a and are responsible for the increase in expression observed in total endometrium treated with conceptuses. It is also possible that there are other cells present in explants but not found in 3-D cultures that could also express ATP11a. In this study, the genes EIF4EBP2 and CHST15 were down-regulated in fibroblast cells in response to 10 and $100 \mathrm{ng} / \mathrm{mL}$ of LGALS1. In the epithelium, decreased expression may depend on concentration of LGALS1 as expression of CHST15 increased in these cells in response to 100 $\mathrm{ng} / \mathrm{mL}$ of LGALS1. Expression of both EIF4EBP2 and CHST15 decreased in the epithelium in response to $10 \mathrm{ng} / \mathrm{mL}$ of LGALS1. Overall, it is possible that conceptuses decrease expression of EIF4EBP2 and CHST15 in the stroma through secretion of LGALS1. In the same study by (Mathew et al., 2019) the genes MST1R, and $I L-6$ were up-regulated in endometrium treated with day 15 conceptuses. Previous studies have shown an embryokine function of IL-6 in bovine preimplantation embryos by enhancing inter-cell mass development in IVP embryos (Wooldridge and Ealy, 2019). The data of the current study shows increased relative expression of $I L-6$ in endometrial epithelial cells treated with LGALS1 (10 or $100 \mathrm{ng} / \mathrm{mL}$ ). Epithelial expression of $M S T 1 R$ however, increased in response to 100 but not $10 \mathrm{ng} / \mathrm{mL}$ of LGALS1. Due to the importance of $I L-6$ during pregnancy of other species, it is hypothesized that it would be important during early pregnancy in cattle. Clearly, expression depends on endometrial cell type and concentration of LGALS1. Therefore, it could be concluded that a delicate balance of conceptus LGALS1 secretion within the uterine lumen is needed to support pregnancy in cattle. 


\section{CONCLUSION}

Results of the present study show evidence for a role of LGALS1 during early pregnancy in the cow. Galectin-1 might increase endometrial expression of CXCR4 and LIF through activation of the NFKB pathway in cattle (Figure 6.1). The CXCR4 and LIF genes are important for trophoblast invasion and communication between the conceptus and maternal endometrium. Galectin-1 induced up-regulation of pro-inflammatory cytokines $I L-1 B$ and $I L-6$ in bovine endometrial epithelial and fibroblast cells suggests that LGALS1 may promote an inflammatory like environment along the uterine surface. Pro-inflammatory cytokines are believed to be necessary for successful pregnancy, especially at the conceptus-maternal interface (Mathew et al., 2015). The gene ontology pathways support these data with many of the enriched pathways being related to pro-inflammatory cytokines and regulation of the immune system. 
Table 4.1- Gene Ontology Biological Process Direct for genes up-regulated in bovine endometrial epithelial cells treated with 100ng/mL of bovine LGALS1 in 3-D culture

\section{Up Biological Process}

inflammatory response

positive regulation of NF-kappaB transcription factor activity

type I interferon signaling pathway

apoptotic process

\section{$\underline{\text { P Value }}$ Genes}

PTGS2, ELF3, S100A8, TBK1, IL19, S100A9, TLR2, TLR3, TLR4, NFKB1, NFKB2, TLR6, CXCL10, CCRL2, S1PR3, TNFRSF11B, CASP4, CXCR4, LTB4R, MGLL, IL-1B, VNN1, FAS, ADAM8, TNIP1, IL1A, CIITA, IRAK2, NFKBIZ, PTGER2, C5AR2, SP100, IL18RAP, GBP5, LYN, RELB,

0.000 CHST2, CD40, IFI16, TNFRSF9, TNFAIP6, PTGDR, RIPK2, NAIP, TNFAIP3, IL36A, TNFRSF21, CCL2, NMI, TNF CXCL5, C3, ADORA2A, CXCL3, CSF1, C5, CXCL2, CXCL8, CCL5, IL34, CCL22, CCL20, ITGB6, ZC3H12A, BLNK, LY75, SELP, IL-6, LIPA, CEBPB, OLR1, CHI3L1, SMAD1, LGALS9, S100A12, LAT, APOL3, CYBA, CLEC7A, IKBKB, CD14, F2R

TRAF1, TNF, S100A8, NFKBIB, S100A9, TLR2, TRIM14, NFKBIA, TLR3, NFKB1, TLR4, NFKB2, TNFSF18, IRAK3, TRIM5, NOD2, TRIM8, RBCK1, LTF, IL-1B, ADAM8, CAMK2A, RNF31, IRAK2, ICAM1, CFLAR, IL-6, TRIM25, MALT1, CD40, LGALS9, S100A12, TRIM38, CARD14, PSMA6, RIPK3, RIPK2, EIF2AK2, IKBKB

RNASEL, SP100, IFITM2, RSAD2, SAMHD1, OAS2, STAT1, IFI35, PSMB8, ISG20, STAT2, TYK2, IRF9, IFIT3, IFNAR2, IFIT2, IFI27, ISG15, IRF7, IRF1, XAF1, MX1, MX2, IFI6, ADAR

S100A8, FAM3B, IL19, S100A9, TLR2, FOXO1, NFKB1, DAXX, ASAH2, CASP3, CASP4, UNC5B, CXCR4, CASP7, CASP8, MAP3K8, IL-1B, FAS, CASP1, MX1, IL1A, MT3, BCL2L15, BCL2L14, NCF1, GZMA, ARHGEF6, PIM1, RHBDD1, AHR, TNFRSF9, CARD14, CLIC4, ARRB1, TNFAIP8, RIPK2, AVEN, CTSC, NAIP, TNFAIP3, PPP1R15A, TRAF1, ZFAND6, ARL6IP1, TNFRSF21, GSDMA, LITAF, ADORA2A, SAV1, PML, EGLN3, NFKBIA, 
RFFL, PRUNE2, PTK2B, SQSTM1, MAP3K1, ZC3H12A, XAF1, EPO, CFLAR, RNF144B, RMDN3, BIRC7, CHI3L1, TMBIM4, GJB6, STAT1, BIRC3, TNFSF9, DRAM2, RPS6KA3, TNFSF10, RASSF6, RABEP1, IFT57, SLC5A8, IRF1, JAK2, EAF2, DRAM1, CD14

S100A8, TBK1, S100A9, TLR2, TLR3, TLR4, NFKB1, NFKB2, TLR6, TRIM5, MAP3K5, NOD2, CASP4, PGLYRP4, CLEC4E, TRIM8, PGLYRP2, PGLYRP3, VNN1, MX1, MX2, LYN, NCF2, BPIFA1, NCF1, RELB, HERC5, SERPING1, IFI16, TYK2, STYK1, RIPK2, NAIP, MST1R, EIF2AK2, IL36A, FRK, IFIH1, FGR, CSF1, PML, TRIM14, C1R, IL34, TRIM10, CLEC10A, SEC14L1, CYLD, PTK2B, C2, DHX58, ZBP1, MALT1, TRIM25, TRIM21, S100A12, IL36RN, DDX58, CYBA, IRF7, IFIT5, JAK2, CLEC7A, IKBKB, CD14, ADAR

CIITA, ICAM1, SP100, NMI, PML, TRIM25, OAS2, STAT1, TRIM21, IRF9, VCAM1, TRIM38, TRIM5, CD44, TRIM8, TRIM34, IRF7, MT2A, IRF1, CAMK2D, JAK2, CAMK2B, CAMK2A

AQP9, IL19, TLR2, TNFSF15, TLR4, ZEB1, TLR6, VIPR1, TAPBP, CXCL10, TNFRSF11B, SH2D6, LTB4R, IL-1B, FAS, LTB, IL1A, CIITA, IL18RAP, GZMA, ACKR4, CD40, PDCD1LG2, TNFRSF9, TNFSF13B, CTSC, IL36A, CSF3, IL1R2, TNFRSF21, CCL2, LST1, TNF, CXCL5, IFITM2, C3, CXCL3, CXCL2, CXCL8, C1R, CX3CL1, OAS2, CCL5, CCL28, LIF, CCL22, CCL20, LY75, IL18R1, IL-6, TNFSF4, CEBPB, IL1RN, SMAD3, SAMHD1, TNFSF9, LAT, IKBKE, TNFSF10, CD274, AIRE, IFI6 IFI44L, OAS2, ISG20, CXCL10, TRIM5, ISG15, ZC3H12A, MX1, MX2, DHX58, IL-6, HERC5, SAMHD1, TRIM25, IFI16, 
response to virus

response to lipopolysaccharide
CD40, STAT1, STAT2, IRF9, IFIT3, IFNAR2, IFIT2, TRIM34, IFIT5, IRF1, SLFN11, EIF2AK2, ADAR

IFIH1, TNF, TNFSF4, FGR, TBK1, IFITM2, RSAD2, IFI44, OAS2, CCL5, ISG20, IFIT3, DDX58, IFNAR2, IFIT2, IRAK3, CCL22, CXCR4, IRF7, BCL3, MST1R, EIF2AK2, MX1, IKBKB, XCL1, MX2, DHX58, ADAR

TNFRSF21, S100A8, CXCL5, PTGS2, CXCL3, EDN1, CXCL2, DUSP10, TLR2, TLR4, CNP, NFKB2, CXCL10, VCAM1, IRAK3, CASP3, TNFRSF11B, PTGES, CASP8, FAS, CASP1, EPO, SELP, PTGER2, CD40, GJB6, IDO1, LGALS9, SOD2, PCK1, TNFRSF9, RPS6KA3, JAK2, F2R 
Table 4.2 Gene Ontology Biological Process Direct for genes down-regulated in bovine endometrial epithelial cells treated with 100ng/mL of bovine LGALS1 in 3-D culture

\section{$\underline{\text { Down }}$ Biological Process}

DNA replication

G1/S transition of mitotic cell cycle

DNA replication initiation

DNA strand elongation involved in DNA replication

telomere maintenance via recombination

positive regulation of transcription from RNA polymerase II promoter

\section{$\underline{\text { P Value } \text { Genes }}$}

CLSPN, CHEK1, POLA2, MCM10, CDT1, RHNO1, ORC1, FEN1, RECQL4, CDC7, CDC6, DTL, GINS3, MCM2, MCM4, CDK2, MCM5, MCM6, RFC3, RFC4, RRM2, POLD1, RRM1, PCNA, CHTF18, CHAF1A, CHAF1B, BARD1

CDC7, CDC6, SKP2, POLA2, MCM2, MCM10, MCM4,

0.000 CDK2, MCM5, CDT1, MCM6, PRIM1, CCNE2, CCNE1, INHBA, PLK2, RRM2, PCNA, ORC1

0.000

CDC7, PRIM1, CCNE2, CCNE1, CDC6, MCM2, POLA2, MCM10, MCM4, ORC1, MCM5, MCM6

0.000

GINS1, PRIM1, RFC3, RFC4, POLD1, GINS3, PCNA, POLA2

0.000

PRIM1, RFC3, RFC4, POLD1, PCNA, BRCA2, POLA2, FEN1

E2F1, AKNA, WNT5A, GLIS3, ELF5, E2F8, ARNT2, PPARG, FSTL3, PRRX1, TGFB3, MYBL2, SRF, MEIS1, IL11, JADE1, PAX8, PSIP1, RARA, NFATC2, TCF3, ETV4, BCL9, CYR61, CEBPA, EGR1, FZD8, FOSB, LPIN1, CAPRIN2, HDAC5, DOT1L, HES1, INHBA, UHRF1, HNF4A, JUN, SALL1, HOXB9, PIAS2, BMP7 
cell division

0.000

regulation of transcription involved in G1/S transition of mitotic cell cycle

positive regulation of peptidyl-threonine phosphorylation

0.000

0.000
HAUS4, CDC7, CDC6, DSN1, KNTC1, SPDL1, SMC2, WEE1, CDK2, RGS14, MCM5, CCNE2, CCNE1, SPC25, VRK1, CENPV, SKA2, KLHL42, HELLS, TERF1

CCNE1, CDC6, RRM2, PCNA, ORC1, CDT1
WNT5A, TRPC6, PRKAG2, SPHK1, CEMIP, BMP7 
Table 4.3 KEGG Pathway Analysis for genes up-regulated in bovine endometrial epithelial cells treated with 100ng/mL of bovine LGALS1 in 3-D culture

Up Biological Process

TNF signaling pathway

Influenza A

NF-kappa B signaling pathway

Cytokine-cytokine receptor interaction

\section{$\underline{\text { P Value }} \underline{\text { Genes }}$}

TRAF1, CCL2, TNF, PTGS2, CXCL3, CSF1, EDN1, CXCL2, NFKBIA, NFKB1, CX3CL1, CCL5, CXCL10, LIF, VCAM1, BAG4, CASP3, MAP3K5, NOD2, CCL20, CASP7, CASP8, MAP3K8, BCL3, IL-1B, PIK3R5, FAS, ICAM1, IL18R1, CFLAR, IL-6, CEBPB, MAP2K1, MAPK10, BIRC3, RIPK3,

0.000 TNFAIP3, IKBKB

XPO1, IFIH1, RNASEL, CCL2, TNF, TBK1, NFKBIB, PML, CXCL8, NFKBIA, TLR3, RSAD2, NFKB1, TLR4, OAS2, CCL5, CXCL10, IL-1B, PIK3R5, FAS, CASP1, MX1, IL1A, CIITA, ICAM1, TMPRSS2, IL-6, MAP2K1, DDX39B, TRIM25, MAPK10, STAT1, STAT2, TYK2, IRF9, DDX58, IKBKE, IFNAR2, TNFSF10, IRF7, JAK2, IKBKB, EIF2AK2, ADAR

TRAF1, TNF, PTGS2, CXCL8, NFKBIA, NFKB1, TLR4, NFKB2, VCAM1, IL-1B, LTB, BLNK, ICAM1, CFLAR, LYN, RELB, BCL2A1, TRIM25, MALT1, CD40, BIRC3, DDX58, LAT, TNFSF13B, IKBKB, TNFAIP3, CD14, PLAU

CSF3, IL1R2, TNFRSF21, CCL2, TNF, CXCL5, IL-6ST, OSMR, CXCL3, CSF1, IL21R, CXCL2, IL19, TNFSF15, CXCL8, CX3CL1, CCL5, TNFSF18, CCL28, CXCL10, LIF, TNFRSF11B, CCL22, CCL20, CXCR4, IL15RA, IL-1B, FAS, IL13RA1, LTB, IL1A, EPO, IL18R1, IL-6, IL2RB, IL18RAP, TNFSF4, ACKR3, CD40, TNFSF9, IFNAR2, TNFRSF9, TNFSF10, TNFSF13B, IL20RA, CXCL16,

0.000 XCL1, IL3RA


Herpes simplex infection

Measles

NOD-like receptor signaling pathway

Pertussis

RIG-I-like receptor signaling pathway

Toll-like receptor signaling pathway

TRAF1, IFIH1, RNASEL, CCL2, TNF, TBK1, C3, NFKBIB, C5, TLR2, PML, NFKBIA, TLR3, NFKB1, OAS2, CCL5, DAXX, CASP3, TAP2, CASP8, TAP1, IL-1B, FAS, IL-6, SP100, TAF4B, NECTIN2, MAPK10, STAT1, STAT2, DDX58, IRF9, TYK2, IKBKE, IFNAR2, IRF7, JAK2,

0.000 EIF2AK2, IKBKB

IFIH1, TBK1, NFKBIB, STAT5A, TLR2, NFKBIA, NFKB1, TLR4, OAS2, IL-1B, PIK3R5, FAS, MSN, MX1, IL1A, IL-6, IL2RB, STAT1, STAT3, STAT2, DDX58, IRF9, TYK2, IKBKE, IFNAR2, TNFSF10, IRF7, JAK2, EIF2AK2,

0.000 TNFAIP3, ADAR

IL-6, TNF, CCL2, NFKBIB, CXCL2, CXCL8, NFKBIA, NFKB1, MAPK10, BIRC3, CCL5, NOD2, CASP8, RIPK2, IL1B, NAIP, IKBKB, CASP1, TNFAIP3

IL-6, TNF, GNAI3, CXCL5, C3, GNAI1, C5, CXCL8, NFKB1, TLR4, C1R, SERPING1, MAPK10, CASP3, CASP7, IRF1, IL1B, NOS2, C2, CASP1, CD14, IL1A

IFIH1, TNF, TBK1, NFKBIB, CXCL8, NFKBIA, NFKB1, TRIM25, MAPK10, TANK, CXCL10, DDX58, RNF125, IKBKE, CYLD, ISG15, IRF7, MAP3K1, CASP8, IKBKB, DHX58

TNF, TBK1, TLR2, CXCL8, TLR3, NFKBIA, TLR4, NFKB1, CCL5, TLR6, CXCL10, MAP3K8, CASP8, IL-1B, PIK3R5, IL-6, MAP2K1, CD40, MAPK10, STAT1, IFNAR2, IKBKE, CD80, IRF7, IKBKB, CD14 
Table 4.4 KEGG Pathway Analysis for genes down-regulated in bovine endometrial epithelial cells treated with 100ng/mL of bovine LGALS1 in 3-D culture

\section{Down Biological Process}

DNA replication

Cell cycle

Pathways in cancer

Signaling pathways regulating pluripotency of stem cells

HTLV-I infection

\section{$\underline{\text { P Value }} \underline{\text { Genes }}$}

0.000

0.000

0.000

0.000

0.000
PRIM1, RFC3, RFC4, POLD1, PCNA, MCM2, POLA2, MCM4, MCM5, FEN1, MCM6

CDC7, E2F1, CDC6, SKP2, TGFB3, CHEK1, MCM2, MCM4, WEE1, CDK2, MCM5, MCM6, CCNE2, CCNE1, PCNA, GADD45B, ORC1

WNT5A, E2F1, FGFR3, PDGFA, ARNT2, PPARG, TGFB3, KITLG, FGF13, CCNE2, CCNE1, IGF1R, PAX8, PLEKHG5, RARA, LAMB1, CEBPA, FZD8, PTGER3, FZD1, SKP2, BRCA2, CDK2, WNT2B, WNT7B, PLCG1, JUN

WNT5A, INHBB, FZD8, IGF1R, INHBA, WNT7B, FGFR3, PCGF6, FZD1, TCF3, MEIS1, WNT2B

WNT5A, EGR1, E2F1, FZD8, PDGFA, FZD1, TGFB3, CHEK1, SRF, WNT2B, WNT7B, JUN, POLD1, PCNA, NFATC2, TCF3 
Table 4.5- Genbank accession number, gene name, primer sequence (forward and reverse), product size, amplification efficiency, and source of primer for gene cDNA amplified during RT-qPCR

\begin{tabular}{|c|c|c|c|c|c|c|}
\hline $\begin{array}{l}\text { GenBank } \\
\text { Acc. Number }\end{array}$ & Gene & Primer & Primer Sequence (5’-3’) & $\begin{array}{l}\text { Product } \\
\text { Size (bp) }\end{array}$ & Amp. E. & Source of Primer \\
\hline NM_174301.3 & CXCR4 & $\begin{array}{l}\text { Forward } \\
\text { Reverse }\end{array}$ & $\begin{array}{l}\text { AAGGCTCAGAAGCGCAAG } \\
\text { GAGTCGATGCTGATCCCAAT }\end{array}$ & 102 & $102.21 \%$ & (Weiner et al., 2012) \\
\hline NM_015459645.2 & $M S T 1 R$ & $\begin{array}{l}\text { Forward } \\
\text { Reverse }\end{array}$ & $\begin{array}{l}\text { GAAAAGGGCGTAGAGCACTG } \\
\text { CAACAGCCCGTTGAATAGGT }\end{array}$ & 195 & $107.23 \%$ & Primer3Plus \\
\hline NM_025000176.1 & ATP11A & $\begin{array}{l}\text { Forward } \\
\text { Reverse }\end{array}$ & $\begin{array}{l}\text { GGTGATGGTGCTCACAGTCA } \\
\text { CCAGATGACTCCTCCCCAGA }\end{array}$ & 133 & $98.64 \%$ & Primer3Plus \\
\hline XM_024986067.1 & CHST15 & $\begin{array}{l}\text { Forward } \\
\text { Reverse }\end{array}$ & $\begin{array}{l}\text { TCTGCTCTCTTGTGTGCGAG } \\
\text { CCTGGGTAGTGAGAGAGGCT }\end{array}$ & 119 & $97.08 \%$ & Primer3Plus \\
\hline NM_173923.2 & $I L-6$ & $\begin{array}{l}\text { Forward } \\
\text { Reverse }\end{array}$ & $\begin{array}{l}\text { CGCATGGTCGACAAAATCTCT } \\
\text { GCTGCTTTCACACTCATCATTCTT }\end{array}$ & 69 & $95.37 \%$ & (Mathew et al., 2019) \\
\hline NM_174093.1 & $I L-1 B$ & $\begin{array}{l}\text { Forward } \\
\text { Reverse }\end{array}$ & $\begin{array}{l}\text { ACCTGAACCCATCAACGAAATG } \\
\text { TAGGGCCATCAGCCTCAAATAACA }\end{array}$ & 74 & $92.97 \%$ & (Mathew et al., 2019) \\
\hline NM_173931.1 & $L I F$ & $\begin{array}{l}\text { Forward } \\
\text { Reverse }\end{array}$ & $\begin{array}{l}\text { GGGACAACTCAACAGCAGTG } \\
\text { GCACAGCTTGTCCAGGTTG }\end{array}$ & 91 & $96.00 \%$ & Primer3Plus \\
\hline NM_001191149.1 & EIF4EBP2 & $\begin{array}{l}\text { Forward } \\
\text { Reverse }\end{array}$ & $\begin{array}{l}\text { GGGTTCAGCATCATTCCTGT } \\
\text { GGGAAGTGGACCTCAAAACA }\end{array}$ & 227 & $107.99 \%$ & Primer3Plus \\
\hline NM_178320 & PPIA & $\begin{array}{l}\text { Forward } \\
\text { Reverse }\end{array}$ & $\begin{array}{l}\text { CATACAGGTCCTGGCATCTTGTCC } \\
\text { CACGTGCTTGCCATCCAACC }\end{array}$ & 108 & - & \\
\hline NM_174814.2 & $Y W H A Z$ & $\begin{array}{l}\text { Forward } \\
\text { Reverse }\end{array}$ & $\begin{array}{l}\text { ACCTACTCCGGACACAGAACATC } \\
\text { GCAGGAGGGGCACGTGAAGG }\end{array}$ & 65 & - & \\
\hline
\end{tabular}




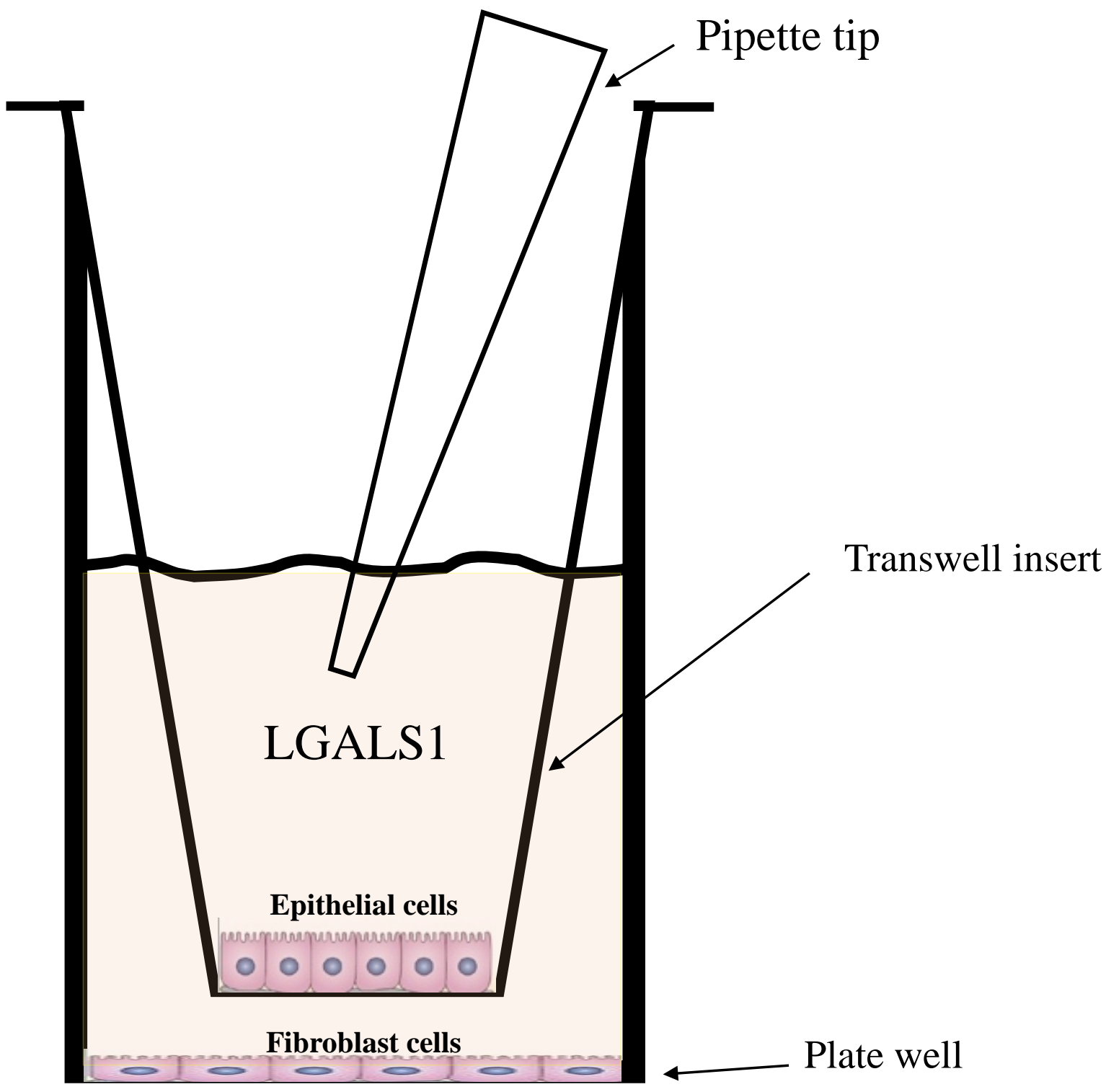

Figure 4.1 Diagram representing 3-D co-culture system of bovine endometrial epithelial and fibroblast cells. Epithelial cells were cultured on transwell inserts that were placed on top of fibroblast cells cultured in 24 well plates. Galectin-1 treatments (10 or $100 \mathrm{ng} / \mathrm{mL}$ ) were applied to the transwell insert containing epithelial cells and above fibroblast cells. 


\section{CXCR4}

A

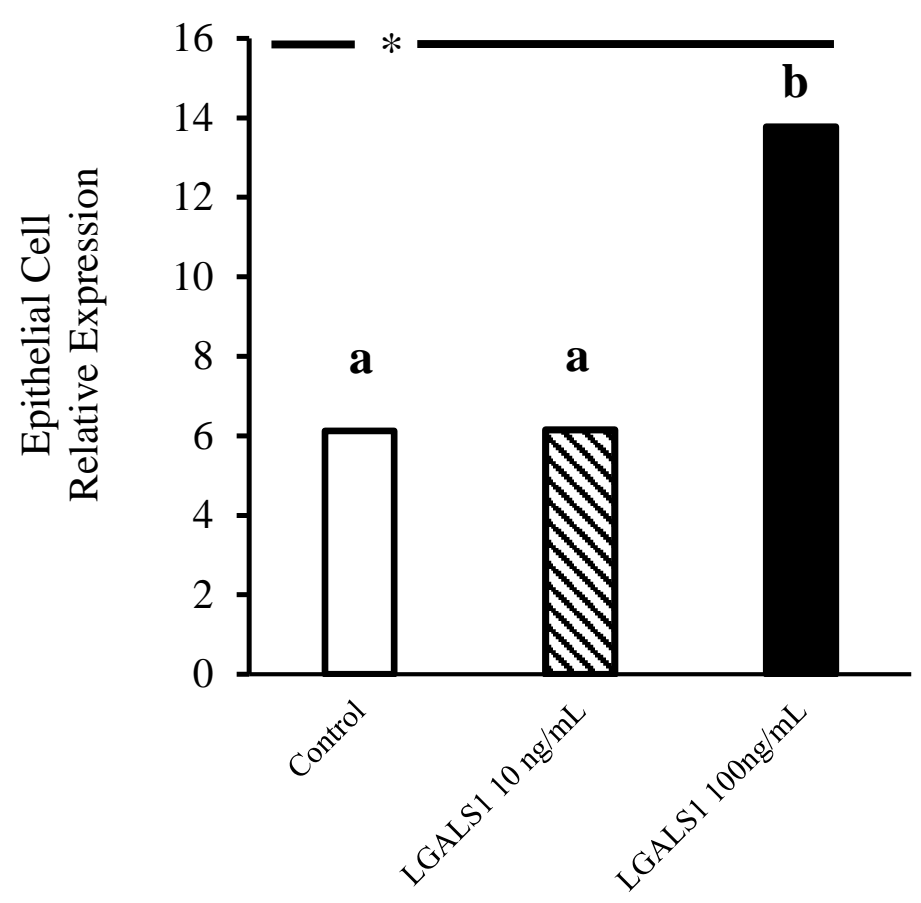

工 $\mathrm{SEM}=0.89$

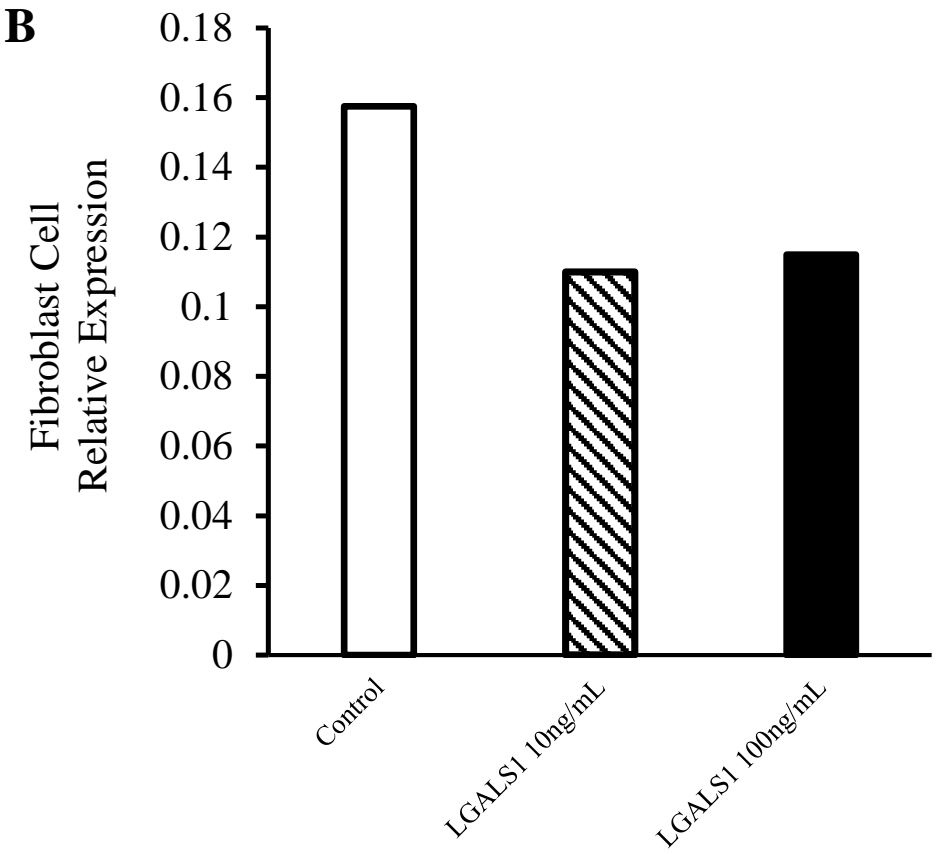

Figure 4.2 Least squares means relative expression values for $C X C R 4$ in endometrial epithelial (A) and fibroblast (B) cells in 3-D culture $(n=4)$ treated with increasing concentrations of LGALS1 (Control, 10 or $100 \mathrm{ng} / \mathrm{mL}$ ). There was a significant effect of treatment in epithelial cells (Contrast; $\mathrm{P} \leq 0.05$ ) when all LGALS1 treatments were compared to Control. Epithelial SEM $=0.89$. Fibroblast $\mathrm{SEM}=$ 0.02 . 


\section{EIF4EBP2}

A
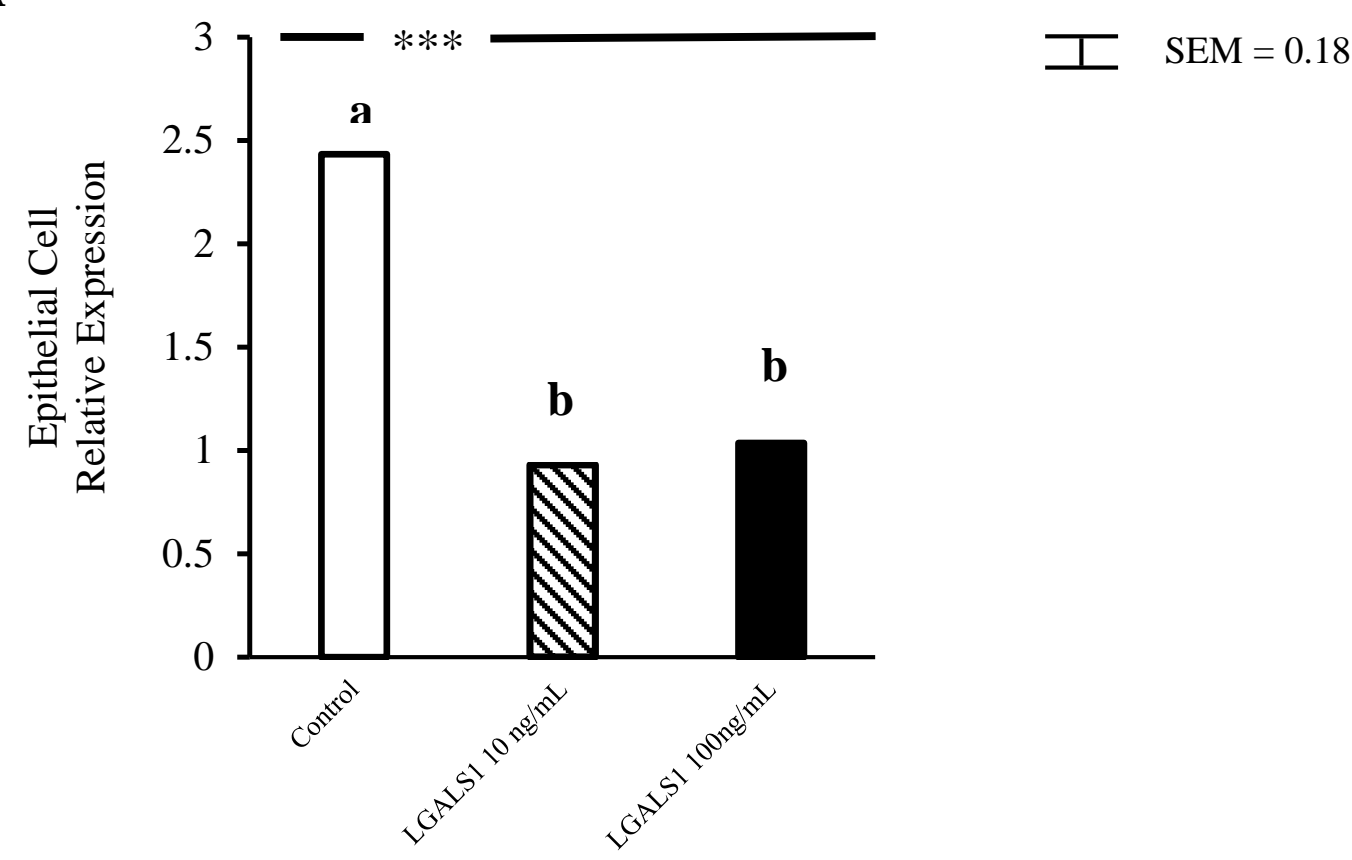

B

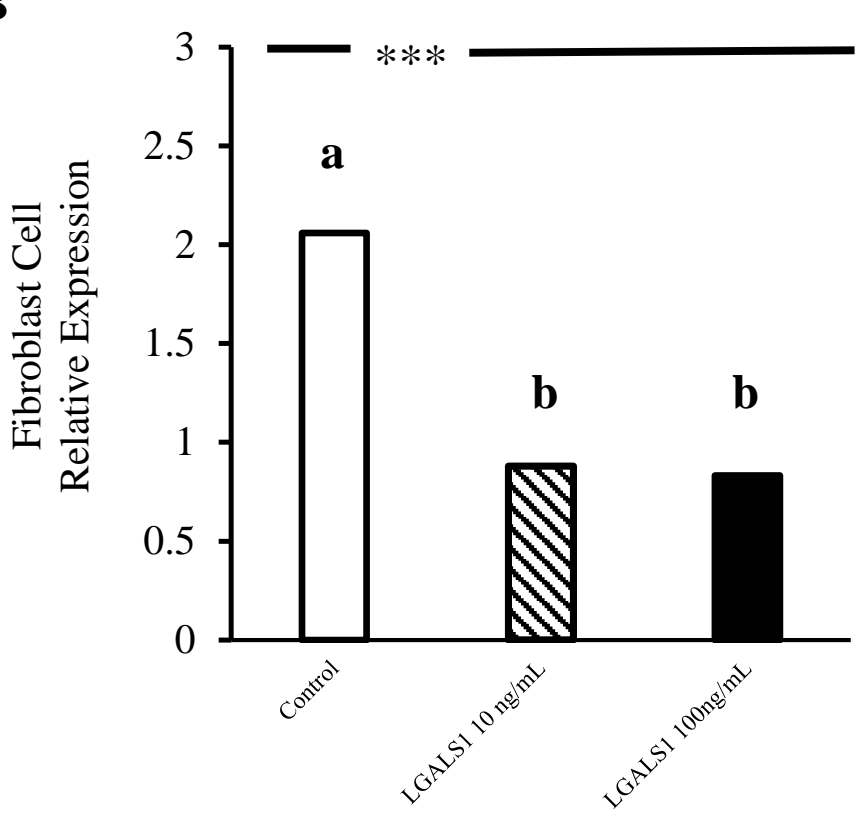

Figure 4.3 Least squares means relative expression values for EIF4EBP2 in endometrial epithelial (A) and fibroblast (B) cells in 3-D culture $(n=4)$ treated with increasing concentrations of LGALS1 (Control, 10 , or $100 \mathrm{ng} / \mathrm{mL}$ ). There was a significant effect of treatment in epithelial and fibroblast cells (Contrast; P $\leq$ 0.001) when all LGALS1 treatments were compared to Control. Epithelial SEM = 0.18 . Fibroblast SEM $=0.17$. 

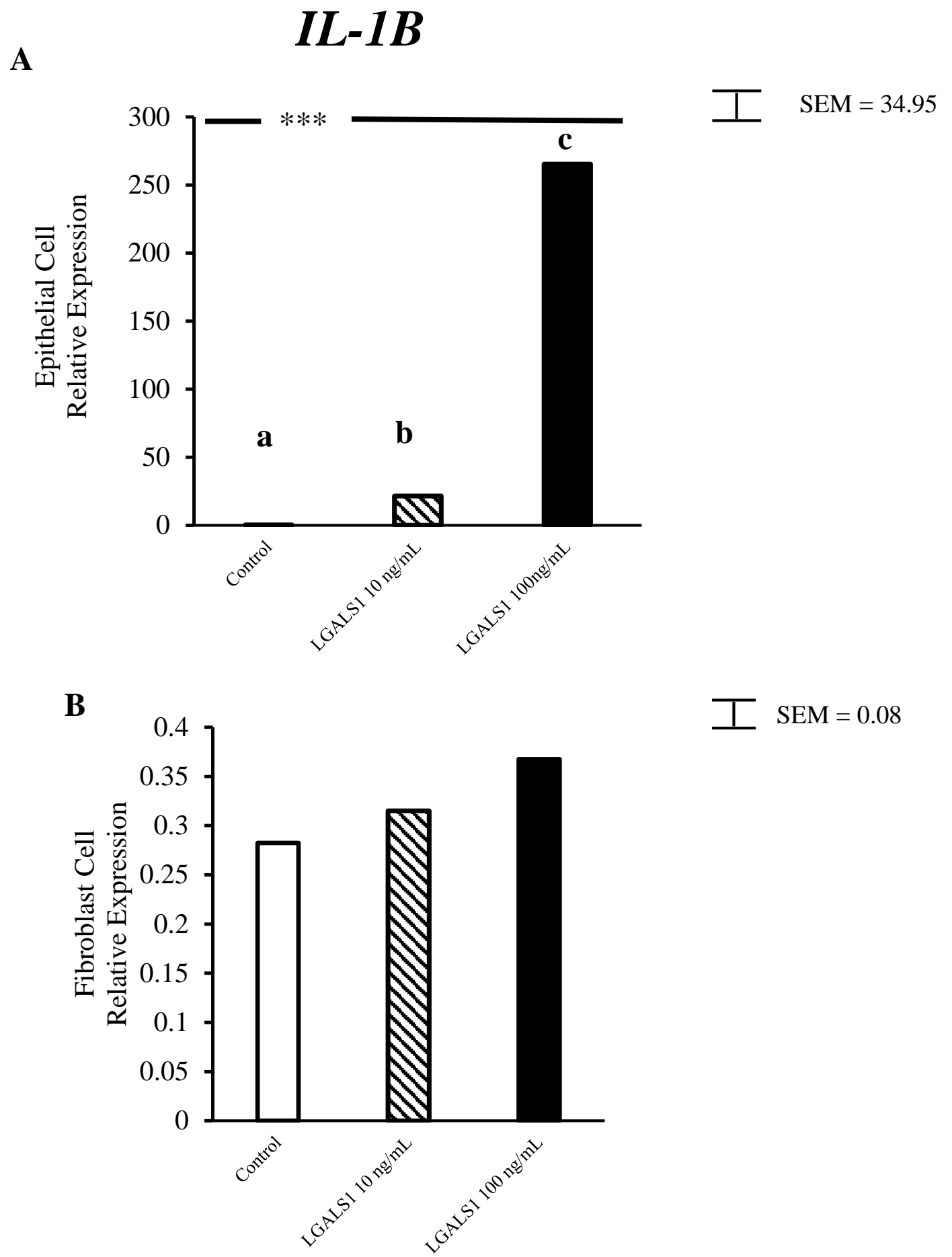

I $\mathrm{SEM}=0.08$

Figure 4.4 Least squares means relative expression values for $I L-1 B$ in endometrial epithelial (A) and fibroblast (B) cells in 3-D culture $(n=4)$ treated with increasing concentrations of LGALS1 (Control, 10, or $100 \mathrm{ng} / \mathrm{mL}$ ). There was a significant effect of treatment in epithelial cells (Contrast; $\mathrm{P} \leq 0.001$ ) when all LGALS1 treatments were compared to control. Epithelial SEM $=34.95$. Fibroblast SEM $=0.08$. 
A

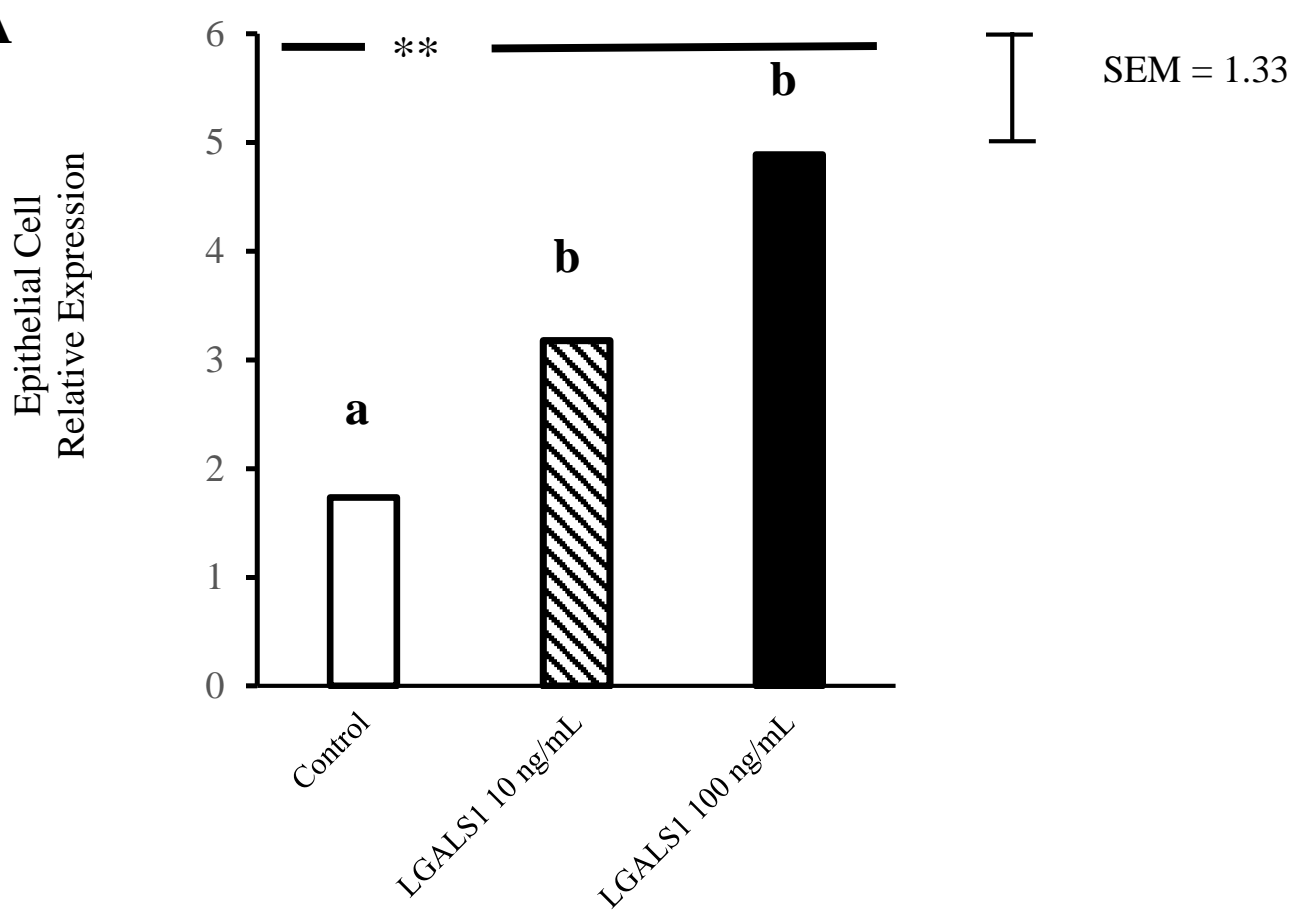

B

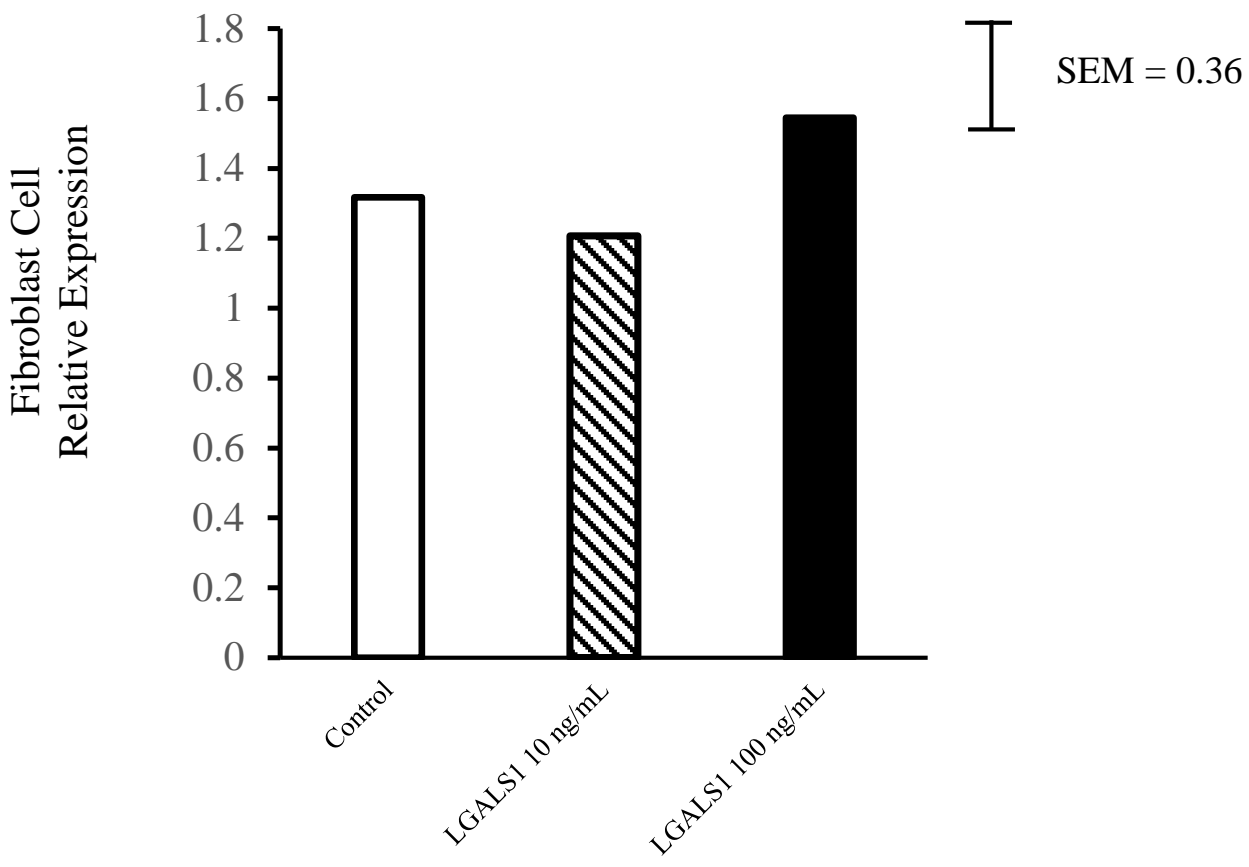

Figure 4.5 Least squares means relative expression values for $I L-6$ in endometrial epithelial (A) and fibroblast (B) cells in 3-D culture $(\mathrm{n}=4)$ treated with increasing concentrations of LGALS1 (Control, 10, or $100 \mathrm{ng} / \mathrm{mL}$ ). There was a significant effect of treatment in epithelial cells (Contrast; $\mathrm{P} \leq 0.01$ ) when all LGALS1 treatments were compared to Control. Epithelial SEM = 1.33. Fibroblast SEM $=0.36$. 
A $\quad$ LIF

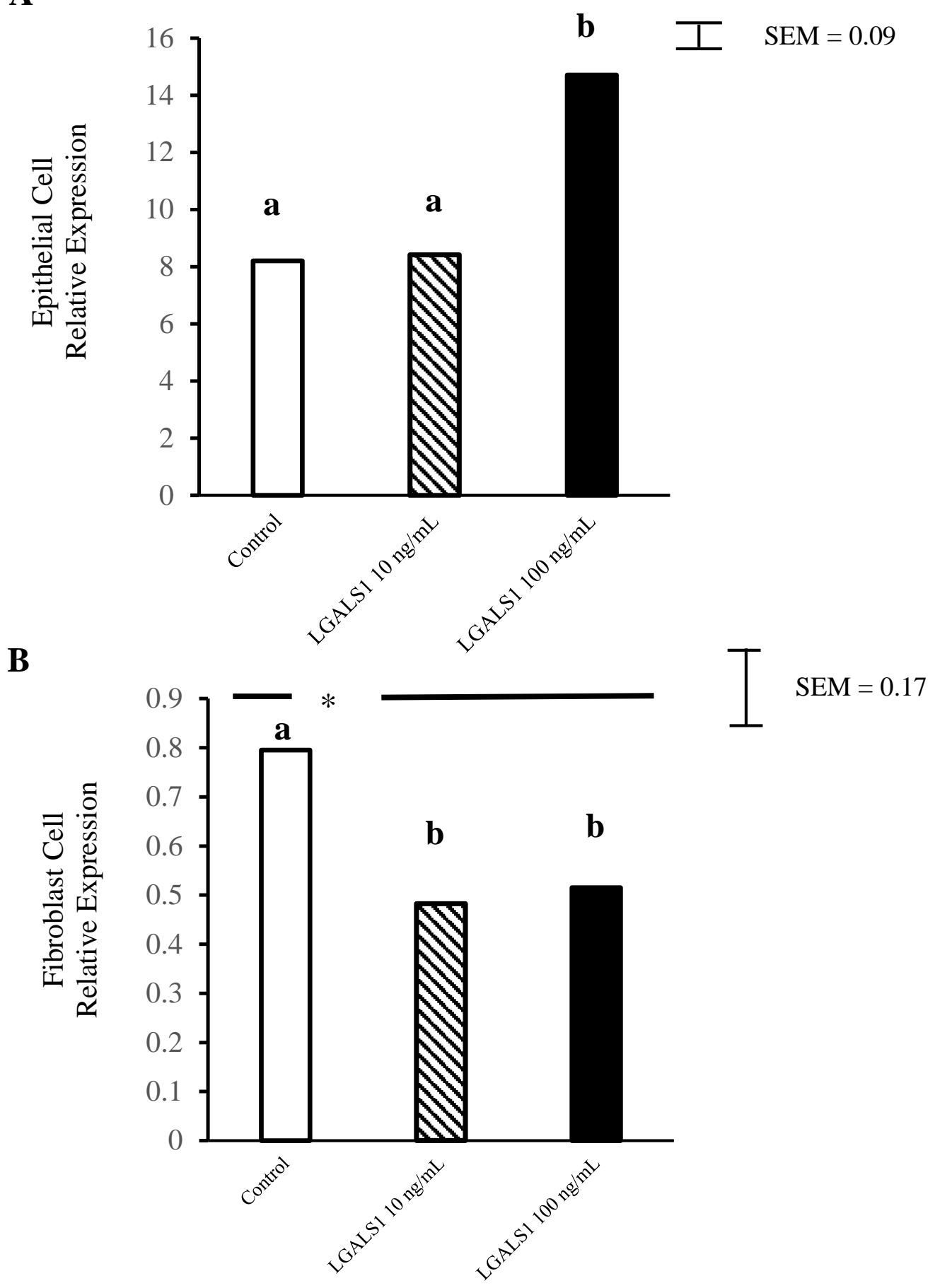

Figure 4.6 Least squares means relative expression values for $L I F$ in endometrial epithelial (A) and fibroblast (B) cells in 3-D culture $(n=4)$ treated with increasing concentrations of LGALS1 (Control, 10, or $100 \mathrm{ng} / \mathrm{mL}$ ). There was a significant effect of treatment in fibroblast cells (Contrast; $\mathrm{P} \leq 0.05$ ) when all LGALS1 treatments were compared to Control. In Epithelial cells $\mathrm{SEM}=0.09$. Fibroblast SEM $=0.17$. 


\section{CHST15}

A
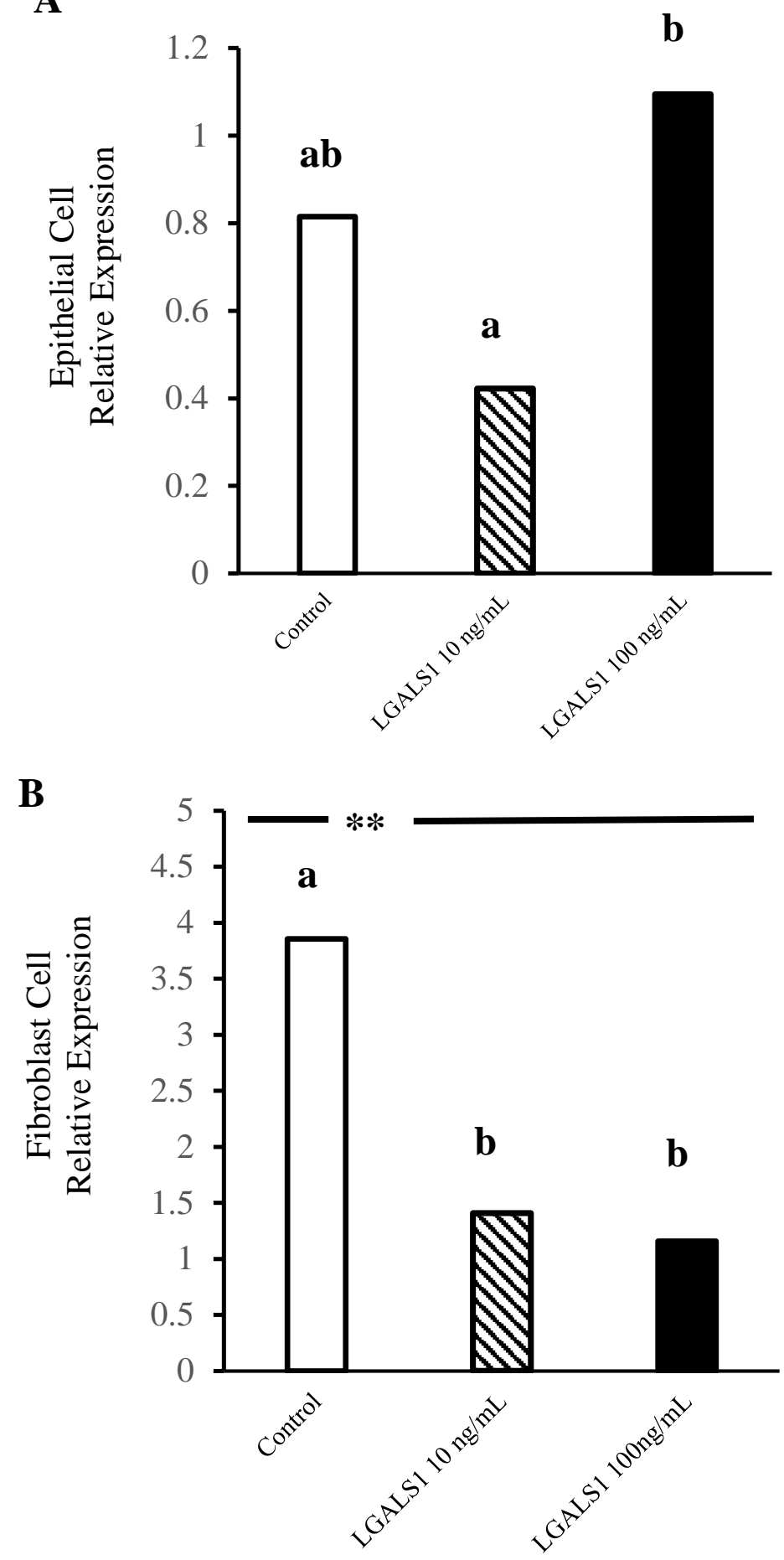

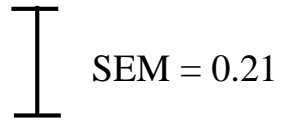

$\beth \mathrm{SEM}=0.93$

Figure 4.7 Least squares means relative expression values for CHST15 in endometrial epithelial (A) and fibroblast (B) cells in 3-D culture $(n=4)$ treated with increasing concentrations of LGALS1 (Control, 10, or $100 \mathrm{ng} / \mathrm{mL}$ ). There was a significant effect of treatment in fibroblast cells (Contrast; $\mathrm{P} \leq 0.01$ ) when all LGALS1 treatments were compared to Control. Epithelial SEM $=0.21$ Fibroblast SEM = 0.93 . 


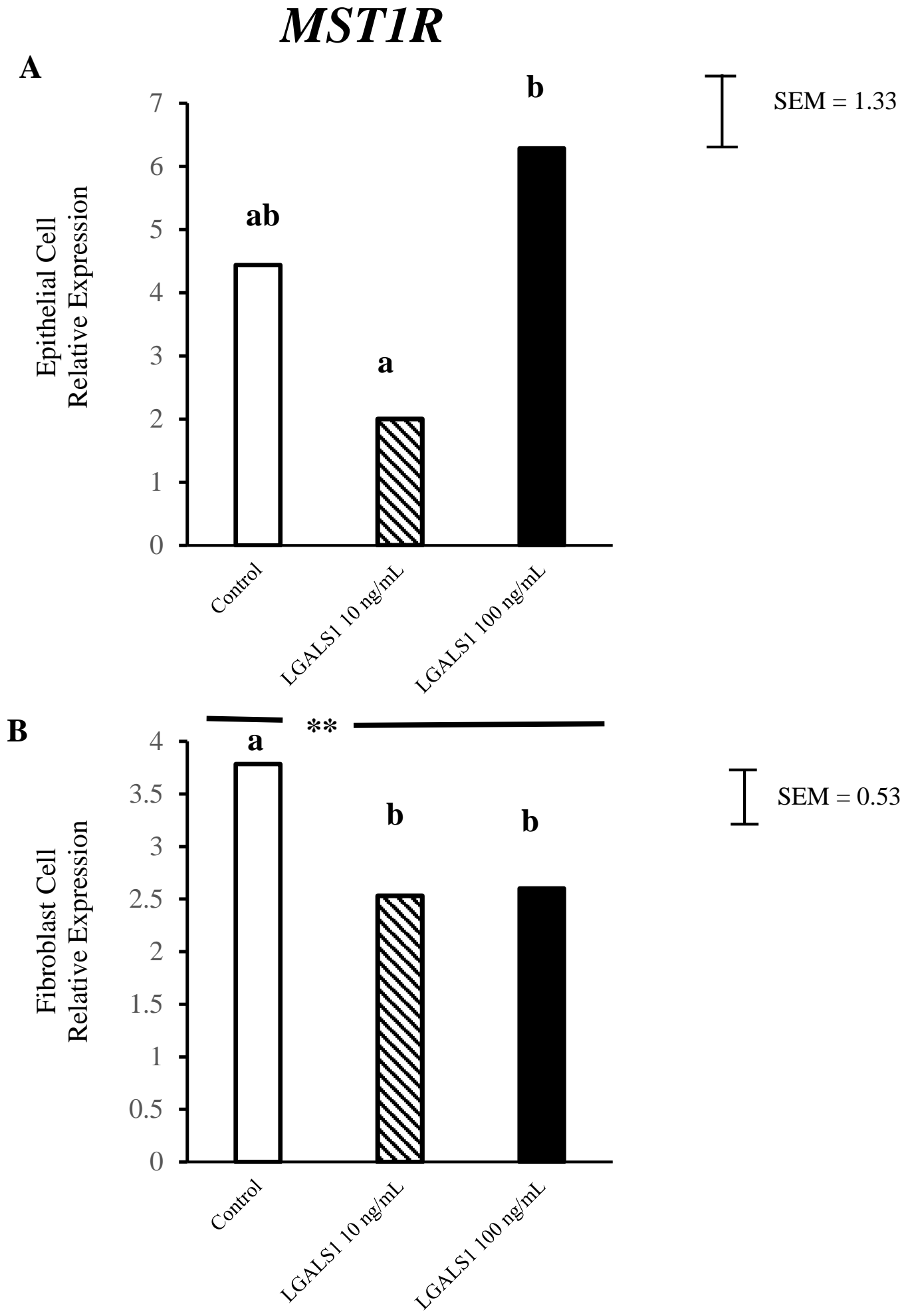

Figure 4.8 Least squares means relative expression values for MST1R in endometrial epithelial (A) and fibroblast (B) cells in 3-D culture $(\mathrm{n}=4)$ treated with increasing concentrations of LGALS1 (Control, 10, or $100 \mathrm{ng} / \mathrm{mL}$ ). There was a significant effect of treatment in fibroblast cells (Contrast; $\mathrm{P} \leq 0.01$ ) when all LGALS1 treatments were compared to Control. Epithelial SEM $=1.33$. Fibroblast SEM $=$ 0.53 . 


\section{ATP11a}
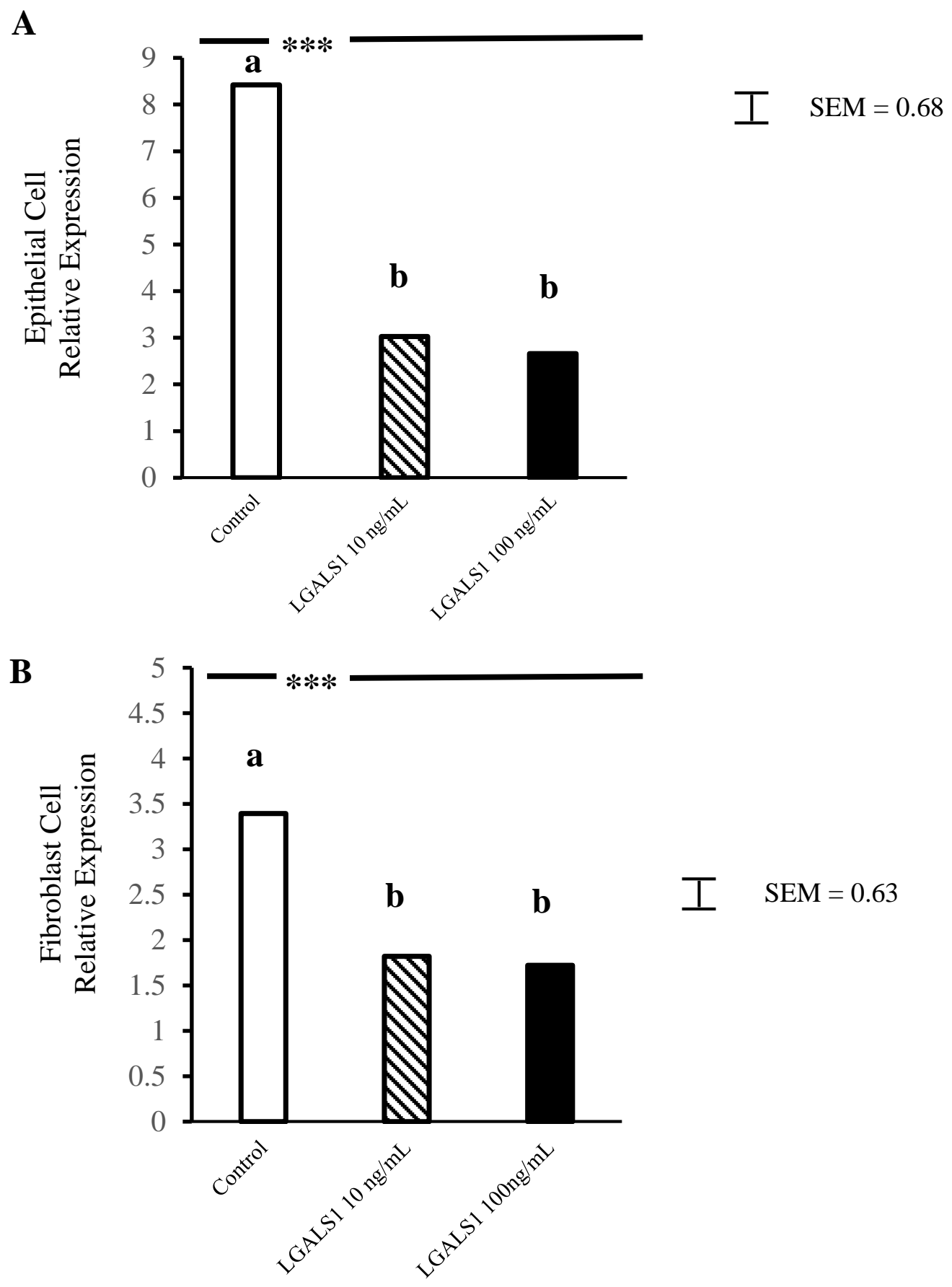

Figure 4.9 Least squares means relative expression values for ATP11a in endometrial epithelial (A) and fibroblast (B) cells in 3-D culture $(n=4)$ treated with increasing concentrations of LGALS1 (Control, 10, or $100 \mathrm{ng} / \mathrm{mL}$ ). There was a significant effect of treatment in epithelial and fibroblast cells (Contrast; $\mathrm{P} \leq 0.001$ ) when all LGALS1 treatments were compared to Control. Epithelial SEM $=0.68$. Fibroblast $\mathrm{SEM}=0.63$. 
Table 4.6 Summary of relative expression data for genes amplified by RT-qPCR in endometrial epithelial cells and fibroblast cells treated with LGALS1. Data are presented as LSM \pm SEM. P-values are that of the log-transformed data. Contrast:

\begin{tabular}{|c|c|c|c|c|c|c|c|}
\hline \multirow[b]{2}{*}{ Gene } & \multicolumn{6}{|c|}{ Treatment } & \multirow{2}{*}{$\frac{\text { Contrast }}{\mathrm{C}}$} \\
\hline & $\begin{array}{c}\text { Cell } \\
\text { Type }\end{array}$ & Control & 10 & 100 & SEM & TRT & \\
\hline \multirow[t]{2}{*}{ CHST15 } & Epi & $0.82^{\mathrm{ab}}$ & $0.42^{\mathrm{a}}$ & $1.10^{\mathrm{b}}$ & 0.21 & NS & NS \\
\hline & Fib & $3.86^{\mathrm{a}}$ & $1.41^{\mathrm{b}}$ & $1.16^{\mathrm{b}}$ & 0.93 & $\leq 0.01$ & $\leq 0.001$ \\
\hline \multirow[t]{2}{*}{ CXCR4 } & Epi & $6.12^{\mathrm{a}}$ & $6.15^{\mathrm{a}}$ & $13.77^{b}$ & 0.89 & $\leq 0.01$ & $\leq 0.05$ \\
\hline & Fib & 0.16 & 0.11 & 0.12 & 0.02 & NS & NS \\
\hline \multirow[t]{2}{*}{ EIF4EBP2 } & Epi & $2.43^{a}$ & $0.93^{\mathrm{b}}$ & $1.04^{\mathrm{b}}$ & 0.18 & $\leq 0.001$ & $\leq 0.001$ \\
\hline & Fib & $2.06^{\mathrm{a}}$ & $0.88^{\mathrm{b}}$ & $0.83^{\mathrm{b}}$ & 0.17 & $\leq 0.001$ & $\leq 0.001$ \\
\hline \multirow[t]{2}{*}{$I L-1 B$} & Epi & $0.40^{\mathrm{a}}$ & $21.41^{b}$ & $265.44^{c}$ & 34.95 & $\leq 0.001$ & $\leq 0.001$ \\
\hline & Fib & 0.28 & 0.32 & 0.37 & 0.08 & NS & NS \\
\hline \multirow[t]{2}{*}{$I L-6$} & Epi & $1.74^{\mathrm{a}}$ & $3.18^{\mathrm{b}}$ & $4.89^{b}$ & 1.33 & $\leq 0.01$ & $\leq 0.01$ \\
\hline & Fib & 1.32 & 1.21 & 1.55 & 0.36 & NS & NS \\
\hline \multirow[t]{2}{*}{$L I F$} & Epi & $8.21^{\mathrm{a}}$ & $8.42^{\mathrm{a}}$ & $14.71^{\mathrm{b}}$ & 1.92 & NS & NS \\
\hline & Fib & $0.79^{\mathrm{a}}$ & $0.48^{\mathrm{b}}$ & $0.52^{\mathrm{b}}$ & 0.28 & NS & $\leq 0.05$ \\
\hline \multirow[t]{2}{*}{ MST1R } & Epi & $4.44^{\mathrm{ab}}$ & $2.00^{\mathrm{a}}$ & $6.29^{b}$ & 1.33 & NS & NS \\
\hline & Fib & $3.79^{\mathrm{a}}$ & $2.53^{\mathrm{b}}$ & $2.60^{\mathrm{b}}$ & 0.53 & $\leq 0.05$ & $\leq 0.01$ \\
\hline \multirow[t]{2}{*}{ ATP11a } & Epi & $8.42^{\mathrm{a}}$ & $3.03^{b}$ & $2.66^{\mathrm{b}}$ & 0.68 & $\leq 0.001$ & $\leq 0.01$ \\
\hline & Fib & $3.40^{\mathrm{a}}$ & $1.82^{\mathrm{b}}$ & $1.72^{\mathrm{b}}$ & 0.63 & $\leq 0.001$ & $\leq 0.01$ \\
\hline
\end{tabular}




\title{
CHAPTER FIVE
}

\section{DIFFERENTIAL GENE EXPRESSION IN DAY 16 PREGNANT AND DAY 17 CYCLIC BOVINE ENDOMETRIUM}

\begin{abstract}
This study investigated the gene expression of pregnant and cyclic bovine endometrium near the time of maternal recognition of pregnancy to better understand the immune environment during that time. Crossbred beef heifers (Angus X Hereford) were synchronized using a 7-day fixed-time artificial insemination (FTAI) protocol. Heifers were either inseminated $(n=4)$ or left as an uninseminated Controls $(n=4)$. On embryonic day 16, inseminated cows were sacrificed and embryos and tissue samples were collected. On Day 17 control animals were slaughtered for collection of tissue samples. Endometrial RNA was extracted and cDNA synthesized.

Endometrial gene expression for potential regulatory T cell (Treg) factors (FOXP3, $I L-2 R A$, and $L G A L S 1)$ and other immune related genes considered important for pregnancy (CXCR4, IL-1B, IL-6, and LIF) were measured by RT-qPCR. Although effect of pregnancy did not affect genes expression, a tendency was observed for in expression of $I L-1 B$ and $I L-6(\mathrm{P}=0.09)$ compared to control endometrium. Expression of $I L-1 B$ tended $(P=0.09)$ to increase compared to control endometrium and $I L-6$ and expression tended $(\mathrm{P}=0.09)$ to decrease in endometrium of pregnant heifers.
\end{abstract}

\section{INTRODUCTION}

In order to understand the mechanics behind early embryonic loss in cattle, this study measured endometrial genes considered important for reproduction. Studies have shown that 
endometrial gene expression is regulated mainly by the actions of progesterone (P4) and conceptus secretory proteins (CSP), especially interferon tau (IFNT) (Gray et al., 2006). Most of the bovine CSP are unknown but are believed to also modify endometrial gene expression (Clemente et al., 2009). This study investigated the expression of those genes that were modified in bovine endometrium treated with CSP LGALS1 (Chapters III and IV) in pregnant and cyclic bovine endometrium. The gene CXCR4 is activated during implantation and placentation in sheep and likely plays a role in the communication between trophoblast cells and the maternal endometrium as well as in placental angiogenesis (Ashley et al., 2011, Fry et al., 1992, Mathew et al., 2016, Laird et al., 1997, Laird et al., 2000). Genes FOXP3, LGALS1, and IL-2RA are related to regulatory T-cell (Treg) activity. In rodents, the CSP, LGALS1 has been shown to promote proliferation of Treg and reduce fetal loss by inducing fetomaternal tolerance (Blois et al., 2007). The presence of Treg has not been confirmed in bovine endometrium. Endometrial expression of genes $I L-1 B, I L-6$, and $L I F$ of which are regulated by the transcription factor, nuclear factor kappa B (NFKB), and are believed to be important for the maintenance of pregnancy, implantation, and conceptus viability in sheep, cattle, humans, and rodents (Ashley et al., 2011). These differences in expression could be coding for proteins that are essential for pregnancy recognition and the maintenance of a successful pregnancy at this time. The genes chosen have roles in modulation of the immune system, are important for conceptus attachment, and may be important in the formation of the placenta (Blois et al., 2007, Mathialagan et al., 1992, Laird et al., 2000). We hypothesize that the genes investigated will increase in the endometrium of pregnant heifers when compared to the endometrium of non-pregnant heifers.

\section{MATERIALS AND METHODS}

\section{$\underline{\text { Animals and Tissue Collection }}$}


The reproductive cycles of crossbred beef heifers (Hereford and Angus), located on the West Virginia University Animal Science Farm were synchronized using a 7-day FTAI protocol. Synchronization carried out by administering P4 intravaginally for 7 days (Controlled Internal Drug Release; CIDR; 1.38g P4; Zoetis Animal Health, Parsippany, NJ). On day of CIDR insertion, $2 \mathrm{~mL}$ of gonadotropin releasing hormone (GnRH; Factrel; containing $100 \mathrm{mcg}$ gonadorelin; Zoetis Animal Health) was administered by intramuscular injection (IM). On day of CIDR removal (day 0) $5 \mathrm{~mL}$ prostaglandin-F2-alpha (PGF $2 \alpha$; Lutalyse; 5mg dinoprost/mL; Zoetis Animal Health) was administered by IM. Heifers then received a second injection of GnRH and were inseminated $(n=4)$ or left uninseminated $(n=4)$ approximately 52-56 hours after

CIDR removal. Bred heifers were slaughtered on embryonic day 16 while uninseminated heifers were slaughtered on day 17 at Young and Stout Wholesale Meats and Provisions in Bridgeport, West. Immediately following slaughter, reproductive tracts were sprayed with 70\% EtOH and the broad ligament of the uterus was dissected away. The uterine horns were flushed twice, using a total of 20 mL 1X Dulbecco's Phosphate-Buffered Saline (DPBS; Gibco, Gaithersburg, MD). Day 16 conceptuses were measured, snap frozen in liquid nitrogen and stored at $-80^{\circ} \mathrm{C}$.

Endometrium was then dissected from the intercaruncular regions of the uterine horn ipsilateral to the corpus luteum (CL), snap frozen, and stored at $-80^{\circ} \mathrm{C}$ until RNA extraction.

\section{RNA Extraction}

Total RNA was extracted from pregnant and open intercaruncular endometrium samples that were previously snap frozen. In order to homogenize the tissue, the sample was placed in a Mini-Beadbeater-24 (Biospec Products; Bartlesville, OK) for 2 min containing $1 \mathrm{~mL}$ of Trizol reagent and a $5 \mathrm{~mm}$ bead. Following homogenization, E.Z.N.A. Total RNA Kit I (Omega Biotek, Norcross, GA) was used per the manufacturer's instructions to extract RNA. On-column 
RNA clean-up was performed. The quantity of RNA was then determined using the NanoDrop 1000 (Thermo Fisher Scientific).

\section{$\underline{R T-q P C R}$}

Explant mRNA (500 ng) was reverse transcribed into cDNA using the High-capacity cDNA Reverse Transcription Kit (Applied Biosystems; Foster City, CA) in a $20 \mu \mathrm{L}$ reaction following the manufacturer's recommendation. The RT-qPCR reactions were carried out using PowerUp SYBR Green Master Mix (Applied Biosystems) and the C1000 Touch Thermal Cycler (Bio-Rad; Hercules, CA). The RT-qPCR thermo cycler settings for all reactions consisted of an initial temperature of $50^{\circ} \mathrm{C}$ for $2 \mathrm{~min}, 95^{\circ} \mathrm{C}$ for 2 min followed by 40 PCR cycles consisting of melting at $95^{\circ} \mathrm{C}$ for $15 \mathrm{sec}$ and annealing and extension at $60^{\circ} \mathrm{C}$ for $1 \mathrm{~min}$. Primers were created using Primer3Plus or obtained from previously published research. The PCR primer amplification efficiencies (E) for each PCR target sequence were calculated from the standard curve generated from seven cDNA dilutions. The equation used for the efficiency calculation was $E=\left[10^{(-1 / \text { slope })}-1\right]$. Percent efficiency was calculated by dividing $E$ by 2 and then multiplying by 100 . Only primers with effiencies between $90-110 \%$ were used. A dissociation analysis was included for each primer pair to evaluate primer specificity for the target sequence. Gel electrophoresis was performed using PCR products in a 3\% agarose gel to further confirm the primers by amplicon size. The qbase+ computer program (Biogazelle; Zwijnaarde, Belgium) was used to calculate the normalized relative expression quantities (NRQ; relative expression) of target genes based on a generalized delta-delta quantification cycle method ( $\Delta \Delta \mathrm{Cq}$; also known as $\Delta \Delta \mathrm{CT}$ ) (Hellemans et al., 2007). To identify potential normalization targets, RT-qPCR was carried out for eight potential genes across a subset of samples representing all treatments. Genes H3 Histone Family Member 3A (H3F3A) and Ring Finger Protein 11 (RNF11) were found to be 
the most stably expressed across treatments using the geNorm analysis (geNorm $\mathrm{M}<0.25$ ) (Vandesompele et al., 2002).

\section{Statistical Analysis}

A general linear model procedure (proc GLM) in the statistical analysis software (SAS) was used to test for an effect of pregnancy on relative gene expression data. All data are presented in their original format; however, all p-values are that of the log base $10(\log 10)$ transformation. Data are presented as least square means \pm standard error of LSM (LSM \pm SEM). Significance was declared at $\mathrm{P} \leq 0.05$.

\section{RESULTS}

There was not an effect of pregnancy on the endometrial gene expression of CXCR4, FOXP3, LGALS1, IL-1B, IL-2RA, IL-6, or LIF. However, there was a tendency $(\mathrm{P}=0.09)$ for an effect of pregnancy on expression of $I L-1 B$ and $I L-6$. Expression of $I L-1 B$ tended to increase and IL-6 tended to decrease in pregnant endometrium.

\section{DISCUSSION}

These genes $L G A L S 1, I L 2-R A, L I F, C X C R 4$, and $I L-1 B$ were measured because of their known importance during pregnancy in mammals and because they were differentially expressed in response to galectin-1 (LGALS1), a protein secreted by the developing bovine conceptus in Chapters III and IV. We did not detect significant effect of pregnancy on expression of genes LGALS1, IL2-RA, LIF, CXCR4, and IL-1B however, their level of expression did increase numerically. We observed similar trends in endometrial explants (Chapter III) and in cultured epithelial cells (Chapter IV) treated with LGALS1. The genes FOXP3 and IL-6 expression was decreased in the current study which does not follow the pattern shown in explants treated with LGALS1 (Chapter III). 
Studies have shown in other species, such as sheep, that CXCR4 and LIF are up-regulated in pregnant endometrium compared to non-pregnant (Ashley et al., 2011, Vogiagis et al., 1997). In cattle, an increase in LIF was observed in day 13 pregnant endometrium when compared to cyclic endometrium. Other studies have also found differential expression of LGALS1 in pregnant human and rodent endometrium (Phillips et al., 1996, Bevan et al., 1994). Galectin-1 mRNA has been detected in day 16 bovine endometrium and conceptus (Mamo et al., 2012). Based on our findings in the previous studies (Chapters III and IV), along with those published by (Blois et al., 2007), brought us to hypothesize that Treg markers, $I L-2 R A$ and FOXP3, might increase in the bovine endometrium during early pregnancy. Decreased expression of the genes $I L-6$ and $I L-1 B$ have been associated with habitual abortion in women (Wolff et al., 2000). In ruminants IL-1B is an adhesion molecule in the IL-1 family and has been found to be produced by the embryo, trophoblast and endometrium (Mathialagan et al., 1992). The cytokine IL-1 has been shown to increase LIF and IL-6 production in endometrial epithelial cells (Laird et al., 2000) In mice, pigs, sheep, and cattle, IL-6 has been shown to be produced by the trophoblast (Mathialagan et al., 1992). IL-6 may be playing a role in chorionic placentation because it increases the permeability of endothelial cells and increases the production of complement inhibitors and proteases (Martal et al., 1997, Maruo et al., 1992).

There are many factors that could possibly be contributing to the reasons our results were not significant or reasons that gene expression patterns did not align with our previous studies. The first could be that the concentrations of LGALS1 used in 3-D and explant cultures did not match the physiological concentrations of the protein present in the bovine uterus during early pregnancy. Intrauterine concentration of LGALS1 of any species is unknown. A human study measured serum concentrations of LGALS1 and were found to be $36.9 \pm 7.8 \mathrm{ng} / \mathrm{mL}$ in normal 
healthy serum donors (Ouyang et al., 2013). Another reason could be that when collecting endometrium, we did not by chance, collect tissue adjacent to the conceptus thus, the endometrium had reduced expression levels. The conceptuses were approximatley $10-15 \mathrm{~cm}$ in length when completely stretched out and only a couple millimeters in width. The uterine horn in beef heifers is between $23-27 \mathrm{~cm}$ in length which creates ample space for the conceptus to be located (Drennan and Macpherson, 1966). Improvements could be made in future research with methods of collecting samples adjacent to the location of the conceptus, and by including more animals in the study to increase the power.

\section{CONCLUSION}

In conclusion, we did not detect expression of potential conceptus induced genes CXCR4, FOXP3, LGALS1, IL-1 $, I L-2 R A, I L-6$, and $L I F$ in pregnant compared to cyclic endometrium. There were tendencies $(\mathrm{P}=0.09)$ for an effect of pregnant status on $I L-6$ and $I L-1 \beta$. Further investigation of conceptus- maternal interaction during early pregnancy in cattle will increase our understanding of factors that contribute to reproductive failure or alternatively, pregnancy success. 


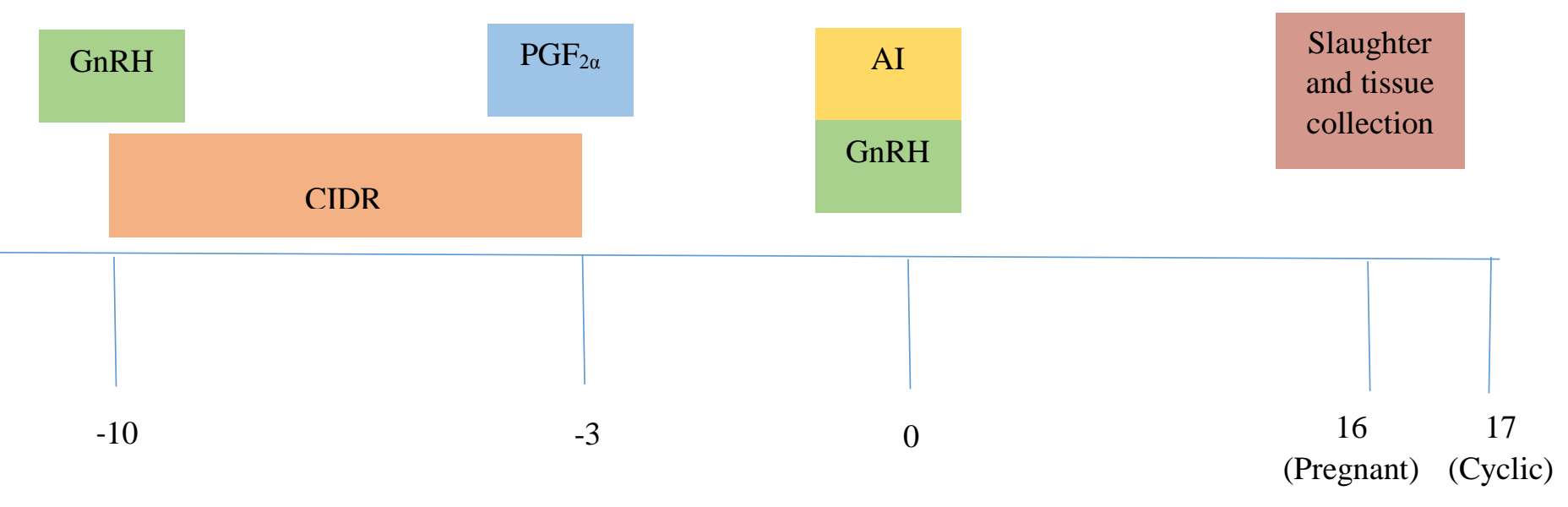

Figure 5.1- Experimental design. 7-day fixed time AI protocol. Pregnant animals were slaughtered on embryonic day 16 while open cows were slaughtered on day 17. 
Table 5.1 Genbank accession number, gene name, primer sequence (forward and reverse), product size, amplification efficiency, and source of primer for gene cDNA amplified during RT-qPCR

\begin{tabular}{|c|c|c|c|c|c|c|}
\hline $\begin{array}{c}\text { GenBank } \\
\text { Acc. Number }\end{array}$ & Gene & Primer & Primer Sequence (3’-5’) & $\begin{array}{l}\text { Product } \\
\text { Size (bp) }\end{array}$ & Amp. E. & Source of Primer \\
\hline NM_174301.3 & CXCR4 & $\begin{array}{l}\text { Forward } \\
\text { Reverse }\end{array}$ & $\begin{array}{l}\text { AAGGCTCAGAAGCGCAAG } \\
\text { GAGTCGATGCTGATCCCAAT }\end{array}$ & 102 & $102.21 \%$ & (Weiner et al., 2012) \\
\hline NM_174358.2 & $I L-2 R A$ & $\begin{array}{l}\text { Forward } \\
\text { Reverse }\end{array}$ & $\begin{array}{l}\text { ACATCGGCAGTGGTCTCAG } \\
\text { GAACCTCCACATCAGCAAGC }\end{array}$ & 59 & $109.13 \%$ & (Zoldan et al., 2014) \\
\hline NM_175782.1 & LGALS1 & $\begin{array}{l}\text { Forward } \\
\text { Reverse }\end{array}$ & $\begin{array}{l}\text { GTGGCCGCAGACGCCAAGAG } \\
\text { ACGTCCCCATGCGCGTTGAAA }\end{array}$ & 98 & $93.67 \%$ & (Okumu et al., 2011) \\
\hline NM_001045933.1 & FOXP3 & $\begin{array}{l}\text { Forward } \\
\text { Reverse }\end{array}$ & $\begin{array}{l}\text { TGGTGCTGGAGAAGGAGAAG } \\
\text { GTCAGATGATGCCGCAGATG }\end{array}$ & 92 & $100.56 \%$ & (Mathew et al., 2018) \\
\hline NM_173923.2 & $I L-6$ & $\begin{array}{l}\text { Forward } \\
\text { Reverse }\end{array}$ & $\begin{array}{l}\text { CGCATGGTCGACAAAATCTCT } \\
\text { GCTGCTTTCACACTCATCATTCTT }\end{array}$ & 69 & $95.37 \%$ & (Mathew et al., 2019) \\
\hline NM_174093.1 & $I L-1 B$ & $\begin{array}{l}\text { Forward } \\
\text { Reverse }\end{array}$ & $\begin{array}{l}\text { ACCTGAACCCATCAACGAAATG } \\
\text { TAGGGCCATCAGCCTCAAATAACA }\end{array}$ & 74 & $92.97 \%$ & (Mathew et al., 2019) \\
\hline NM_173931.1 & $L I F$ & $\begin{array}{l}\text { Forward } \\
\text { Reverse }\end{array}$ & $\begin{array}{l}\text { GGGACAACTCAACAGCAGTG } \\
\text { GCACAGCTTGTCCAGGTTG }\end{array}$ & 91 & $96.00 \%$ & Primer3Plus \\
\hline NM_001014389.2 & HЗFЗА & $\begin{array}{l}\text { Forward } \\
\text { Reverse }\end{array}$ & $\begin{array}{l}\text { CATGGCTCGTACAAAGCAGA } \\
\text { ACCAGGCCTGTAACGATGAG }\end{array}$ & 136 & - & \\
\hline NM_001077953.1 & RNF11 & $\begin{array}{l}\text { Forward } \\
\text { Reverse }\end{array}$ & $\begin{array}{l}\text { TCCGGGAGTGTGTGATCTGTATGAT } \\
\text { GCAGGAGGGGCACGTGAAGG }\end{array}$ & 131 & - & \\
\hline
\end{tabular}




\section{CXCR4}

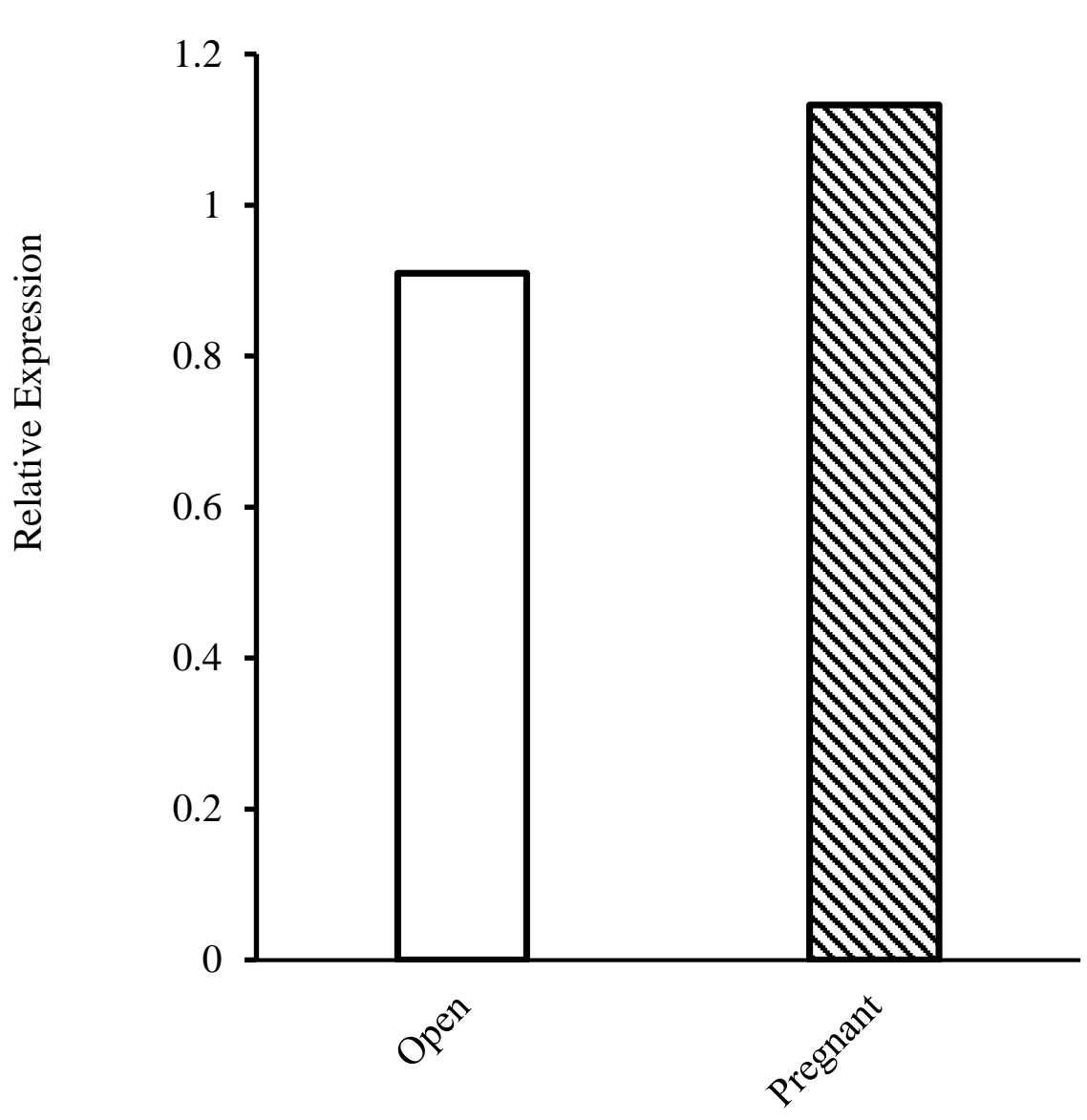

$\mathrm{SEM}=0.09$

Figure 5.2 Least squares means relative expression values for CXCR4 in day 16 pregnant $(\mathrm{n}=4)$ and day 17 cyclic $(\mathrm{n}=4)$ endometrium. There was not a significant effect of pregnancy status on expression of CXCR4. SEM $=0.09$. 


\section{FOXP3}

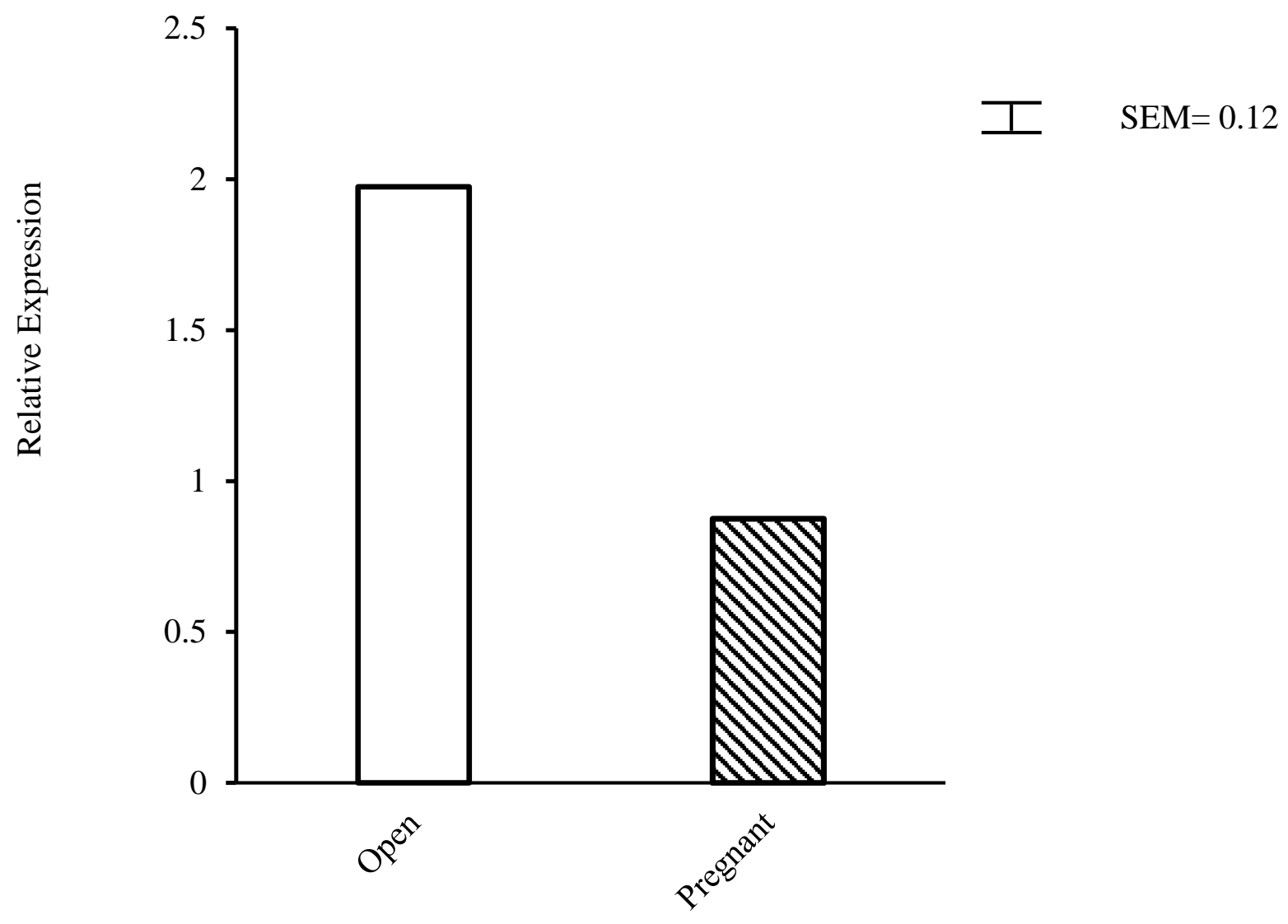

Figure 5.3 Least squares means relative expression values for FOXP3 in day 16 pregnant $(\mathrm{n}=4)$ and day 17 cyclic $(\mathrm{n}=4)$ endometrium. There was not a significant effect of pregnancy status on expression of FOXP3. SEM $=0.12$. 


\section{LGALS1}

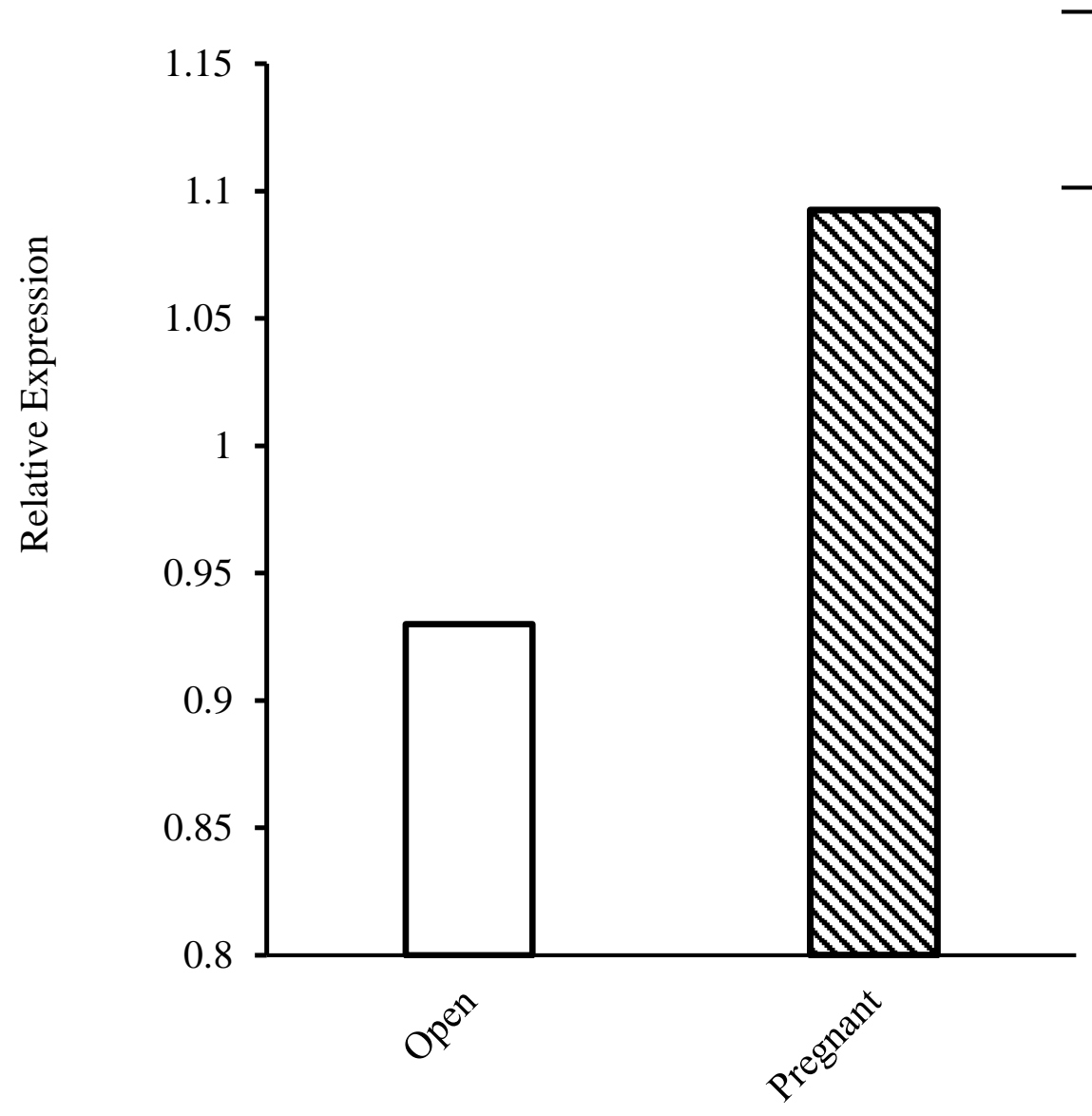

Figure 5.4 Least squares means relative expression values for LGALS1 in day 16 pregnant $(\mathrm{n}=4)$ and day 17 cyclic $(\mathrm{n}=4)$ endometrium. There was not a significant effect of pregnancy status on expression of LGALS1. SEM $=0.08$. 


\section{IL-1B}

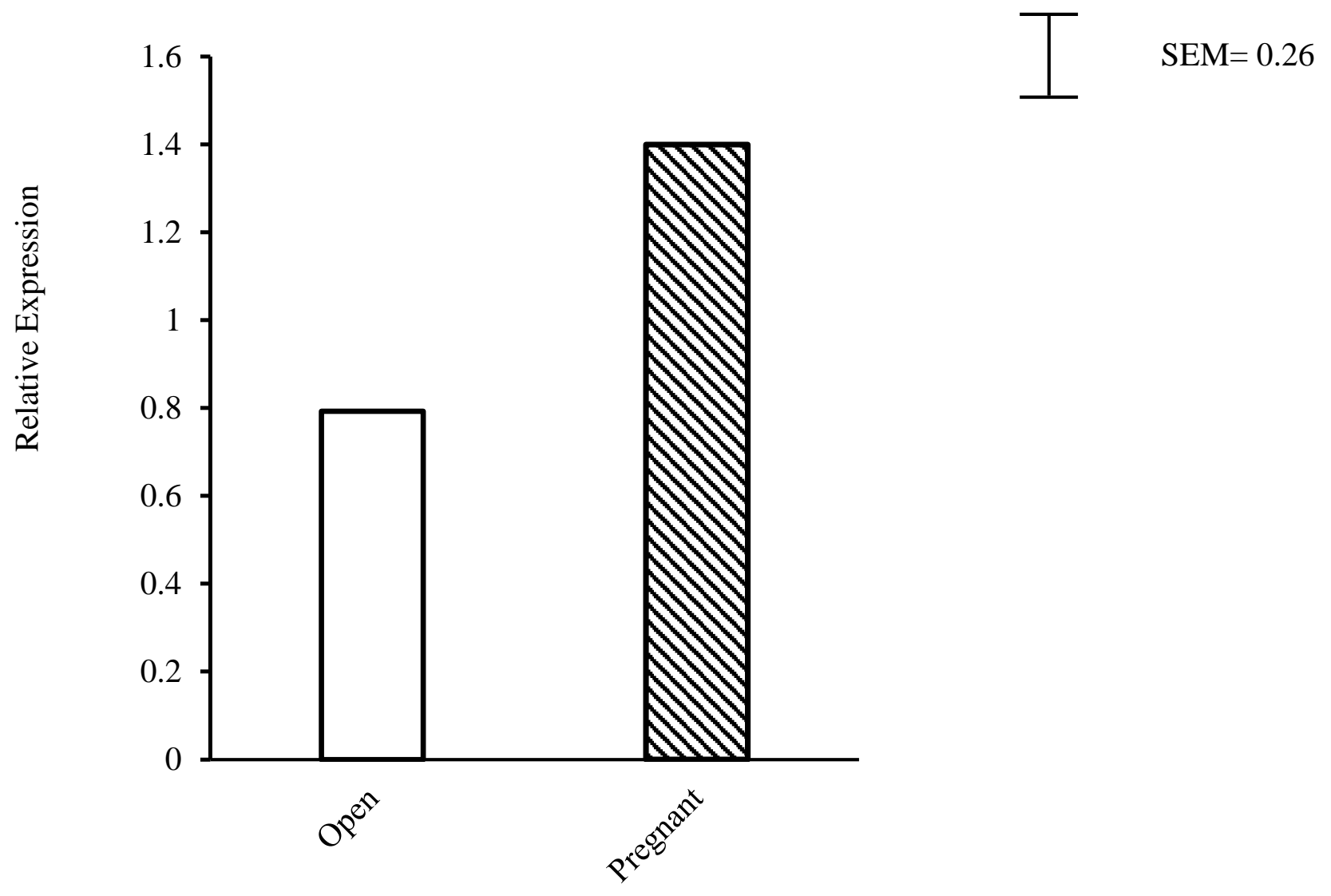

Figure 5.5 Least squares means relative expression values for $I L-1 B$ in day 16 pregnant $(\mathrm{n}=4)$ and day 17 cyclic $(\mathrm{n}=4)$ endometrium. There was a tendency $(\mathrm{P}=0.09)$ for an effect of pregnancy status on expression of $I L-1 B$. SEM $=$ 0.26 . 


\section{IL-2RA}

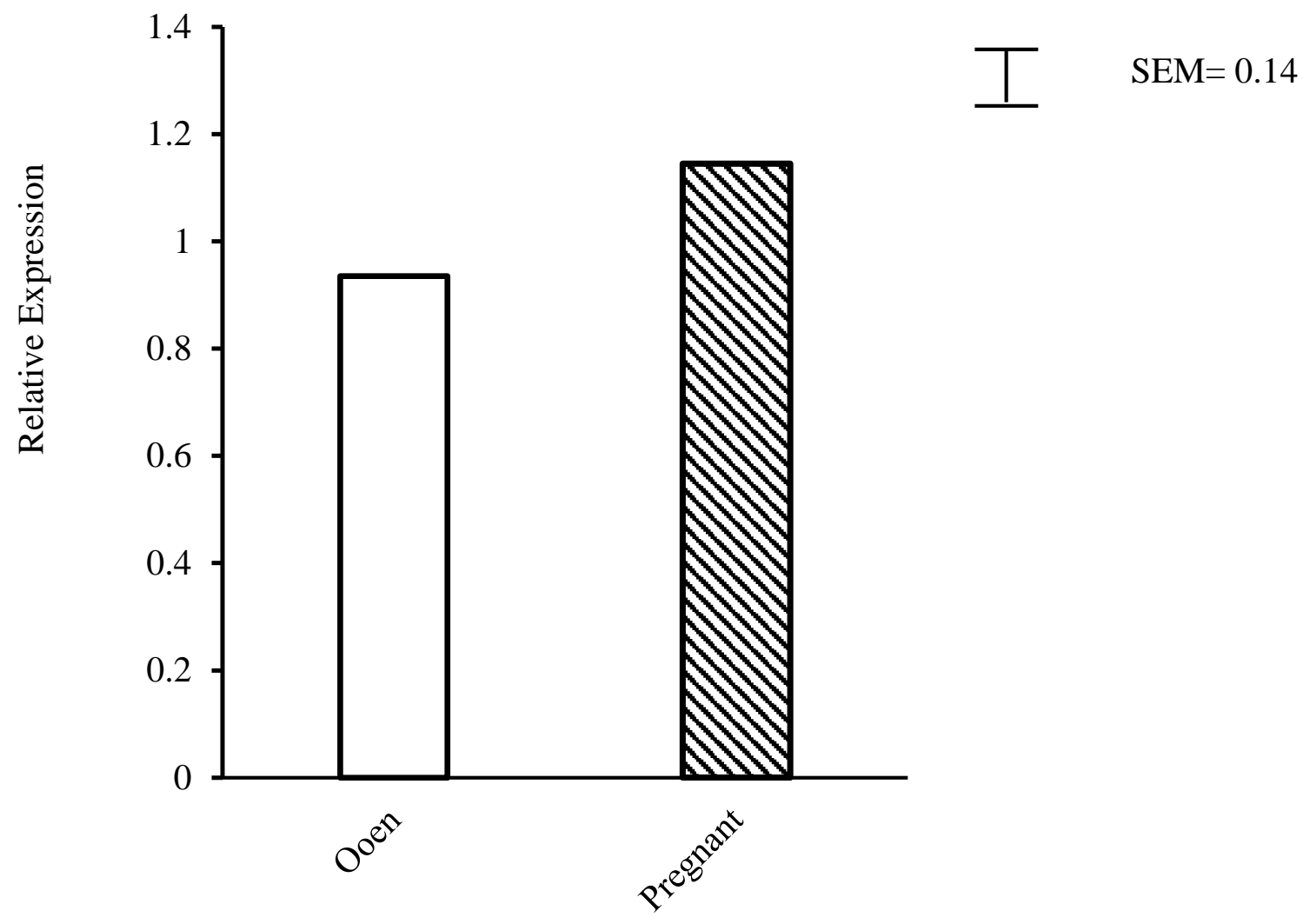

Figure 5.6 Least squares means relative expression values for $I L-2 R A$ in day 16 pregnant $(\mathrm{n}=4)$ and day 17 cyclic $(\mathrm{n}=4)$ endometrium. There was not a significant effect of pregnancy status on expression of IL-2RA. SEM $=0.14$. 


\section{IL-6}

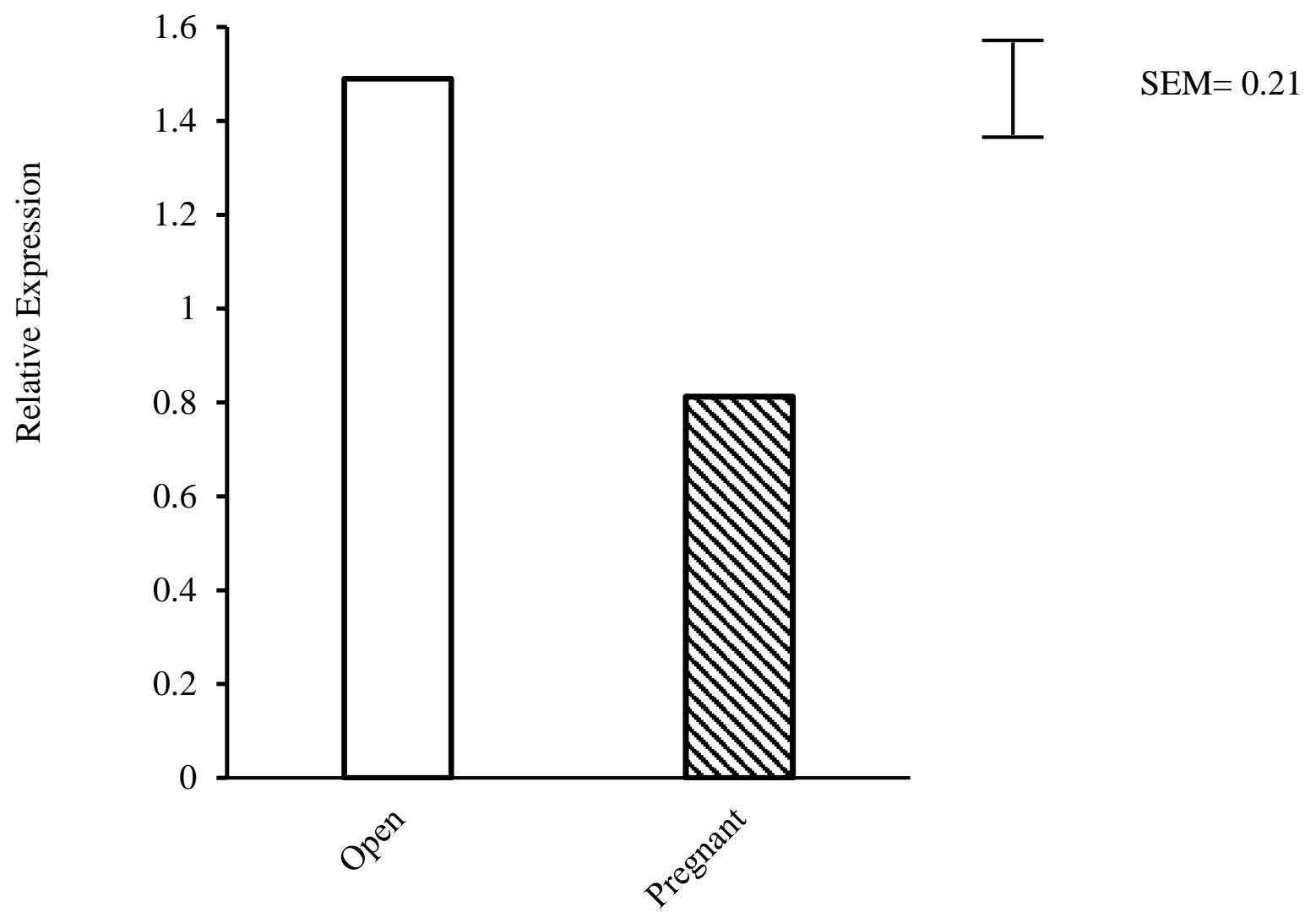

Figure 5.7 Least squares means relative expression values for $I L-6$ in day 16 pregnant $(\mathrm{n}=4)$ and day 17 cyclic $(\mathrm{n}=4)$ endometrium. There was a tendency $(\mathrm{P}=0.09)$ for an effect of pregnancy status on expression of $I L-6$. SEM $=0.21$. 


\section{LIF}

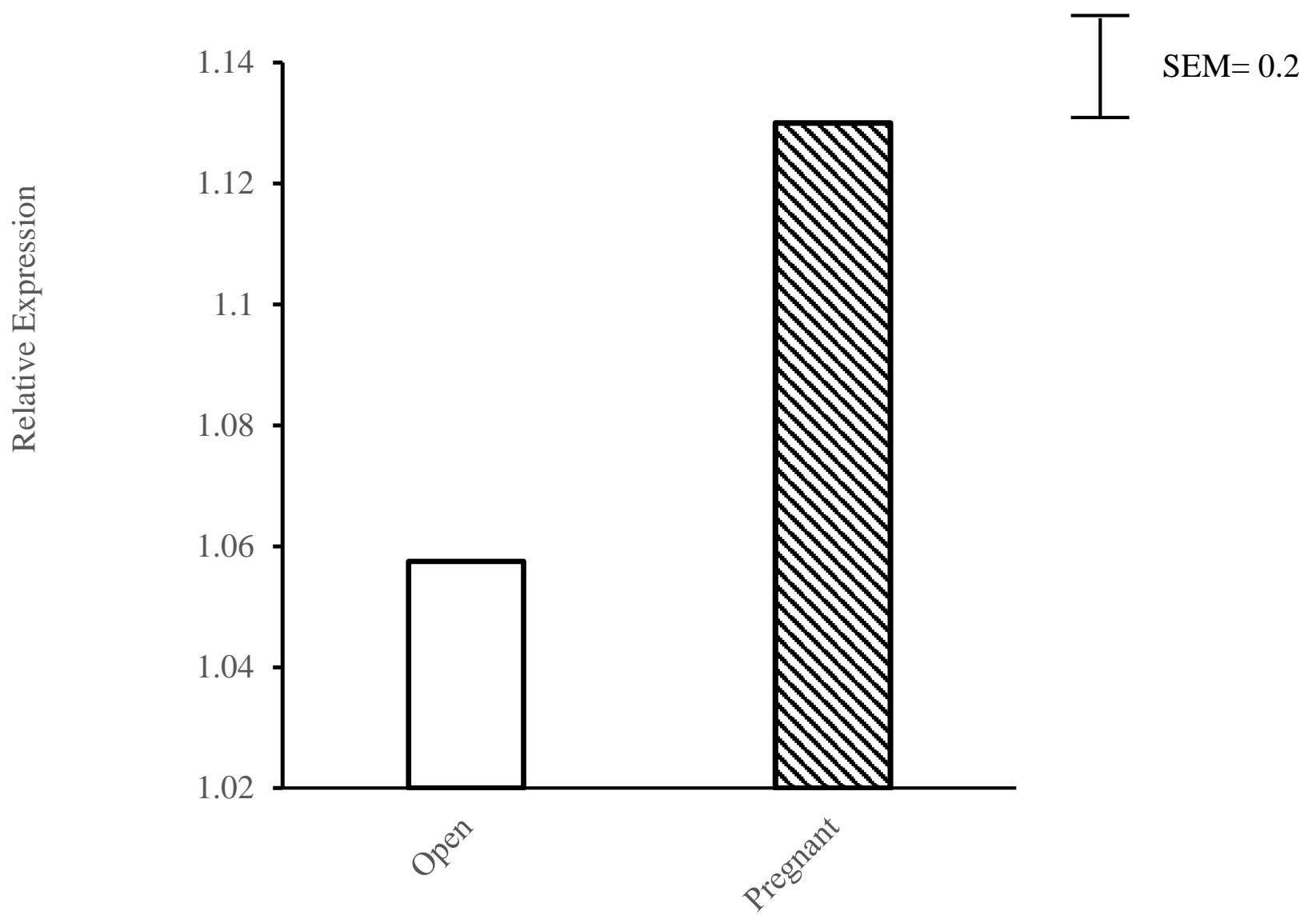

Figure 5.8 Least squares means relative expression values for LIF in day 16 pregnant $(n=4)$ and day 17 cyclic $(n=4)$ endometrium. There was not a significant effect of pregnancy status on expression of LIF. SEM $=0.2$. 


\section{CHAPTER SIX}

\section{CONCLUSIONS}

Based on the results presented and previously published findings, it is possible that LGALS1 secreted by the day 16 bovine conceptus is increasing the expression of transcription factor, FOXP3 which in turn, increases regulatory T cells (Treg) that express $I L-2 R A$. The LGALS1 may also increase tolerogenic dendritic cells (DC) that express CD11c. Previous studies found that LGALS1 reduced fetal loss in sound stressed rodents possibly by increasing the presence of Treg in the uterus, thus suppressing the immune system and promoting fetomaternal tolerance (Blois et al., 2007). Figure 6.1 illustrates the possibility that conceptus produced LGALS1 is increasing expression of $N F K B$ transcription factor which causes increased expression of $I L-1 B$. Increased $I L-1 B$ in turn, causes an increase in $L I F$. Increased $N F K B$ is also possibly causing increased expression of $I L-6$. This hypothesis is supported by research that shows NFKB is involved in cellular signaling from IL-1 in many cell types (Martal et al., 1997). Research has also shown that IL-1 increases LIF production in endometrial epithelial cells of women (Laird et al., 2000). The promoter regions of $L I F$ and $I L-6$ genes contain NFKB binding sites and expression of these cytokines in other cells has been shown to be controlled by NFKB (Van der Burg and Van der Saag, 1996). We hypothesize that LGALS1 secreted by the developing bovine conceptus is also causing an increase in the expression of CXCR4, possibly through the activation of NFKB. Previous studies in human kidney cancer patients showed that LGALS1 up-regulated CXCR4 gene expression though NFKB (Huang et al., 2014). Research in sheep have shown CXCR4 is activated during implantation and placentation (Ashley et al., 
2011). The up-regulation of all of these genes leads to a potential role of LGALS1 in increased adhesion, increased implantation, increased invasiveness, increased immune modulation, and increased conceptus quality. 

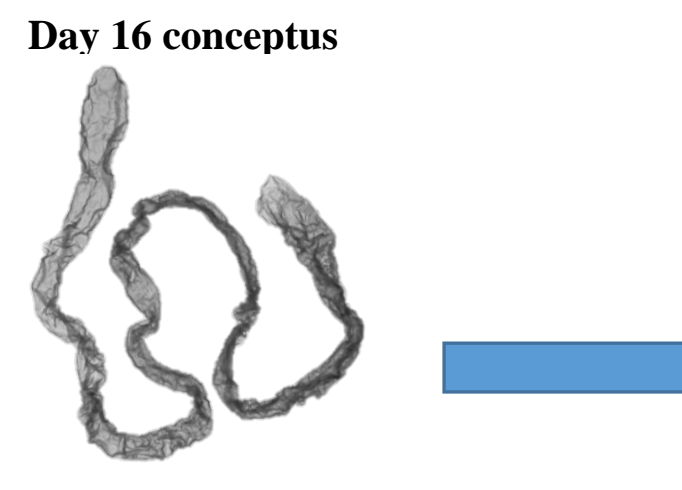

- Pro-inflammatory/ embryokines

- Increased adhesion

- Increased conceptus quality

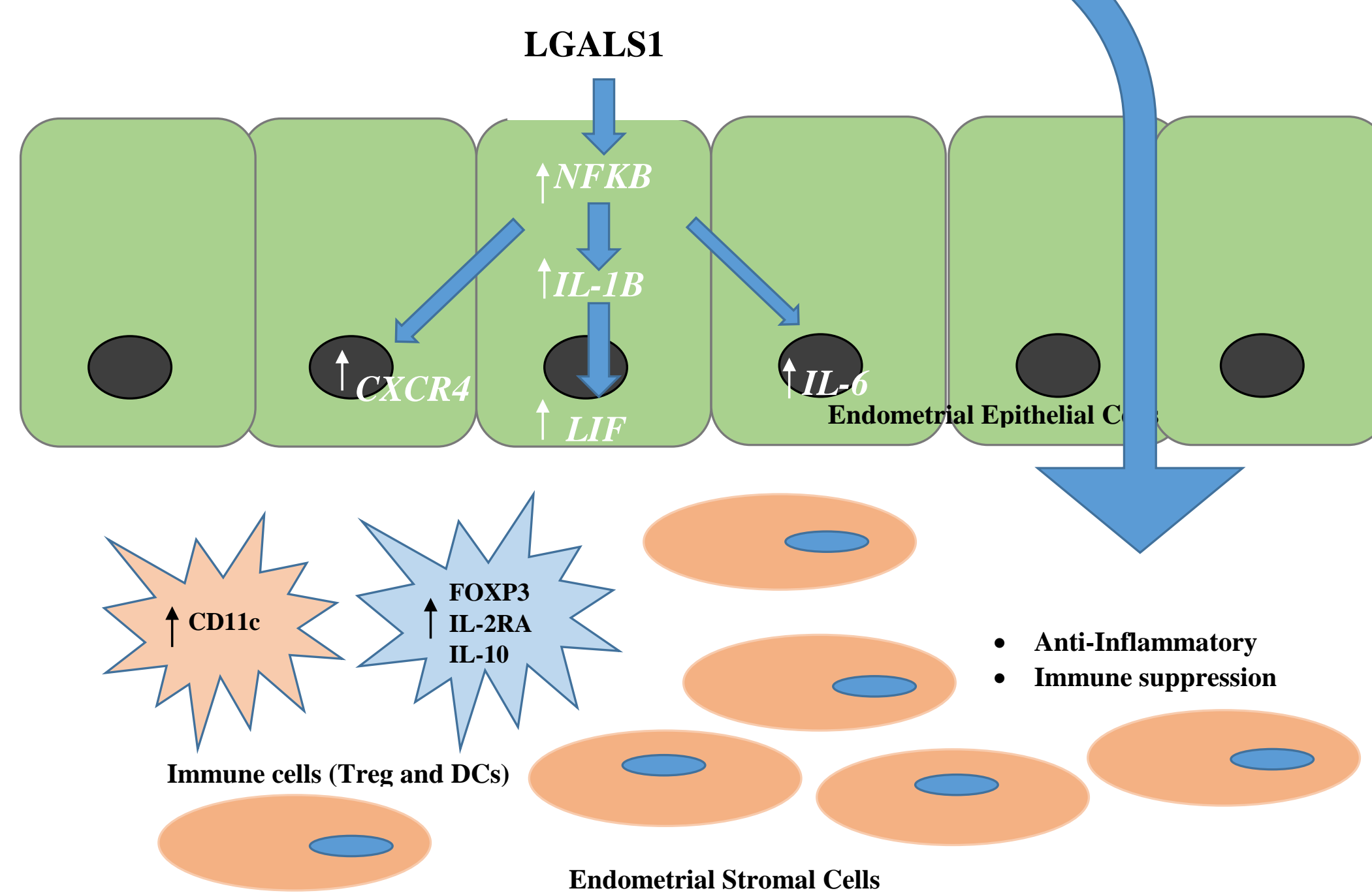

Figure 6.1 Proposed pathway for the effect of conceptus produced LGALS1 on the endometrium during early pregnancy in cattle. In the epithelial cells of the endometrium, production of LGALS1 increases the transcription factor, $N F K B$, which in turn increases expression of $I L-1 B, I L-6$, and $C X C R 4$. The increased expression of $I L-1 B$ causes an increased expression of $L I F$. In the stroma of the endometrium, LGALS1 secretion from the conceptus also increases FOXP3 which in turn causes an increase in Treg cells. Tolergenic dendritic cells that express CD11c. are also increased. 


\section{References}

Adams, L., Kenneth Scott, G. \& Weinberg, C. S. 1996. Biphasic modulation of cell growth by recombinant human galectin-1. Biochimica et Biophysica Acta (BBA) - Molecular Cell Research, 1312, 137-144.

Andersen, H., Jensen, O. N., Moiseeva, E. P. \& Eriksen, E. F. 2009. A Proteome Study of Secreted Prostatic Factors Affecting Osteoblastic Activity: Galectin-1 Is Involved in Differentiation of Human Bone Marrow Stromal Cells. Journal of Bone and Mineral Research, 18, 195-203.

Arck, P., Hansen, P. J., Mulac Jericevic, B., Piccinni, M.-P. \& Szekeres-Bartho, J. 2007. Progesterone During Pregnancy: Endocrine-Immune Cross Talk in Mammalian Species and the Role of Stress. American Journal of Reproductive Immunology, 58, 268-279.

Ashley, R. L., Antoniazzi, A. Q., Anthony, R. V. \& Hansen, T. R. 2011. The chemokine receptor CXCR4 and its ligand CXCL12 are activated during implantation and placentation in sheep. Reproductive biology and endocrinology : RB\&E, 9, 148-148.

Barrientos, G., Freitag, N., Tirado-Gonzalez, I., Unverdorben, L., Jeschke, U., Thijssen, V. L. \& Blois, S. M. 2014. Involvement of galectin-1 in reproduction: past, present and future. Hum Reprod Update, 20, 175-93.

Bauersachs, S., Ulbrich, S. E., Gross, K., Schmidt, S. E. M., Meyer, H. H. D., Wenigerkind, H., Vermehren, M., Sinowatz, F., Blum, H. \& Wolf, E. 2006. Embryo-induced transcriptome changes in bovine endometrium reveal species-specific and common molecular markers of uterine receptivity. Reproduction, 132, 319-331.

Bazer, F., Song, G.-H. \& W. Thatcher, W. 2012. Roles of Conceptus Secretory Proteins in Establishment and Maintenance of Pregnancy in Ruminants.

Bazer, F. W., Burghardt, R. C., Johnson, G. A., Spencer, T. E. \& Wu, G. 2008. Interferons and progesterone for establishment and maintenance of pregnancy: interactions among novel cell signaling pathways11The content of the paper was presented at the V Jubilee Congress of the Society for Reproductive Biology in Wrocław, Poland (10-13 September, 2008). Reproductive Biology, 8, 179-211.

Bellows, D. S., Ott, S. L. \& Bellows, R. A. 2002. Review: Cost of Reproductive Diseases and Conditions in Cattle. The Professional Animal Scientist, 18, 26-32.

Benight, N. M. \& Waltz, S. E. 2012. Ron receptor tyrosine kinase signaling as a therapeutic target. Expert opinion on therapeutic targets, 16, 921-931.

Benirschke, K. \& Kaufmann, P. 1995. Pathology of the human placenta, 3rd edn. SpringerVerlag, New York.

Betteridge, K. J., Eaglesome, M. D., Randall, G. C. \& Mitchell, D. 1980. Collection, description and transfer of embryos from cattle 10--16 days after oestrus. J Reprod Fertil, 59, 20516.

Bevan, B. H., Kilpatrick, D. C., Liston, W. A., Hirabayashi, J. \& Kasai, K. 1994. Immunohistochemical localization of a $\beta$-d-galactoside-binding lectin at the human maternofetal interface. The Histochemical Journal, 26, 582-586.

Blankenship, T. N., Enders, A. C. \& King, B. F. 1992. Distribution of laminin, type IV collagen, and fibronectin in the cell columns and trophoblastic shell of early macaque placentas. Cell and Tissue Research, 270, 241-248.

Blankenship, T. N. \& King, B. F. 1993. Developmental changes in the cell columns and trophoblastic shell of the macaque placenta: an immunohistochemical study localizing 
type IV collagen, laminin, fibronectin and cytokeratins. Cell and Tissue Research, 274, 457-466.

Blois, S. M., Ilarregui, J. M., Tometten, M., Garcia, M., Orsal, A. S., Cordo-Russo, R., Toscano, M. A., Bianco, G. A., Kobelt, P., Handjiski, B., Tirado, I., Markert, U. R., Klapp, B. F., Poirier, F., Szekeres-Bartho, J., Rabinovich, G. A. \& Arck, P. C. 2007. A pivotal role for galectin-1 in fetomaternal tolerance. Nat Med, 13, $1450-7$.

Blois, S. M., Joachim, R., Kandil, J., Margni, R., Tometten, M., Klapp, B. F. \& Arck, P. C. 2004. Depletion of CD8 $<$ sup $>+</$ sup $>$ Cells Abolishes the Pregnancy Protective Effect of Progesterone Substitution with Dydrogesterone in Mice by Altering the Th1/Th2 Cytokine Profile. The Journal of Immunology, 172, 5893.

Bolger, A. M., Lohse, M. \& Usadel, B. 2014. Trimmomatic: a flexible trimmer for Illumina sequence data. Bioinformatics (Oxford, England), 30, 2114-2120.

Borges, A. M., Healey Gd Fau - Sheldon, I. M. \& Sheldon, I. M. 2012. Explants of intact endometrium to model bovine innate immunity and inflammation ex vivo.

Bättig, P., Saudan, P., Gunde, T. \& Bachmann, M. F. 2004. Enhanced apoptotic activity of a structurally optimized form of galectin-1. Molecular Immunology, 41, 9-18.

Camby, I., Le Mercier, M., Lefranc, F. \& Kiss, R. 2006. Galectin-1: a small protein with major functions. Glycobiology, 16, 137R-157R.

Choe, Y. S., Shim, C., Choi, D., Lee, C. S., Lee, K.-K. \& Kim, K. 1997. Expression of galectin-1 mRNA in the mouse uterus is under the control of ovarian steroids during blastocyst implantation. Molecular Reproduction and Development, 48, 261-266.

Choe, Y. S., Shim, C., Choi, D., Lee, C. S., Lee, K.-K. \& Kim, K. 1998. Expression of galectin-1 mRNA in the mouse uterus is under the control of ovarian steroids during blastocyst implantation. Molecular Reproduction and Development, 48, 261-266.

Clemente, M., de La Fuente, J., Fair, T., Al Naib, A., Gutierrez-Adan, A., Roche, J. F., Rizos, D. \& Lonergan, P. 2009. Progesterone and conceptus elongation in cattle: a direct effect on the embryo or an indirect effect via the endometrium? REPRODUCTION, 138, 507-517.

Corthay, A. 2009. How do regulatory T cells work? Scand J Immunol, 70, 326-36.

Cronin, J. G., Healey, G., Mackintosh, S., Turner, M., Healy, L. \& Sheldon, I. 2014. Bovine Endometrial Epithelial and Stromal Cells Standard Operating Procedures for Isolation and Culture of Primary Bovine Endometrial Epithelial and Stromal Cells.

Cummings, R. D. \& Liu, F.-T. 2009. Essentials of Glycobiology, 2 edn. Cold Spring Harbor Laboratory Press, Cold Spring Harbor, NY.

Degrelle, S. A., Campion, E., Cabau, C., Piumi, F., Reinaud, P., Richard, C., Renard, J.-P. \& Hue, I. 2005. Molecular evidence for a critical period in mural trophoblast development in bovine blastocysts. Developmental Biology, 288, 448-460.

Diep, C. H., Ahrendt, H. \& Lange, C. A. 2016. Progesterone induces progesterone receptor gene (PGR) expression via rapid activation of protein kinase pathways required for cooperative estrogen receptor alpha (ER) and progesterone receptor (PR) genomic action at ER/PR target genes. Steroids, 114, 48-58.

Diskin, M. G. \& Morris, D. G. 2008. Embryonic and early foetal losses in cattle and other ruminants.

Diskin, M. G., Murphy, J. J. \& Sreenan, J. M. 2006. Embryo survival in dairy cows managed under pastoral conditions. Animal Reproduction Science, 96, 297-311. 
Domanska, U. M., Kruizinga, R. C., Nagengast, W. B., Timmer-Bosscha, H., Huls, G., de Vries, E. G. E. \& Walenkamp, A. M. E. 2013. A review on CXCR4/CXCL12 axis in oncology: No place to hide. European Journal of Cancer, 49, 219-230.

Drennan, W. G. \& Macpherson, J. W. 1966. The reproductive tract of bovine slaughter heifers (a biometrical study). Canadian journal of comparative medicine and veterinary science, 30, 224-227.

Farin, C. E., Imakawa, K. \& Roberts, R. M. 1989. In Situ Localization of mRNA for the Interferon, Ovine Trophoblast Protein-1, during Early Embryonic Development of the Sheep. Molecular Endocrinology, 3, 1099-1107.

Fisher, S. J. \& Damsky, C. H. 1993. Human cytotrophoblast invasion. Seminars in Cell Biology, 4, 183-188.

Fonseca, I., Silva, P. V., Lange, C. C., Guimarães, M. F. M., Weller, M. M. D. C. A., Sousa, K. R. S., Lopes, P. S., Guimarães, J. D. \& Guimarães, S. E. F. 2009. Expression profile of genes associated with mastitis in dairy cattle. Genetics and molecular biology, 32, 776781.

Forde, N., Bazer, F. W., Spencer, T. E. \& Lonergan, P. 2015. 'Conceptualizing' the Endometrium: Identification of Conceptus-Derived Proteins During Early Pregnancy in Cattle. Biol Reprod, 92, 156.

Forde, N., Carter F Fau - Fair, T., Fair T Fau - Crowe, M. A., Crowe Ma Fau - Evans, A. C. O., Evans Ac Fau - Spencer, T. E., Spencer Te Fau - Bazer, F. W., Bazer Fw Fau - McBride, R., McBride R Fau - Boland, M. P., Boland Mp Fau - O'Gaora, P., O'Gaora P Fau Lonergan, P., Lonergan P Fau - Roche, J. F. \& Roche, J. F. 2009. Progesterone-regulated changes in endometrial gene expression contribute to advanced conceptus development in cattle.

Forde, N., Carter, F., Spencer, T. E., Bazer, F. W., Sandra, O., Mansouri-Attia, N., Okumu, L. A., McGettigan, P. A., Mehta, J. P., McBride, R., O'Gaora, P., Roche, J. F. \& Lonergan, P. 2011. Conceptus-Induced Changes in the Endometrial Transcriptome: How Soon Does the Cow Know She Is Pregnant?1. Biology of Reproduction, 85, 144-156.

Froehlich, R., Hambruch, N., Haeger, J. D., Dilly, M., Kaltner, H., Gabius, H. J. \& Pfarrer, C. 2012. Galectin fingerprinting detects differences in expression profiles between bovine endometrium and placentomes as well as early and late gestational stages. Placenta, 33, 195-201.

Fry, R. C., Batt, P. A., Fairclough, R. J. \& Parr, R. A. 1992. Human Leukemia Inhibitory Factor Improves the Viability of Cultured Ovine Embryos1. Biology of Reproduction, 46, 470474.

Garin, M. I., Chu Cc Fau - Golshayan, D., Golshayan D Fau - Cernuda-Morollon, E., CernudaMorollon E Fau - Wait, R., Wait R Fau - Lechler, R. I. \& Lechler, R. I. 2007. Galectin-1: a key effector of regulation mediated by CD4+CD25+ T cells.

Geary, T. W., Burns, G. W., Moraes, J. G., Moss, J. I., Denicol, A. C., Dobbs, K. B., Ortega, M. S., Hansen, P. J., Wehrman, M. E., Neibergs, H., O'Neil, E., Behura, S. \& Spencer, T. E. 2016. Identification of Beef Heifers with Superior Uterine Capacity for Pregnancy. Biol Reprod, 95, 47.

Gray, C. A., Abbey, C. A., Beremand, P. D., Choi, Y., Farmer, J. L., Adelson, D. L., Thomas, T. L., Bazer, F. W. \& Spencer, T. E. 2006. Identification of Endometrial Genes Regulated by Early Pregnancy, Progesterone, and Interferon Tau in the Ovine Uterus1. Biology of Reproduction, 74, 383-394. 
Gray, C. A., Taylor, K. M., Ramsey, W. S., Hill, J. R., Bazer, F. W., Bartol, F. F. \& Spencer, T. E. 2001. Endometrial Glands Are Required for Preimplantation Conceptus Elongation and Survival1. Biology of Reproduction, 64, 1608-1613.

Grealy, M., Diskin Mg Fau - Sreenan, J. M. \& Sreenan, J. M. 1996. Protein content of cattle oocytes and embryos from the two-cell to the elongated blastocyst stage at day 16.

Guillomot, M., Fléchon, J. E. \& Wintenberger-Torres, S. 1981. Conceptus attachment in the Ewe: an ultrastructural study. Placenta, 2, 169-181.

Guillomot, M., Michel, C., Gaye, P., Charlier, N., Trojan, J. \& Martal, J. 1990. Cellular localization of an embryonic interferon, ovine trophoblastin and its mRNA in sheep embryos during early pregnancy. Biology of the Cell, 68, 205-211.

Hansen, P. J. \& Block, J. 2004. Towards an embryocentric world: the current and potential uses of embryo technologies in dairy production.

Hellemans, J., Mortier, G., De Paepe, A., Speleman, F. \& Vandesompele, J. 2007. qBase relative quantification framework and software for management and automated analysis of realtime quantitative PCR data. Genome biology, 8, R19-R19.

Homburg, R. 2014. Ovulation Induction and Controlled Ovarian Stimulation.

Huang, C.-S., Tang, S.-J., Chung, L.-Y., Yu, C.-P., Ho, J.-Y., Cha, T.-L., Hsieh, C.-C., Wang, H.-H., Sun, G.-H. \& Sun, K.-H. 2014. Galectin-1 upregulates CXCR4 to promote tumor progression and poor outcome in kidney cancer. Journal of the American Society of Nephrology : JASN, 25, 1486-1495.

Huang da, W., Sherman Bt Fau - Lempicki, R. A. \& Lempicki, R. A. 2009. Systematic and integrative analysis of large gene lists using DAVID bioinformatics resources.

Ireland, J. J., Murphee, R. L. \& Coulson, P. B. 1980. Accuracy of predicting stages of bovine estrous cycle by gross appearance of the corpus luteum.

Ito, Z., Takakura, K., Suka, M., Kanai, T., Saito, R., Fujioka, S., Kajihara, M., Yanagisawa, H., Misawa, T., Akiba, T., Koido, S. \& Ohkusa, T. 2017. Prognostic impact of carbohydrate sulfotransferase 15 in patients with pancreatic ductal adenocarcinoma. Oncology letters, 13, 4799-4805.

Jeschke, U., Walzel, H., Mylonas, I., Papadopoulos, P., Shabani, N., Kuhn, C., Schulze, S., Friese, K., Karsten, U., Anz, D. \& Kupka, M. S. 2009. The Human Endometrium Expresses the Glycoprotein Mucin-1 and Shows Positive Correlation for ThomsenFriedenreich Epitope Expression and Galectin-1 Binding. Journal of Histochemistry \& Cytochemistry, 57, 871-881.

Killeen, A. P., Morris, D. G., Kenny, D. A., Mullen, M. P., Diskin, M. G. \& Waters, S. M. 2014. Global gene expression in endometrium of high and low fertility heifers during the midluteal phase of the estrous cycle. BMC Genomics, 15, 234.

Kim, D., Langmead, B. \& Salzberg, S. A.-O. 2015. HISAT: a fast spliced aligner with low memory requirements.

Kopitz, J., von Reitzenstein C Fau - Burchert, M., Burchert M Fau - Cantz, M., Cantz M Fau Gabius, H. J. \& Gabius, H. J. 1998. Galectin-1 is a major receptor for ganglioside GM1, a product of the growth-controlling activity of a cell surface ganglioside sialidase, on human neuroblastoma cells in culture.

Laird, S. M., Tuckerman, E. M., Cork, B. A. \& Li, T. C. 2000. Expression of nuclear factor $\kappa$ B in human endometrium; role in the control of interleukin 6 and leukaemia inhibitory factor production. Molecular Human Reproduction, 6, 34-40. 
Laird, S. M., Tuckerman, E. M., Dalton, C. F., Dunphy, B. C., Li, T. C. \& Zhang, X. 1997. The production of leukaemia inhibitory factor by human endometrium: presence in uterine flushings and production by cells in culture. Human Reproduction, 12, 569-574.

Langlais, J. \& Roberts, K. D. 1985. A molecular membrane model of sperm capacitation and the acrosome reaction of mammalian spermatozoa. Gamete Research, 12, 183-224.

Larson, R. C., Ignotz, G. G. \& Currie, W. B. 1992. Effect of fibronectin on early embryo development in cows. J Reprod Fertil, 96, 289-97.

Liao, Y., Smyth Gk Fau - Shi, W. \& Shi, W. 2014. featureCounts: an efficient general purpose program for assigning sequence reads to genomic features.

Liu, F.-T., Patterson, R. J. \& Wang, J. L. 2002. Intracellular functions of galectins. Biochimica et Biophysica Acta (BBA) - General Subjects, 1572, 263-273.

Lonergan, P., Fair, T., Forde, N. \& Rizos, D. 2016. Embryo development in dairy cattle. Theriogenology, 86, 270-277.

MacIntyre, D. M., Lim, H. C., Ryan, K., Kimmins, S., Small, J. A. \& MacLaren, L. A. 2002. Implantation-Associated Changes in Bovine Uterine Expression of Integrins and Extracellular Matrix1. Biology of Reproduction, 66, 1430-1436.

MacKintosh, S. B., Serino Lp Fau - Iddon, P. D., Iddon Pd Fau - Brown, R., Brown R Fau Conlan, R. S., Conlan Rs Fau - Wright, C. J., Wright Cj Fau - Maffeis, T. G. G., Maffeis Tg Fau - Raxworthy, M. J., Raxworthy Mj Fau - Sheldon, I. M. \& Sheldon, I. M. 2015. A three-dimensional model of primary bovine endometrium using an electrospun scaffold.

Maeda, N., Kawada, N., Seki, S., Ikeda, K., Okuyama, H., Hirabayashi, J., Kasai, K.-I. \& Yoshizato, K. 2004. Involvement of Galectin-1 and Galectin-3 in Proliferation and Migration of Rat Hepatic Stellate Cells in Culture. Comparative hepatology, 3 Suppl 1, S10-S10.

Maeda, Y., Ohtsuka, H., Tomioka, M. \& Oikawa, M. 2013. Effect of progesterone on Th1/Th2/Th17 and Regulatory T cell-related genes in peripheral blood mononuclear cells during pregnancy in cows. Veterinary Research Communications, 37, 43-49.

Mamo, S., Mehta, J. P., Forde, N., McGettigan, P. \& Lonergan, P. 2012. Conceptusendometrium crosstalk during maternal recognition of pregnancy in cattle. Biol Reprod, 87, 6, 1-9.

Mansouri-Attia, N., Aubert, J., Reinaud, P., Giraud-Delville, C., Taghouti, G., Galio, L., Everts, R. E., Degrelle, S., Richard, C., Hue, I., Yang, X., Tian, X. C., Lewin, H. A., Renard, J. P. \& Sandra, O. 2009. Gene expression profiles of bovine caruncular and intercaruncular endometrium at implantation. Physiol Genomics, 39, 14-27.

Mapletoft, R. 2013. History and perspectives on bovine embryo transfer.

Maquoi, E., van den Brûle, F. A., Castronovo, V. \& Foidart, J. M. 1997. Changes in the distribution pattern of galectin-1 and galectin-3 in human placenta correlates with the differentiation pathways of trophoblasts. Placenta, 18, 433-439.

Martal, J., ChÊne, N., Camous, S., Huynh, L., Lantier, F., Hermier, P., L'Haridon, R., Charpigny, G., Charlier, M. \& Chaouat, G. 1997. Recent developments and potentialities for reducing embryo mortality in ruminants: The role of IFN-tau and other cytokines in early pregnancy.

Maruo, N., Morita, I., Shirao, M. \& Murota, S. 1992. IL-6 increases endothelial permeability in vitro. Endocrinology, 131, 710-714. 
Mathew, D. J., Browne, J. A., Grose, L. F., Baldwin, H. L. \& Lonergan, P. 2018. Galectin-1 Increases Forkhead BoxP3 Protein in Bovine Caruncular Endometrium. Abstract. Society for the Study of Reproduction Annual Meeting 2018.

Mathew, D. J., Lucy, M. C. \& Geisert, R. D. 2016. Interleukins, interferons, and establishment of pregnancy in pigs. Reproduction, 151, R111-R122.

Mathew, D. J., Sánchez, J. M., Passaro, C., Charpigny, G., Behura, S. K., Spencer, T. E. \& Longergan, P. 2019. Interferon tau-dependent and independent effects of the bovine conceptus on theendometrial transcriptome. Biology of Reproduction.

Mathialagan, N., Bixby, J. A. \& Roberts, R. M. 1992. Expression of interleukin-6 in porcine, ovine, and bovine preimplantation conceptuses. Molecular Reproduction and Development, 32, 324-330.

McMillan, W. H. 1998. Statistical models predicting embryo survival to term in cattle after embryo transfer. Theriogenology, 50, 1053-1070.

Meade, K. G., Gormley, E., O'Farrelly, C., Park, S. D., Costello, E., Keane, J., Zhao, Y. \& MacHugh, D. E. 2008. Antigen stimulation of peripheral blood mononuclear cells from Mycobacterium bovis infected cattle yields evidence for a novel gene expression program. BMC genomics, 9, 447-447.

Mohan, M., Hurst, A. G. \& Malayer, J. R. 2004. Global gene expression analysis comparing bovine blastocysts flushed on day 7 or produced in vitro. Mol Reprod Dev, 68, 288-98.

Moiseeva, E. P., Javed Q Fau - Spring, E. L., Spring El Fau - de Bono, D. P. \& de Bono, D. P. 2000. Galectin 1 is involved in vascular smooth muscle cell proliferation.

Moore, K. \& Thatcher, W. W. 2006. Major Advances Associated with Reproduction in Dairy Cattle. Journal of Dairy Science, 89, 1254-1266.

Moraes, J. G. N., Behura, S. K., Geary, T. W., Hansen, P. A.-O., Neibergs, H. L. \& Spencer, T. E. 2018. Uterine influences on conceptus development in fertility-classified animals.

Munson, L., Wilhite, A., Boltz, V. \& Wilkinson, J. E. 1996. Transforming Growth Factor $\beta$ in Bovine Placentas1. Biology of Reproduction, 55, 748-755.

Musunuru, K. 2003. Cell-Specific RNA-Binding Proteins in Human Disease. Trends in Cardiovascular Medicine, 13, 188-195.

O'Hara, L., Forde, N., Carter, F., Rizos, D., Maillo, V., Ealy, A., Kelly, A., Rodríguez Fernandez, P., Isaka, N., Evans, A. \& Lonergan, P. 2013. Paradoxical effect of supplementary progesterone between Day 3 and Day 7 on corpus luteum function and conceptus development in cattle.

Okumu, L. A., Fair, T., Szekeres-Bartho, J., O'Doherty, A. M., Crowe, M. A., Roche, J. F., Lonergan, P. \& Forde, N. 2011. Endometrial expression of progesterone-induced blocking factor and galectins-1, $-3,-9$, and -3 binding protein in the luteal phase and early pregnancy in cattle. Physiological Genomics, 43, 903-910.

Oliveira, M. L., D'Alexandri, F. L., Pugliesi, G., Van Hoeck, V., Mesquita, F. S., Membrive, C. M. B., Negrão, J. A., Wheelock, C. E. \& Binelli, M. 2017. Peri-ovulatory endocrine regulation of the prostanoid pathways in the bovine uterus at early dioestrus. Reproduction, Fertility and Development, 29, 544-556.

Ouyang, J., Plutschow A Fau - Pogge von Strandmann, E., Pogge von Strandmann E Fau Reiners, K. S., Reiners Ks Fau - Ponader, S., Ponader S Fau - Rabinovich, G. A., Rabinovich Ga Fau - Neuberg, D., Neuberg D Fau - Engert, A., Engert A Fau - Shipp, M. A. \& Shipp, M. A. 2013. Galectin-1 serum levels reflect tumor burden and adverse clinical features in classical Hodgkin lymphoma. 
Patel, O. V., Sulon, J., Beckers, J.-F., Takahashi, T., Hirako, M., Sasaki, N. \& Domeki, I. 1997. Plasma bovine pregnancy-associated glycoprotein concentrations throughout gestation in relationship to fetal number in cow.

Perry, G. 2015. 2014 statistics of embryo collection and transfer in domestic farm animals.

Phillips, B., Knisley, K., Weitlauf, K. D., Dorsett, J., Lee, V. \& Weitlauf, H. 1996. Differential Expression of Two $\beta$-Galactoside-Binding Lectins in the Reproductive Tracts of Pregnant Mice1. Biology of Reproduction, 55, 548-558.

Piotrowska, K. \& Zernicka-Goetz, M. 2001. Role for sperm in spatial patterning of the early mouse embryo.

Pohler, K. G., Peres, R. F. G., Green, J. A., Graff, H., Martins, T., Vasconcelos, J. L. M. \& Smith, M. F. 2016. Use of bovine pregnancy-associated glycoproteins to predict late embryonic mortality in postpartum Nelore beef cows. Theriogenology, 85, 1652-1659.

Poirier, F., Timmons, P. M., Chan, C. T., Guenet, J. L. \& Rigby, P. W. 1992. Expression of the L14 lectin during mouse embryogenesis suggests multiple roles during pre- and postimplantation development. Development, 115, 143.

Ramathal, C. Y., Bagchi Ic Fau - Taylor, R. N., Taylor Rn Fau - Bagchi, M. K. \& Bagchi, M. K. 2010. Endometrial decidualization: of mice and men.

Rashid, M. B., Talukder, A. K., Kusama, K., Haneda, S., Takedomi, T., Yoshino, H., Moriyasu, S., Matsui, M., Shimada, M., Imakawa, K. \& Miyamoto, A. 2018. Evidence that interferon-tau secreted from Day-7 embryo in vivo generates anti-inflammatory immune response in the bovine uterus. Biochemical and Biophysical Research Communications, 500, 879-884.

Roberts, R. M., Xie, S., Nagel, R. J., Low, B., Green, J. \& Beckers, J. F. 1995. Glycoproteins of the aspartyl proteinase gene family secreted by the developing placenta. Adv Exp Med Biol, 362, 231-40.

Sanford, G. L. \& Harris-Hooker, S. 1990. Stimulation of vascular cell proliferation by betagalactoside specific lectins.

Santucci, L., Fiorucci, S., Rubinstein, N., Mencarelli, A., Palazzetti, B., Federici, B., Rabinovich, G. A. \& Morelli, A. 2003. Galectin-1 suppresses experimental colitis in mice. Gastroenterology, 124, 1381-1394.

Schlafer, D. H., Fisher, P. J. \& Davies, C. J. 2000. The bovine placenta before and after birth: placental development and function in health and disease. Animal Reproduction Science, 60-61, 145-160.

Senger, P. L. 2005. Pathways to pregnancy and parturition, 2nd rev. edn. Current Conceptions, Pullman, WA.

Shuya, L. L., Menkhorst, E. M., Yap, J., Li, P., Lane, N. \& Dimitriadis, E. 2011. Leukemia inhibitory factor enhances endometrial stromal cell decidualization in humans and mice. PloS one, 6, e25288-e25288.

Spencer, T. E., Forde, N., Dorniak, P., Hansen, T. R., Romero, J. J. \& Lonergan, P. 2013. Conceptus-derived prostaglandins regulate gene expression in the endometrium prior to pregnancy recognition in ruminants. REPRODUCTION, 146, 377-387.

Spencer, T. E., Forde, N. \& Lonergan, P. 2017. Insights into conceptus elongation and establishment of pregnancy in ruminants. Reproduction, Fertility and Development, 29, 84-100.

Spencer, T. E. \& Hansen, T. R. 2015a. Implantation and Establishment of Pregnancy in Ruminants. In: Geisert, R. D. \& Bazer, F. W. (eds.) Regulation of Implantation and 
Establishment of Pregnancy in Mammals: Tribute to 45 Year Anniversary of Roger V. Short's "Maternal Recognition of Pregnancy". Springer International Publishing, Cham. Spencer, T. E. \& Hansen, T. R. 2015b. Regulation of implantation and establishment of pregnancy in mammals : tribute to 45 year anniversary of Roger $V$. Short's maternal recognition of pregnancy. Springer Berlin Heidelberg, New York, NY.

Sreenan, J. M., Diskin, M. G. \& Commission of the European Communities. Coordination of Agricultural Research. 1986. Embryonic mortality in farm animals : a seminar in the CEC programme of coordination of research on livestock productivity and management. M. Nijhoff for the Commission of the European Communities ;Distributors for the U.S. and Canada, Kluwer Academic, Dordrecht ; Boston Hingham, MA, USA.

Stewart, C. L., Kaspar, P., Brunet, L. J., Bhatt, H., Gadi, I., Köntgen, F. \& Abbondanzo, S. J. 1992. Blastocyst implantation depends on maternal expression of leukaemia inhibitory factor. Nature, 359, 76-79.

Takatsu, H., Tanaka, G., Segawa, K., Suzuki, J., Nagata, S., Nakayama, K. \& Shin, H.-W. 2014. Phospholipid flippase activities and substrate specificities of human type IV P-type ATPases localized to the plasma membrane. The Journal of biological chemistry, 289, 33543-33556.

Than, N. G., Erez, O., Wildman, D. E., Tarca, A. L., Edwin, S. S., Abbas, A., Hotra, J., Kusanovic, J. P., Gotsch, F., Hassan, S. S., Espinoza, J., Papp, Z. \& Romero, R. 2008. Severe preeclampsia is characterized by increased placental expression of galectin-1. $J$ Matern Fetal Neonatal Med, 21, 429-42.

Than, N. G., Romero, R., Kim, C. J., McGowen, M. R., Papp, Z. \& Wildman, D. E. 2012. Galectins: guardians of eutherian pregnancy at the maternal-fetal interface. Trends Endocrinol Metab, 23, 23-31.

Thatcher, W. W., Bartol, F. F., Knickerbocker, J. J., Curl, J. S., Wolfenson, D., Bazer, F. W. \& Michael Roberts, R. 1984. Maternal Recognition of Pregnancy in Cattle. Journal of Dairy Science, 67, 2797-2811.

Thomas, E. S., Greg, A. J., Fuller, W. B. \& Robert, C. B. 2004. Implantation mechanisms: insights from the sheep. Reproduction, 128, 657-668.

Ulbrich, S. E., Groebner, A. E. \& Bauersachs, S. 2013. Transcriptional profiling to address molecular determinants of endometrial receptivity - Lessons from studies in livestock species. Methods, 59, 108-115.

Van der Burg, B. \& Van der Saag, P. T. 1996. Endocrinology and paracrinology: Nuclear factorkappa-B/steroid hormone receptor interactions as a functional basis of anti-inflammatory action of steroids in reproductive organs. Molecular Human Reproduction, 2, 433-438.

Vandesompele, J., De Preter K Fau - Pattyn, F., Pattyn F Fau - Poppe, B., Poppe B Fau - Van Roy, N., Van Roy N Fau - De Paepe, A., De Paepe A Fau - Speleman, F. \& Speleman, F. 2002. Accurate normalization of real-time quantitative RT-PCR data by geometric averaging of multiple internal control genes.

Vas, V., Fajka-Boja, R., Ion, G., Dudics, V., Monostori, É. \& Uher, F. 2009. Biphasic Effect of Recombinant Galectin-1 on the Growth and Death of Early Hematopoietic Cells. STEM CELLS, 23, 279-287.

Vićovac, L., Janković, M. \& Cuperlović, M. 1998. Galectin-1 and -3 in cells of the first trimester placental bed. Human reproduction (Oxford, England), 13, 730-735. 
Vogiagis, D., Fry, R. C., Sandeman, R. M. \& Salamonsen, L. A. 1997. Leukaemia inhibitory factor in endometrium during the oestrous cycle, early pregnancy and in ovariectomized steroid-treated ewes. Reproduction, 109, 279-288.

von Wolff, M., Wang X Fau - Gabius, H. J., Gabius Hj Fau - Strowitzki, T. \& Strowitzki, T. Galectin fingerprinting in human endometrium and decidua during the menstrual cycle and in early gestation.

von Wolff, M., Wang X Fau - Gabius, H. J., Gabius Hj Fau - Strowitzki, T. \& Strowitzki, T. 2005. Galectin fingerprinting in human endometrium and decidua during the menstrual cycle and in early gestation.

Weiner, C. M., Smirnova, N. P., Webb, B. T., Van Campen, H. \& Hansen, T. R. 2012. Interferon stimulated genes, CXCR4 and immune cell responses in peripheral blood mononuclear cells infected with bovine viral diarrhea virus. Research in Veterinary Science, 93, 10811088.

Wiltbank, M. C., Baez, G. M., Garcia-Guerra, A., Toledo, M. Z., Monteiro, P. L., Melo, L. F., Ochoa, J. C., Santos, J. E. \& Sartori, R. 2016. Pivotal periods for pregnancy loss during the first trimester of gestation in lactating dairy cows. Theriogenology, 86, 239-53.

Wolff, M. v., Thaler, C. J., Strowitzki, T., Broome, J., Stolz, W. \& Tabibzadeh, S. 2000. Regulated expression of cytokines in human endometrium throughout the menstrual cycle: dysregulation in habitual abortion. MHR: Basic science of reproductive medicine, 6, 627-634.

Wooding, F. B. \& Wathes, D. C. 1980. Binucleate cell migration in the bovine placentome.

Wooldridge, L. K. \& Ealy, A. D. 2019. Interleukin-6 increases inner cell mass numbers in bovine embryos. BMC Developmental Biology, 19, 2.

Wu, X., Li, D.-J., Yuan, M.-M., Zhu, Y. \& Wang, M.-Y. 2004. The Expression of CXCR4/CXCL12 in First-Trimester Human Trophoblast Cells1. Biology of Reproduction, 70, 1877-1885.

Zhou, X., Lindsay, H. \& Robinson, M. D. 2014. Robustly detecting differential expression in RNA sequencing data using observation weights. Nucleic acids research, 42, e91-e91.

Zoldan, K., Moellmer, T., Schneider, J., Fueldner, C., Knauer, J. \& Lehmann, J. 2014. Increase of CD25 expression on bovine neutrophils correlates with disease severity in post-partum and early lactating dairy cows. Developmental \& Comparative Immunology, 47, 254-263. 


\section{APPENDIX A}

STAINS OF BOVINE CARUNCULAR ENDOMETRIUM FOR FOXP3 AND CD4 PROTEIN

\section{INTRODUCTION}

In a previous study Mathew et al. (2018), caruncular bovine endometrium explants were treated with increasing concentrations of LGALS1. Galectin-1 increased expression of CD11c and FOXP3 as well as the number of FOXP3+ stained cells in the caruncular tissue. Because the number of FOXP3+ cells increased with increasing concentrations of LGALS1, they hypothesized that LGALS1 may promote expansion of dendritic cells (DC) and regulatory Tcells (Treg) within the bovine endometrial caruncle, contributing to immune suppression at the fetal-maternal interface in cattle. The aim of this experiment was to co-localize FOXP3 and CD4 protein in serial sectioned caruncular endometrial explants treated with LGALS1 using immunohistochemistry (IHC) in preparation of intercaruncular staining.

\section{MATERIALS AND METHODS}

$\underline{\text { Immunohistochemistry }}$

Bovine caruncular tissue that was collected and treated with LGALS1 during a previous study was used for this experiment (Mathew et al., 2018). Caruncular tissue samples fixed in $10 \%$ non-buffered formalin (NBF) and imbedded into paraffin blocks were sectioned to $5 \mu \mathrm{m}$ thickness and mounted on charged glass slides. To begin tissue staining, the paraffin was removed using xylene, increasing serial dilutions of EtOH, distilled water, and $1 \mathrm{X}$ phosphate buffered solution (PBS). Slides were then placed into 0.01M Sodium Citrate Buffer, boiled for 6 
min, and allowed to cool for 45 min on ice. Sections were then washed twice in $1 \mathrm{X}$ PBS for 5 min each time. Tissues were incubated in $0.3 \%$ hydrogen peroxide in methanol for $30 \mathrm{~min}$ at room temperature then washed in $1 \mathrm{X}$ PBS for 5 min to block endogenous peroxidase activity. Blocking of non-specific binding was performed by using rabbit IgG (VECTASTAIN Elite ABC- Peroxidase Kit; Vector Labs; Burlington, ON, Canada) followed by Streptavidin/Biotin Blocking Kit (Vector Labs) were used per manufacturer's instructions. A 1:25 dilution of mouse anti-bovine CD4 (initial concentration predicted to be $1.0 \mu \mathrm{g} / \mathrm{mL}$; BioRad; Hercules, CA) to $1 \mathrm{X}$ PBS and 1:1000 dilution of rabbit anti-bovine FOXP3 (original concentration predicted to be 4-8 $\mu \mathrm{g} / \mathrm{mL}$; Sigma Aldrich, St. Louis, MO) in 1X PBS was added to slides of serial tissue sections and incubated overnight at $4^{\circ} \mathrm{C}$. Following incubation, slides were washed twice for 5 min each in 1X PBS and then the secondary antibody solution was added to slides (goat- FOXP3 or mouse- CD4, respectively) for 30 min. ImmPACT DABPeroxidase Substrate (Vector Labs) was used at a 3:100 dilution and added to slides for $1.5 \mathrm{~min}$ then rinsed in running tap water for 5 min. Hematoxylin (Sigma Aldrich; St. Louis, MO) was used to stain slides by dipping them 3 times, for 3 seconds each, rinsed with distilled water twice, then Scott's tap water was added to tissues for 1 minute and slides were again placed in distilled water. Dehydration was performed by submerging slides in decreasing serial dilutions of EtOH. Slides were allowed to air dry, and Permount (Fisher Scientific; Hampton, NH) was used to mount glass cover slips. Slides were imaged using a Zeiss fluorescent microscope (Zeiss; Oberkochen, Germany) mounted with AxioCam ICc1 R 4 and AxioVision Rel 4.8.2 Software (Zeiss).

\section{RESULTS AND DISCUSSION}

Immunohistochemisty resulted in staining of FOXP3 and CD4 cells in caruncular endometrial explants treated with LGALS1. Serial sections, one stained for FOXP3 and the other 
for CD4, had apparent overlapping staining for a group of stromal cells, seemingly lymphocytes, based on size and morphology. Control slides were not included, therefore, the specificity of the antibodies cannot be confirmed. In rodent endometrium, LGALS1 increases the number of Treg cellsthat express FOXP3 (Blois et al., 2007). Overlapping staining for FOXP3 and CD4 protein in bovine caruncular endometrium would provide evidence of Treg within the endometrium of cattle. Further investigations are needed to conclude the presence of Treg within the bovine endometrium. 
FOXP3
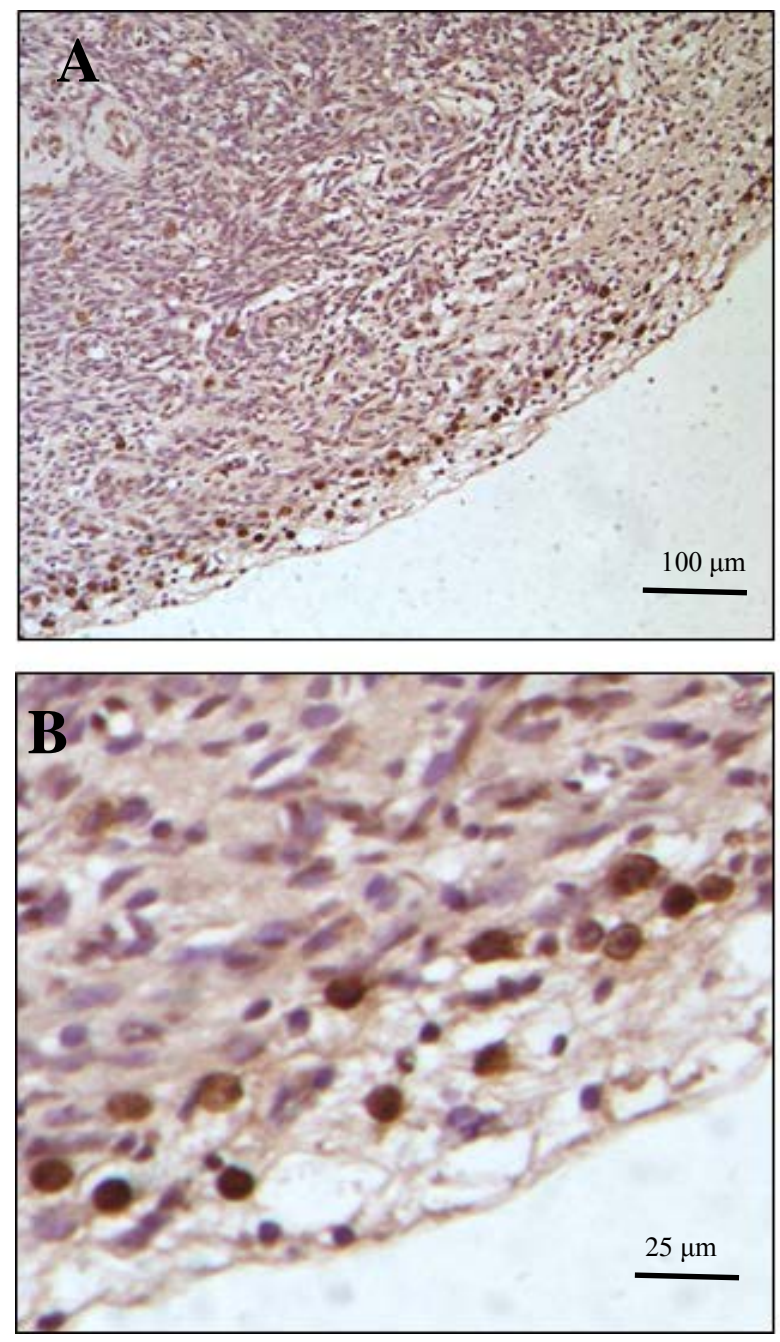

CD4
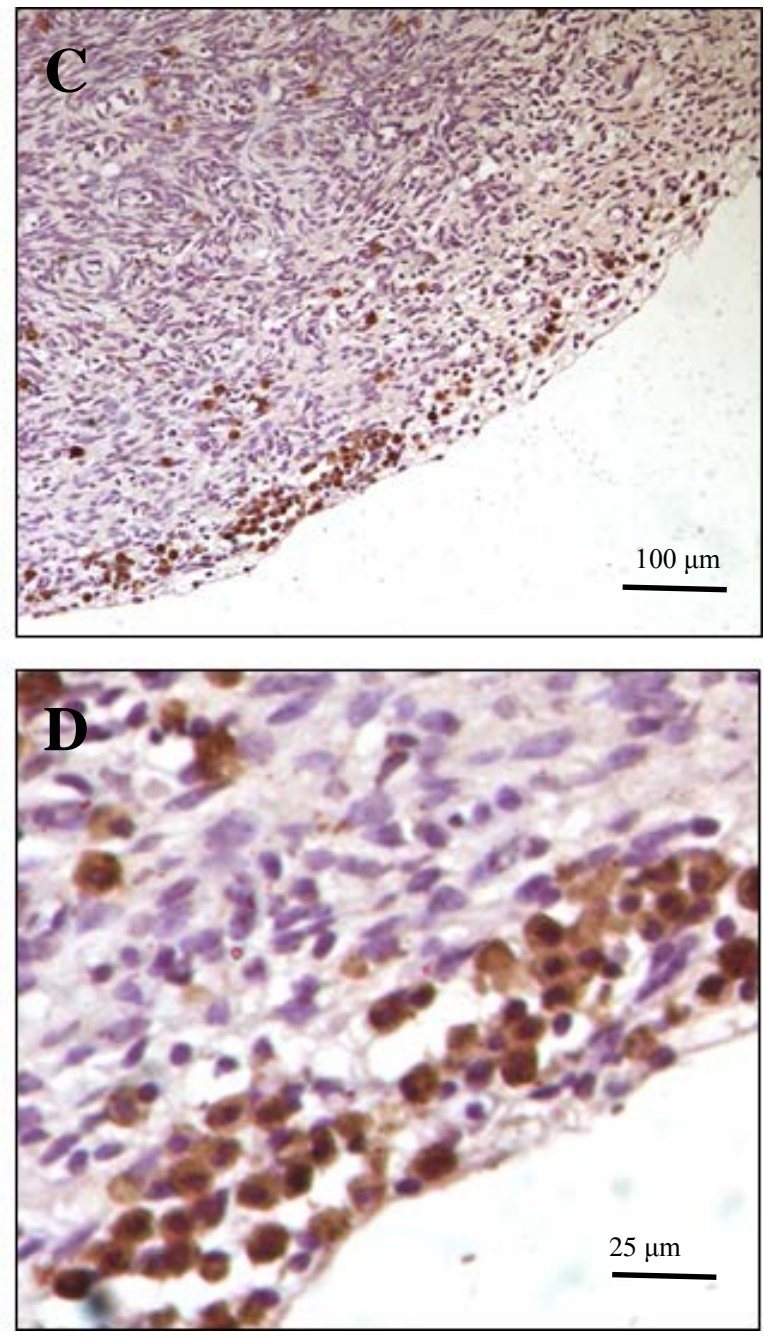

Figure A.1- Immunohistochemistry using DAB staining of caruncular explant tissue treated with LGALS1. A- anti FOXP3 10X magnification. B- anti FOXP3 40x magnification. C- anti CD4 10X magnification. D- anti CD4 40X magnification. 


\section{APPENDIX B}

\section{Gene Ontology direct Pathways up-regulated in Epithelial Cells treated with 100ng/mL of LGALS1}

inflammatory response

positive regulation of NF-kappaB transcription factor activity

type I interferon signaling pathway

apoptotic process
PTGS2, ELF3, S100A8, TBK1, IL19, S100A9, TLR2, TLR3, TLR4, NFKB1, NFKB2, TLR6, CXCL10, CCRL2, S1PR3, TNFRSF11B, CASP4, CXCR4, LTB4R, MGLL, IL-1B, VNN1, FAS, ADAM8, TNIP1, IL1A, CIITA, IRAK2, NFKBIZ, PTGER2, C5AR2, SP100, IL18RAP, GBP5, LYN, RELB,

0.000 CHST2, CD40, IFI16, TNFRSF9, TNFAIP6, PTGDR, RIPK2, NAIP, TNFAIP3, IL36A, TNFRSF21, CCL2, NMI, TNF, CXCL5, C3, ADORA2A, CXCL3, CSF1, C5, CXCL2, CXCL8, CCL5, IL34, CCL22, CCL20, ITGB6, ZC3H12A, BLNK, LY75, SELP, IL-6, LIPA, CEBPB, OLR1, CHI3L1, SMAD1, LGALS9, S100A12, LAT, APOL3, CYBA, CLEC7A, IKBKB, CD14, F2R

TRAF1, TNF, S100A8, NFKBIB, S100A9, TLR2, TRIM14, NFKBIA, TLR3, NFKB1, TLR4, NFKB2, TNFSF18, IRAK3, TRIM5, NOD2, TRIM8, RBCK1, LTF, IL-1B, ADAM8, CAMK2A, RNF31, IRAK2, ICAM1, CFLAR, IL-6, TRIM25, MALT1, CD40, LGALS9, S100A12, TRIM38, CARD14, PSMA6, RIPK3, RIPK2, EIF2AK2, IKBKB

RNASEL, SP100, IFITM2, RSAD2, SAMHD1, OAS2, STAT1, IFI35, PSMB8, ISG20, STAT2, TYK2, IRF9, IFIT3, IFNAR2, IFIT2, IFI27, ISG15, IRF7, IRF1, XAF1, MX1, MX2, IFI6, ADAR

S100A8, FAM3B, IL19, S100A9, TLR2, FOXO1, NFKB1, DAXX, ASAH2, CASP3, CASP4, UNC5B, CXCR4, CASP7, 0.000 CASP8, MAP3K8, IL-1B, FAS, CASP1, MX1, IL1A, MT3, BCL2L15, BCL2L14, NCF1, GZMA, ARHGEF6, PIM1, RHBDD1, AHR, TNFRSF9, CARD14, CLIC4, ARRB1, TNFAIP8, RIPK2, AVEN, CTSC, NAIP, TNFAIP3, 
innate immune response

0.000

interferon-gamma-mediated signaling pathway

immune response

defense response to virus
PPP1R15A, TRAF1, ZFAND6, ARL6IP1, TNFRSF21, GSDMA, LITAF, ADORA2A, SAV1, PML, EGLN3, NFKBIA, RFFL, PRUNE2, PTK2B, SQSTM1, MAP3K1, ZC3H12A, XAF1, EPO, CFLAR, RNF144B, RMDN3, BIRC7, CHI3L1, TMBIM4, GJB6, STAT1, BIRC3, TNFSF9, DRAM2, RPS6KA3, TNFSF10, RASSF6, RABEP1, IFT57, SLC5A8, IRF1, JAK2, EAF2, DRAM1, CD14

S100A8, TBK1, S100A9, TLR2, TLR3, TLR4, NFKB1, NFKB2, TLR6, TRIM5, MAP3K5, NOD2, CASP4, PGLYRP4, CLEC4E, TRIM8, PGLYRP2, PGLYRP3, VNN1, MX1, MX2, LYN, NCF2, BPIFA1, NCF1, RELB, HERC5, SERPING1, IFI16, TYK2, STYK1, RIPK2, NAIP, MST1R, EIF2AK2, IL36A, FRK, IFIH1, FGR, CSF1, PML, TRIM14, C1R, IL34, TRIM10, CLEC10A, SEC14L1, CYLD, PTK2B, C2, DHX58, ZBP1, MALT1, TRIM25, TRIM21, S100A12, IL36RN, DDX58, CYBA, IRF7, IFIT5, JAK2, CLEC7A, IKBKB, CD14, ADAR

CIITA, ICAM1, SP100, NMI, PML, TRIM25, OAS2, STAT1, TRIM21, IRF9, VCAM1, TRIM38, TRIM5, CD44, TRIM8, TRIM34, IRF7, MT2A, IRF1, CAMK2D, JAK2, CAMK2B, CAMK2A

AQP9, IL19, TLR2, TNFSF15, TLR4, ZEB1, TLR6, VIPR1, TAPBP, CXCL10, TNFRSF11B, SH2D6, LTB4R, IL-1B, FAS, LTB, IL1A, CIITA, IL18RAP, GZMA, ACKR4, CD40, PDCD1LG2, TNFRSF9, TNFSF13B, CTSC, IL36A, CSF3, IL1R2, TNFRSF21, CCL2, LST1, TNF, CXCL5, IFITM2, C3, CXCL3, CXCL2, CXCL8, C1R, CX3CL1, OAS2, CCL5, CCL28, LIF, CCL22, CCL20, LY75, IL18R1, IL-6, TNFSF4, CEBPB, IL1RN, SMAD3, SAMHD1, TNFSF9, LAT, IKBKE, TNFSF10, CD274, AIRE, IFI6

RNASEL, APOBEC1, IFITM2, TBK1, PML, TLR3, RSAD2, IFI44L, OAS2, ISG20, CXCL10, TRIM5, ISG15, ZC3H12A, MX1, MX2, DHX58, IL-6, HERC5, SAMHD1, TRIM25, IFI16, 
response to virus

response to lipopolysaccharide

positive regulation of inflammatory response

I-kappaB kinase/NF-kappaB signaling

cellular response to lipopolysaccharide

activation of cysteine-type endopeptidase activity involved in apoptotic process

cellular response to interleukin-1

JAK-STAT cascade
0.000

OAS2, CCL5, ISG20, IFIT3, DDX58, IFNAR2, IFIT2, IRAK3, CCL22, CXCR4, IRF7, BCL3, MST1R, EIF2AK2, MX1,

IKBKB, XCL1, MX2, DHX58, ADAR

TNFRSF21, S100A8, CXCL5, PTGS2, CXCL3, EDN1, CXCL2, DUSP10, TLR2, TLR4, CNP, NFKB2, CXCL10,

0.000 VCAM1, IRAK3, CASP3, TNFRSF11B, PTGES, CASP8, FAS, CASP1, EPO, SELP, PTGER2, CD40, GJB6, IDO1, LGALS9, SOD2, PCK1, TNFRSF9, RPS6KA3, JAK2, F2R

LPL, CCL2, TNFSF4, S100A8, S100A9, TLR2, TLR3, TLR4, CX3CL1, CCL5, TNFSF18, S100A12, CD47, SERPINE1, TGM2, PLA2G7, NLRP12, JAK2, XCL1, TNIP1

0.000

IRAK2, TNF, TBK1, RELB, TLR3, TIFA, TLR4, NFKB1, NFKB2, BIRC3, TANK, RIPK3, RBCK1, BCL3, RIPK2, IKBKB, CD14, RNF31

CSF3, ICAM1, IL-6, SBNO2, CCL2, TNFSF4, CEBPB, TNF,

0.000 ITAF, NFKBIB, CXCL8, NFKB1, TLR4, CD40, CMPK2, CXCL10, EDNRB, CCL20, CD80, CXCL16, SERPINE1, ZC3H12A, NOS2, TNFAIP3, CD14

XDH, TNF, S100A8, S100A9, PML, EGLN3, TNFSF15, 0.000 SMAD3, SLC11A2, CASP3, TNFSF10, IFI27, ROBO1, IFT57, CASP8, NLRP12, NKX3-1, JAK2, FAS, CASP1, F2R

ICAM1, IL-6, CCL2, CEBPB, EDN1, CHI3L1, CXCL8,

NFKB1, CX3CL1, CCL5, TANK, PCK1, ADAMTS7, CCL22, HIF1A, CCL20, ZC3H12A, NKX3-1, XCL1

STAMBP, IFNAR2, STAT4, NMI, CCL2, SOCS2, STAT5A, SOCS1, IL15RA, JAK2, STAT1, STAT3, STAT2 
negative regulation of viral genome replication

positive regulation of I-kappaB kinase/NF-kappaB signaling

tumor necrosis factor-mediated signaling pathway

cellular response to tumor necrosis factor

negative regulation of type I interferon production

regulation of inflammatory response

positive regulation of GTPase activity

signal transduction
0.000

0.000

0.000

0.000

0.000

0.000

0.000

0.000
RNASEL, TNF, IFITM2, RSAD2, IFI16, PARP10, CCL5, ISG20, ISG15, LTF, EIF2AK2, MX1, TNIP1, ADAR

TNF, LITAF, TBK1, TLR6, TRIM5, NOD2, TRIM8, CASP8, TGM2, RBCK1, LTF, CASP1, IL1A, RNF31, CFLAR, NDFIP2, TRIM25, MALT1, CD40, BIRC3, LGALS9, S100A12, IKBKE, APOL3, TRIM38, TNFSF10, RIPK2, IKBKB, F2R

PSMB10, TNFRSF21, TNF, TNFSF4, TNFSF15, CD40, BIRC3, STAT1, TNFSF18, PSMB8, PSMB9, BAG4, TNFRSF9, PSMF1, CARD14, TNFRSF11B, TNFSF13B, PSMA6, PSME2, PTK2B, JAK2, FAS, IKBKB, LTB

ZFAND6, ICAM1, TNFRSF21, IL-6, CCL2, EDN1, CHI3L1, CXCL8, CX3CL1, CCL5, TANK, PCK1, VCAM1, ADAMTS7, BAG4, CYBA, MAP3K5, CCL22, CCL20, NKX3-1, ZC3H12A, IKBKB, XCL1

DDX58, IKBKE, CYLD, IFIH1, ISG15, TBK1, HERC5, UBA7, UBE2L6, TRIM25, TNFAIP3, DHX58

SBNO2, TNFSF4, LYN, PTGS2, RICTOR, BIRC3, NOD2, CASP4, PSMA6, PGLYRP2, MGLL, PIK3AP1, JAK2, XCL1, CASP1, TNFAIP3, TNIP1

FGF18, RASGEF1B, RASGEF1A, ITSN2, GDPGP1, SMAP2, S1PR1, RINL, STARD8, ANGPT1, DOCK10, RAPGEF2, NET1, ARHGAP9, ICAM1, ARHGEF6, ARHGEF9, CD40, ARHGAP26, THY1, ARHGEF11, ARHGAP31, SH2D3A, ARFGEF3, GNAQ, ARRB1, NCK1, RIN3, KALRN, FGFR1, CCL2, CX3CL1, CCL5, DENND2D, OCRL, FAM13A, TAGAP, CCL22, CCL20, ARHGAP42, TEK, CAMK2D, CAMK2B, TRIP10, CAMK2A, FGD3, RASA2, ELMOD1, IL2RB, NF1, DENND1A, DOCK9, LAT, FNBP1, ADAP2, RGS2, RABEP1, RGS3, DENND4C, RGS7, JAK2, XCL1, ST5, IL3RA, ARHGAP10

FGF18, S100A9, IL19, TNFSF15, TLR2, TLR3, PLPPR3, TLR6, TNFSF18, CXCL10, ANK1, UNC5B, STARD8, 
positive regulation of interleukin-6 production

response to hypoxia

angiogenesis

positive regulation of chemokine production

positive regulation of ERK1 and ERK2 cascade
IL15RA, IL-1B, FAS, MX1, ITPK1, NET1, OPTN, TANK, TNFAIP6, HIF1A, ARRB1, CD34, LRP12, RIPK3, RIPK2, MST1R, KALRN, TRAF1, SRI, ZNF516, CCL2, LITAF, NFKBIB, NOSTRIN, SP110, CD72, OCRL, VDR, TAGAP, LGALS3BP, CD69, TEK, NDRG2, MAP2K1, NR4A2, NDFIP2, SMAD1, ATF6, LAT, APOL3, TNFSF10, CD274, HIVEP2, HIVEP1, XCL1, PLAU, ARHGAP10, NAMPT, NFKB1, SDC4, ASAH2, FLT3LG, LNPEP, TNFRSF11B, PTGES, CASP1, LTB, ARHGAP9, LYN, NRXN3, NECTIN2, ARHGAP26, CD83, ARHGAP31, TNFSF13B, RASSF10, ICOSLG, RIN3, TNFRSF21, CXCL5, C3, SAV1, CXCL8, FAM13A, CCL22, CCL20, PTK2B, ARHGAP42, CAMK2B, TRIP10, PLA2R1, RASA2, EPO, LY75, IL18R1, IL2RB, TNFSF4, NF1, COL15A1, ASIC3, MAPK10, TNFSF9, STAT3, ITPR2, RASSF4, RPS6KA3, RASSF6, NLRP12, JAK2

IL-6, TNF, TNFSF4, ADORA2B, TLR2, TLR3, TLR4, DDX58, CYBA, NOD2, IL-1B, RIPK2, IL1A, IL36A

CCL2, TLR2, EGLN3, PML, ADA, SLC11A2, VCAM1, HMOX2, CASP3, CXCR4, PTK2B, TEK, CAMK2D, NOS2, CASP1, EPO, MT3, MUC1, PLAT, NF1, FUNDC1, NR4A2, SMAD3, SOD2, ITPR2, CYBA, HIF1A, NPPC, PLAU

NRP2, FGF18, FGFR1, CCL2, PTGS2, CXCL8, ANPEP, ESM1, EPHB2, WARS, S1PR1, HEY1, UNC5B, PTK2B, ITGAV, TEK, SERPINE1, ERAP1, ZC3H12A, ANGPT1, ADAM8, C1GALT1, CEACAM1, FMNL3, NRXN3, COL15A1, ACKR3, TMPRSS6, THY1, HIF1A, CLIC4, RBPJ, TNFAIP2, SEMA4A

0.000 IL-6, TNF, HIF1A, ADORA2B, TLR2, RIPK2, TLR3, TLR4, EIF2AK2

FGF18, CCL2, TNF, TLR4, CX3CL1, CCL5, CCL22, NOD2, CD44, CCL20, PTK2B, TEK, CAMK2D, ANGPT1, RAPGEF2, EPO, MT3, ICAM1, C5AR2, IL-6, MAP2K1, CHI3L1, ACKR3, LGALS9, ARRB1, RIPK2, XCL1, ST5, F2R 
positive regulation of nitric oxide biosynthetic process

lipopolysaccharide-mediated signaling pathway

chemotaxis

positive regulation of NF-kappaB import into nucleus

chemokine-mediated signaling pathway

TRIF-dependent toll-like receptor signaling pathway

cytokine-mediated signaling pathway

acute inflammatory response

positive regulation of nitric-oxide synthase biosynthetic process

response to tumor necrosis factor

negative regulation of apoptotic process
0.000

0.000

0.000

0.000

IL18R1, TNF, PTGS2, TLR2, RBCK1, TLR3, IL-1B, TLR4, LGALS9

CCL2, CXCL5, CXCL3, CXCL2, CXCL8, ACKR3, ACKR4, 0.000 CX3CL1, CCL5, CXCL10, CCRL2, CCL22, CCL20, CXCR4, PTK2B, XCL1

0.000

IKBKE, TBK1, IRF7, CASP8, TLR3, TLR4, BIRC3, IKBKB, CD14, TANK

LRRC4, CSF3, IL1R2, IL-6, IL2RB, CCL2, SOCS2, IL-6ST, 0.000 SOCS1, CX3CL1, STAT3, IRAK3, STAT4, IL17REL, IL20RA, TGM2, IL-1B, IL15RA, JAK2, IL13RA1, IL1A, IL36A

0.000 B4GALT1, VCAM1, IL-6, TNFSF4, S100A8, PTGES, VNN1

0.000

NAMPT, NOD2, CCL2, CCL20, TLR2, TLR4, JAK2

0.000

CASP3, PTGS2, NUB1, CXCL16, CASP8, CHI3L1, JAK2, YTHDC2, CD14

IL-6ST, FOXO1, NFKB1, TNFSF18, SETX, EDNRB, BAG4, CASP3, CD44, LTF, ANGPT1, FAS, MT3, SOX10, SOCS2, 0.000 BCL2A1, PIM1, RHBDD1, MAP4K4, CARD14, TNFAIP8, RIPK2, AVEN, NAIP, EIF2AK2, ALOX12, ARL6IP1, ZFAND6, NFKBIA, SQSTM1, PTK2B, TEK, TGM2, BCL3, CFLAR, IL2RB, IL-6, TMBIM4, BIRC7, SMAD3, MALT1, 
positive regulation of interferon-beta production

regulation of I-kappaB kinase/NF-kappaB signaling

regulation of cell proliferation

regulation of adaptive immune response

cellular response to organic cyclic compound

response to cytokine

regulation of apoptotic process

regulation of tumor necrosis factor-mediated signaling pathway

MAPK cascade

antigen processing and presentation of endogenous peptide antigen via MHC class I

BIRC3, STAT3, SOD2, PLAC8, IFIT3, RPS6KA3, IKBKB, ADAR, ARHGAP10

0.000

0.000

0.000

0.000

0.000

0.000

0.000

0.000

0.000

0.000
DDX58, IFIH1, TBK1, IRF7, TLR2, IRF1, RIPK2, TLR3, TLR4

ZFAND6, TNF, SQSTM1, NLRP12, IL-1B, ANGPT1, OPTN

TNFRSF21, TNF, APOBEC1, FGR, CXCL3, TNC, SAV1,

CXCL2, EGLN3, NFKBIA, CXCL10, TNFRSF11B, PTK2B, NOS2, FAS, RAPGEF2, PTGER2, BIRC7, CD40, TYK2, PLA2G4A, STYK1, MELTF, TFRC, JAK2, PLAU

TNFSF4, IRF7, RIPK3, DUSP10, IRF1

TNF, CEBPB, CCL2, NFKBIA, STAT1, CCL5, STAT3, CYBA, NOD2, CASP3, P2RY6, CASP8, IL-1B

IFI27, SP100, PTGES, OSMR, IL-6ST, CXCL16, CD274, RELB, PML, NFKB2, SKIL, STAT1

TNFRSF21, BCAR1, NOD2, TNFRSF11B, CASP4, DYNAP, CASP8, BCL3, FAS, SKIL, CASP1, BMP3, CFLAR, BCL2L14, BMP1, NOS1AP, STK26, MALT1, WRN, TRIM24, BIRC3, STAT1, TNFRSF9, CARD14, RASSF6, IFT57, JAK2, EIF2AK2

TRAF1, CYLD, TNF, CASP8, RBCK1, BIRC3, IKBKB, TNFAIP3, RNF31

PSMB10, FGF18, FGFR1, CCL2, TNF, RASGEF1A, CCL5, MAP3K7CL, SETX, PSMF1, MAP3K5, PTK2B, MAP3K1, TEK, CAMK2D, IL-1B, ANGPT1, CAMK2B, RAPGEF2, CAMK2A, RASA2, IL2RB, MAP2K1, NF1, SMAD1, PSMB8, PSMB9, LAT, PSMA6, PSME2, JAK2, IL3RA

TAP2, TAP1, ERAP1, ERAP2, TAPBP 
response to amino acid

sodium ion transmembrane transport

positive regulation of interferon-alpha production

positive regulation of phosphatidylinositol 3-kinase signaling

cell chemotaxis

cellular response to interferon-gamma

neutrophil chemotaxis

positive regulation of sequence-specific DNA binding transcription factor activity

JNK cascade

negative regulation of extrinsic apoptotic signaling pathway via death domain receptors

regulation of innate immune response

positive regulation of interleukin-8 production

ion transport
0.000

ICAM1, SLC1A2, CASP3, IL-6, CCL2, LYN, EDN1, AARS, NAIP

SLC8A3, SLC5A5, SHROOM2, ASIC3, KCNK1, PKD2L1, 0.000 SLC34A2, SLC17A2, SLC24A1, SLC4A7, NALCN, SLC8B1, SCNN1D, TRAPPC10

0.000 DDX58, IFIH1, TBK1, IRF7, RIPK2, TLR4

0.001 CSF3, SELP, FGFR1, FGR, CCL5, PRR5, UNC5B, TEK, NKX3-1, PIK3AP1, ANGPT1, JAK2, F2R

0.001

CCL2, CXCL5, BCAR1, C5, CXCL2, SAA4, CX3CL1, CCL5, CCL28, CXCL10, VCAM1, CCL20, SAA2

0.001

CIITA, CCL22, CCL2, GBP5, CCL20, EDN1, TLR3, CX3CL1, NOS2, CCL5, XCL1, LGALS9

0.001

CCL2, S100A8, CXCL3, S100A9, EDN1, CXCL8, CX3CL1, CCL5, S100A12, CCL22, CCL20, IL-1B, XCL1

IL-6, TNF, SP100, SAV1, FOXA1, EDN1, TRIM14, TRIM25, 0.001 PLPP3, TRIM21, DDX58, TRIM5, TRIM38, TRIM8, TRIM34, IL-1B, JAK2

0.001

IRAK2, MAP3K5, NOD2, TNF, SH2D3A, ADORA2B, ARHGEF6, NPHS1, DUSP10, RIPK2, MAPK10

0.001

ICAM1, CFLAR, TNFSF10, CASP8, SERPINE1, TMBIM1, RFFL, FAS, TNFAIP3

0.001 FGR, IRF1, SAMHD1, ERAP1, BIRC3, DHX58

0.001

DDX58, NOD2, TNF, SERPINE1, TLR2, TLR3, IL-1B, TLR4

SLC8A3, SLC9A8, SLC5A5, SLCO4A1, TMC5, SLC22A15, SLC9A2, ATP11B, SLCO2B1, SLC26A2, LRRC38, SLC26A4, SLC1A2, SLC24A1, SLC5A8, LTF, SLC8B1, SLC15A3, SLC1A1 
positive regulation of transcription from RNA polymerase II promoter

pattern recognition receptor signaling pathway

positive regulation of cell migration
NAMPT, RNASEL, ELF3, TBK1, EDN1, TLR2, FOXO1, TLR3, NFKB1, TLR4, ZEB1, NFKB2, CXCL10, FLT3LG, SETX, PCGF5, NOD2, S1PR1, SPX, HEY1, SERPINE1, IL1B, TNIP1, IL1A, CIITA, SOX10, SSBP3, SSBP2, TAF4B, RELB, NCOA7, SIX5, CD40, IFI16, ELL3, AHR, NRIP1, ADRB2, HIF1A, NCOA2, ARRB1, NCK1, RIPK2, CSF3, SBNO2, TNF, PML, NFKBIA, EHF, LIF, VDR, STAT4, SQSTM1, POU2F2, BCL3, AGO2, ZC3H12A, NKX3-1, BCL9L, ETV6, SLC30A9, MAFF, IL-6, CEBPB, IKZF2, ZBTB7C, CEBPD, FOXA1, NR4A2, SMAD3, SMAD1, STAT1, TMPRSS6, STAT3, PLAC8, DDX58, ATF6, RPS6KA3, MEOX1, IRF7, AIRE, IRF1, ID4, EAF2, RBPJ, IKBKB

0.001

TRIM5, PGLYRP4, PGLYRP2, PGLYRP3, CLEC7A

FGR, LYN, DIAPH1, BCAR1, CSF1, FERMT3, EDN1, SMAD3, CCL5, TNFAIP6, S1PR1, PTK2B, ITGAV, CARMIL1, RRAS2, CXCL16, CD274, SEMA4B, JAK2, INSR, PLAU, SEMA4A, F2R, ALOX12 


\section{KEGG analysis pathways that were up-regulated in epithelial cells treated with $100 \mathrm{ng} / \mathrm{mL}$ LGALS1}

\section{Legionellosis}

Chagas disease (American trypanosomiasis)

Chemokine signaling pathway

Rheumatoid arthritis

Cytosolic DNA-sensing pathway

Tuberculosis

Toxoplasmosis

Hepatitis B
IL-6, TNF, C3, CXCL3, CXCL2, TLR2, CXCL8, NFKBIA, TLR4, NFKB1, NFKB2, CASP3, CASP7, CASP8, IL-1B,

0.000 NAIP, CASP1, CD14

ADCY1, TNF, GNAI3, CCL2, GNAI1, C3, TLR2, CXCL8, NFKBIA, TLR4, NFKB1, TLR6, CCL5, SERPINE1, CASP8, IL-1B, PIK3R5, NOS2, FAS, CFLAR, IL-6, SMAD3, MAPK10, 0.000 GNAQ, IKBKB

ADCY1, CCL2, GNAI3, FGR, CXCL5, GNAI1, NFKBIB, CXCL3, BCAR1, CXCL2, CXCL8, NFKBIA, NFKB1, CX3CL1, CCL5, CCL28, CXCL10, CCL22, CCL20, CXCR4, PTK2B, PIK3R5, MAP2K1, LYN, NCF1, STAT1, STAT3, 0.000 STAT2, GNGT2, ARRB1, CXCL16, JAK2, XCL1, IKBKB

ICAM1, IL-6, TNF, CCL2, CXCL5, CSF1, TLR2, CXCL8, TLR4, ATP6V1B2, CCL5, MMP1, ATP6V1C2, TNFSF13B,

0.000 CCL20, CD80, TEK, IL-1B, ANGPT1, LTB, IL1A

IL-6, TBK1, NFKBIB, NFKBIA, TREX1, NFKB1, CCL5, CXCL10, DDX58, IKBKE, IRF7, RIPK3, IL-1B, IKBKB,

0.000 CASP1, ADAR, ZBP1

TNF, RAB5B, C3, TLR2, NFKB1, TLR4, TLR6, VDR, CASP3, NOD2, CLEC4E, CASP8, CAMK2D, IL-1B, CAMK2B, NOS2, PLA2R1, CAMK2A, IL1A, CIITA, IRAK2, IL-6, CEBPB, RFX5, MALT1, MAPK10, STAT1, 0.000 RIPK2, JAK2, CLEC7A, CD14

CIITA, TNF, GNAI3, GNAI1, NFKBIB, SOCS1, BIRC7, TLR2, NFKBIA, NFKB1, TLR4, MAPK10, CD40, BIRC3, STAT1, STAT3, TYK2, CASP3, LAMA4, CASP8, JAK2, 0.000 NOS2, IKBKB

0.000 IFIH1, TNF, TBK1, STAT5A, TLR2, CXCL8, TLR3, NFKBIA, TLR4, NFKB1, STAT4, CASP3, PTK2B, MAP3K1, CASP8, 
HIF-1 signaling pathway

Osteoclast differentiation

Leishmaniasis

Jak-STAT signaling pathway

Inflammatory bowel disease (IBD)

Hepatitis C

Malaria

Epstein-Barr virus infection

Hematopoietic cell lineage
PIK3R5, FAS, IL-6, MAP2K1, MAPK10, STAT1, STAT3,

STAT2, DDX58, IKBKE, IRF7, IKBKB

IL-6, MAP2K1, EDN1, EGLN3, HK2, HK1, NFKB1, TLR4,

STAT3, HIF1A, TFRC, TEK, SERPINE1, CAMK2D, ANGPT1,

0.000 PIK3R5, CAMK2B, NOS2, CAMK2A, INSR, EPO

TNF, NCF2, MAP2K1, NCF1, CSF1, SOCS1, RELB, NFKBIA, NFKB1, NFKB2, MAPK10, STAT1, STAT2, TYK2, IRF9, IFNAR2, CYLD, CYBA, TNFRSF11B, SQSTM1, IL-1B,

0.000 PIK3R5, IKBKB, IL1A, BLNK

TNF, PTGS2, NCF2, MARCKSL1, C3, NCF1, NFKBIB, TLR2, NFKBIA, NFKB1, TLR4, STAT1, CYBA, IL-1B, JAK2, NOS2,

0.000 IL1A

CSF3, OSMR, IL-6ST, STAT5A, IL19, IL21R, LIF, STAT4, IL15RA, PIK3R5, IL13RA1, EPO, IL-6, IL2RB, SOCS2,

SOCS1, PIM1, STAT1, STAT3, STAT2, IRF9, TYK2, IFNAR2,

0.000 IL20RA, JAK2, IL3RA

IL18R1, IL-6, TNF, IL18RAP, IL21R, TLR2, SMAD3, NFKB1, TLR4, STAT1, STAT3, NOD2, STAT4, IL-1B, 0.000 IL1A

RNASEL, TNF, TBK1, CXCL8, NFKBIA, TLR3, NFKB1, OAS2, MAPK10, STAT1, STAT3, STAT2, DDX58, IRF9,

TYK2, IKBKE, IFNAR2, IRF7, IRF1, PIK3R5, EIF2AK2,

0.001 IKBKB

VCAM1, CSF3, ICAM1, SELP, IL-6, TNF, CCL2, TLR2,

0.001 CXCL8, IL-1B, TLR4, CD40

ICAM1, LYN, TBK1, NFKBIE, NFKBIB, RELB, NFKBIA, NFKB1, NFKB2, CD40, MAPK10, STAT3, DDX58, TYK2,

0.001 CD44, PIK3R5, EIF2AK2, RBPJ, IKBKB, TNFAIP3

CSF3, IL1R2, IL-6, TNF, CSF1, ANPEP, FLT3LG, DNTT, 0.001 TFRC, CD44, CD34, IL-1B, CD14, IL1A, IL3RA, EPO 
Adipocytokine signaling pathway

Apoptosis

Type II diabetes mellitus

African trypanosomiasis

Amoebiasis

Pathways in cancer

Inflammatory mediator regulation of TRP channels

Sphingolipid signaling pathway

Phagosome
TNF, NFKBIE, NFKBIB, NFKBIA, NFKB1, MAPK10,

STAT3, PCK1, JAK2, ACSL4, IKBKB, ACSL3, ACSL6,

0.001 ACSL5

CFLAR, CASP3, TNFSF10, TNF, CASP7, CASP8, NFKBIA,

0.001 NFKB1, PIK3R5, FAS, BIRC3, IKBKB, IL3RA

TNF, SOCS2, GCK, SOCS1, HK2, HK1, CACNA1E,

0.002 PIK3R5, MAPK10, IKBKB, INSR

VCAM1, ICAM1, LAMA4, IL-6, TNF, GNAQ, IL-1B,

0.002 IDO1, FAS

IL1R2, ADCY1, IL-6, TNF, RAB5B, TLR2, CXCL8, TLR4, NFKB1, LAMA4, CASP3, GNAQ, SERPINB1, IL-1B, PIK3R5,

0.004 NOS2, CD14

TRAF1, FGF18, FGFR1, ADCY1, GNAI3, PTGS2, GNAI1, STAT5A, EGLN3, PML, CXCL8, NFKBIA, LPAR3, FOXO1, NFKB1, NFKB2, MMP1, FLT3LG, EDNRB, CASP3, CXCR4, ITGAV, CASP8, NKX3-1, PIK3R5, FAS, NOS2, IL-6, PTGER2, MAP2K1, BIRC7, SMAD3, MAPK10, BIRC3, STAT1, STAT3, ARHGEF11, CBLC, LAMA4, GNGT2,

0.004 HIF1A, GNAQ, IKBKB, F2R

ADCY1, PTGER2, ASIC3, MAPK10, ITPR3, ITPR2, PLA2G4A, GNAQ, P2RY2, CAMK2D, IL-1B, PIK3R5, 0.005 CAMK2B, CAMK2A, ALOX12, PLA2G4D

PLD1, TNF, PPP2R3A, GNAI3, MAP2K1, GNAI1, SGPP2, NFKB1, CERS4, MAPK10, ASAH2, S1PR3, MAP3K5,

0.006 S1PR1, GNAQ, ABCC1, PIK3R5, PPP2R3C

STX7, OLR1, RAB5B, NCF2, NCF1, C3, TLR2, TLR4, C1R, ATP6V1B2, TLR6, ATP6V1C2, CYBA, TFRC,

0.006 ITGAV, TAP2, TAP1, CLEC7A, PLA2R1, CD14, TUBA1C 